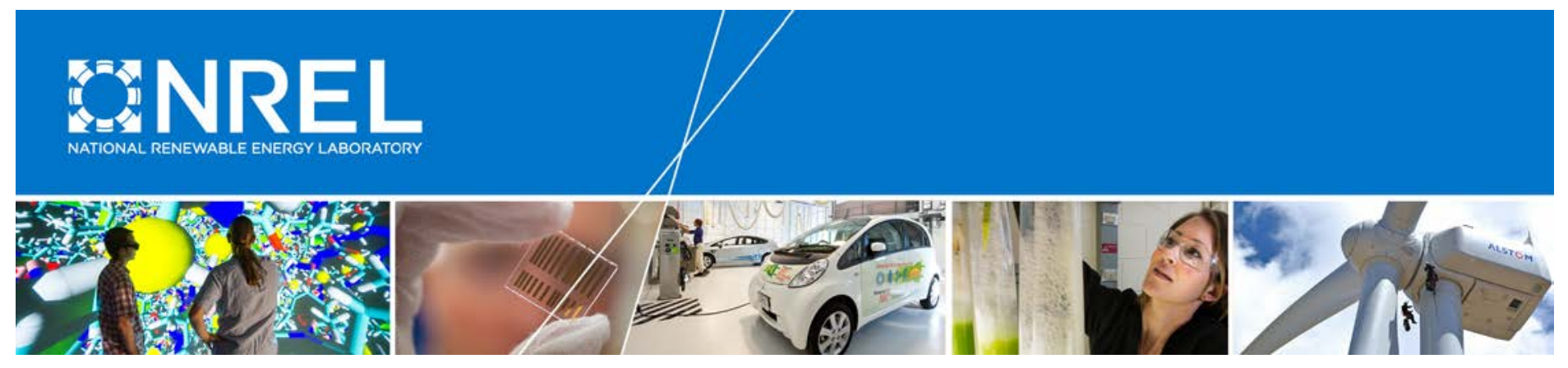

\title{
Fatigue Test Design: Scenarios for Biaxial Fatigue Testing of a 60-Meter Wind Turbine Blade
}

\author{
Nathan Post \\ National Renewable Energy Laboratory \\ Falko Bürkner \\ Fraunhofer Institute for Wind Energy and Energy \\ Systems
}

NREL is a national laboratory of the U.S. Department of Energy Office of Energy Efficiency \& Renewable Energy Operated by the Alliance for Sustainable Energy, LLC

This report is available at no cost from the National Renewable Energy Laboratory (NREL) at www.nrel.gov/publications.

Technical Report

NREL/TP-5000-65227

Revised August 2019

Contract No. DE-AC36-08G028308 


\section{Fatigue Test Design: Scenarios for Biaxial Fatigue Testing of a 60-Meter Wind Turbine Blade}

Nathan Post

National Renewable Energy Laboratory

Falko Bürkner

Fraunhofer Institute for Wind Energy and Energy Systems

Prepared under Task No. WE15.1G01

NREL is a national laboratory of the U.S. Department of Energy Office of Energy Efficiency \& Renewable Energy Operated by the Alliance for Sustainable Energy, LLC

This report is available at no cost from the National Renewable Energy Laboratory (NREL) at www.nrel.gov/publications.

National Renewable Energy Laboratory 15013 Denver West Parkway Golden, CO 80401

303-275-3000 • www.nrel.gov

\section{Technical Report}

NREL/TP-5000-65227

Revised August 2019

Contract No. DE-AC36-08GO28308 


\section{NOTICE}

This report was prepared as an account of work sponsored by an agency of the United States government. Neither the United States government nor any agency thereof, nor any of their employees, makes any warranty, express or implied, or assumes any legal liability or responsibility for the accuracy, completeness, or usefulness of any information, apparatus, product, or process disclosed, or represents that its use would not infringe privately owned rights. Reference herein to any specific commercial product, process, or service by trade name, trademark, manufacturer, or otherwise does not necessarily constitute or imply its endorsement, recommendation, or favoring by the United States government or any agency thereof. The views and opinions of authors expressed herein do not necessarily state or reflect those of the United States government or any agency thereof.

This report is available at no cost from the National Renewable Energy Laboratory (NREL) at www.nrel.gov/publications.

Available electronically at SciTech Connect http:/www.osti.gov/scitech

Available for a processing fee to U.S. Department of Energy and its contractors, in paper, from:

U.S. Department of Energy

Office of Scientific and Technical Information

P.O. Box 62

Oak Ridge, TN 37831-0062

OSTI http://www.osti.gov

Phone: 865.576.8401

Fax: 865.576.5728

Email: reports@osti.gov

Available for sale to the public, in paper, from:

U.S. Department of Commerce

National Technical Information Service

5301 Shawnee Road

Alexandria, VA 22312

NTIS http://www.ntis.gov

Phone: 800.553 .6847 or 703.605 .6000

Fax: 703.605.6900

Email: orders@ntis.gov 


\section{Errata}

This report, originally published in July 2016, has been revised in August 2019 to include Falko Bürkner as a coauthor in recognition of his insights that contributed to this research and to correct an error in the representation of the equation relating the structural damping coefficient to the log decrement damping in Eq. 22. The subsequent Eq. 33, 54, 55, and 56 that build on this have also been corrected. The results and conclusions presented are not impacted by this correction. The authors would like to thank Brenen Thul of MTS Systems Corporation for identifying and notifying us of this error. 


\section{Abstract}

Current practice in commercial certification of wind turbine blades is to perform separate flap and lead-lag fatigue tests. The National Renewable Energy Laboratory (NREL) has been researching and evaluating biaxial fatigue testing techniques and demonstrating various options, typically on smaller-scale test articles at the National Wind Technology Center (NWTC). This report evaluates some of these biaxial fatigue options in the context of application to a multimegawatt blade certification test program at the Wind Technology Testing Center (WTTC) in Charlestown, Massachusetts. To perform this evaluation, a fictional 60-meter $(\mathrm{m})$ blade test specification is generated by extrapolating data from recent test programs to provide a realistic problem statement for evaluating biaxial fatigue test designs. A simple simulation technique including the addition of virtual mass is introduced that enables tuning of the frequency and moment curve in one direction independent of the other direction. This virtual mass tuning has been demonstrated at a smaller scale by installing mass on a slide table connected to the blade by a pushrod as in the Hybrid test program at the NWTC. Alternatively, virtual mass may be added — or in theory removed — using a hydraulic actuator with a force function that is in phase with the displacement. This has been shown to be possible using a Ground-based Resonance EXciter (GREX)-type approach at the WTTC where the bending moment distribution of a blade can be significantly altered by changing the test frequency. Several testing scenarios are generated and compared, including a quantum biaxial fatigue test and two phase-locked scenarios with 1:1 and 1:2 ratios between the flap and lead-lag frequencies. Each method offers some advantages and disadvantages when compared to the other approaches. Future work toward implementation of these phase-locked test techniques will require development of hardware capable of implementing virtual masses near the tip of blades where there are large deflection amplitudes to achieve target moment curves during biaxial testing of megawatt-scale blades. 


\section{Acknowledgments}

This project was possible through the collaboration between NREL and the Massachusetts Clean Energy Center's WTTC. Experience and test data gained through this partnership have been key to making the observations, analysis, and conclusions of this report possible. The test designs considered are based on concepts that have been prototyped at a small scale at NREL's NWTC with the goal of applying these to large wind turbine blades at the WTTC. This would not have been possible without detailed knowledge of the available hardware and test technology at the WTTC. The author would like to acknowledge WTTC Executive Director Rahul Yarala for supporting these collaborative efforts that are mutually beneficial to both laboratories and the industry at large.

Research projects conducted at the NWTC were integral in developing and prototyping the concepts that are employed in the blade test simulations presented in this paper. Key NREL staff working on these projects include Michael Desmond, David Snowberg, Ryan Beach, Bill Gauge, Michael Jenks, and Scott Hughes.

Special thanks also go to Eric Harvey at Massachusetts Clean Energy Center and David Snowberg at NREL for their detailed review of this report.

This work was supported by the U.S. Department of Energy under Contract No. DE-AC3608GO28308 with the National Renewable Energy Laboratory. Funding for the work was provided by the DOE Office of Energy Efficiency and Renewable Energy, Wind and Water Power Technologies Office. 


\section{List of Acronyms}

BREX

GREX

$\mathrm{Hz}$

IREX

$\mathrm{kg}$

$\mathrm{kN}$

$\mathrm{m}$

MTS

MW

NREL

NWTC

PHLEX

R-ratio

Sandia

WTTC
Blade Resonance EXciter

Ground-based Resonance EXciter

hertz

Inertial Resonance EXciter (formerly UREX or

Universal Resonance EXciter)

kilogram

kilonewton

meter

MTS Systems Corporation

megawatt

National Renewable Energy Laboratory

National Wind Technology Center

PHase Locked EXcitation

load ratio for a fatigue cycle (minimum

load/maximum load)

Sandia National Laboratories

Wind Technology Testing Center 


\section{Mathematical Symbols}

Symbol

EI

[M]

$\vec{u}$

[K]

$\vec{F}$

$i$

$u_{i}$

$\alpha_{i}$

$\lambda_{i}$

$l_{i}$

$m_{s, i}$

$I_{s, i}$

$[m]^{(i)}$

$[k]^{(i)}$

$M_{i}$

$V_{i}$

$(E I)_{i}$

$M_{T i}$

$m$

F

$f$

$t$

$f_{n}$

$\zeta$

$x$

$c$

$k$

$c_{c}$

$\delta$

$q$

E

$E_{q}$

$v_{i, \max }$

\section{Description}

Beam stiffness where $\mathrm{E}$ is the elastic modulus and I

is the second moment of area

\section{Mass matrix}

Displacement vector

Stiffness matrix

Force vector

Index for indicating the node $\{0,1, \ldots, n\}$ or element

$\{1,2, \ldots, n\}$ along the blade span

Displacement at node $i$

Rotation at node $i$

Mass per unit length of element $i$

Length of element $i$

Mass of saddle applied at node $i$

Rotational moment of inertia of saddle at node $i$

Subset of mass matrix corresponding to the contribution from element $i$ and point mass at node $i$

with individual matrix elements indicated as $m_{j k}^{(i)}$

where $j$ is the row and $k$ is the column in the $4 \times 4$

submatrix

Subset of the stiffness matrix corresponding to the contribution for each element with individual matrix elements indicated as $k_{j k}^{(i)}$ where $j$ is the row and $k$ is the column in the $4 \times 4$ submatrix

Internal reaction moment at node $i$

$\mathrm{kNm}$

Internal shear reaction at node $i$

Beam bending stiffness for element $i$

Target moment at node $i$

Mass

Force

Frequency (typically resonance frequency)

Time

Undamped natural frequency

Damping ratio

Displacement

Damping coefficient

Spring constant

Critical damping coefficient

Log decrement damping

Index referring to a specific cycle

Energy

Energy (potential and kinetic) during cycle $q$

Maximum velocity of node $i$
$\mathrm{kN}$

$\mathrm{kN}-\mathrm{m}^{2}$

$\mathrm{kNm}$

$\mathrm{kg}$

$\mathrm{N}$

$\mathrm{Hz}$.

$\mathrm{s}$

$\mathrm{Hz}$.

$\mathrm{m}$

$\mathrm{kg} / \mathrm{s}$

$\mathrm{kg} / \mathrm{s}^{2}$

$\mathrm{kg} / \mathrm{s}$

J

J

$\mathrm{m} / \mathrm{s}$

\section{Typical units}

$\mathrm{kN}-\mathrm{m}^{2}$

$\mathrm{m}$

$\mathrm{rad}$

$\mathrm{kg} / \mathrm{m}$

$\mathrm{m}$

$\mathrm{kg}$

kg-m 
$\omega_{i, \max }$

$\rho$

$h_{i}$

$C_{D}$

$x_{b}$

$u_{b}$

$a_{I}$

$x_{I}$

$u_{I}$

$m_{\text {moving }}$

$a_{b}$

$F_{G}$

$g$

$\left\{x_{g}, y_{g}, z_{g}\right\}$

$d_{i}$

$m_{b, i}$

$A_{i}$

$\beta_{i+1}$
Maximum rotational velocity of node $i$

Density, specifically density of air

Cross section height of element

Coefficient of drag

Displacement of the blade at the exciter location

Displacement amplitude of the blade at the exciter location

Acceleration of IREX moving mass relative to the blade

Displacement of IREX moving mass

Displacement amplitude of IREX moving mass

Mass of portion of IREX that moves relative to the blade

Acceleration of the blade at exciter location

Force amplitude applied by a GREX

Gravitational acceleration constant

Global coordinate system in the laboratory with

gravity acting in the negative $z_{g}$ direction

Local displacement of a node $i$

Mass of blade element $i$

Axial force in an element acting at a node

Angle of applied force at a node $\mathrm{rad} / \mathrm{s}$

$1.2 \mathrm{~kg} / \mathrm{m}^{3}$

$\mathrm{m}$

$\mathrm{m}$

$\mathrm{m}$

$\mathrm{m} / \mathrm{s}^{2}$

m

$\mathrm{m}$

$\mathrm{kg}$

$\mathrm{m} / \mathrm{s}^{2}$

$\mathrm{kN}$

$9.80665 \mathrm{~m} / \mathrm{s}^{2}$

$\mathrm{m}$

m

kg

$\mathrm{kN}$

$\mathrm{rad}$ 


\section{Executive Summary}

Structural testing of new wind turbine blade designs is conducted as part of third-party certification to help ensure the reliability and durability of these large complex structures over their lifetime. The goal is to apply mechanical loads in the laboratory that approximate the maximum loads and fatigue loads the blade will see over its lifetime on the turbine. Current industry practice for utility-scale wind turbines is to apply fatigue loads separately in the flap and lead-lag directions in the laboratory using resonance testing techniques where the structure is oscillated at its first natural frequency in the respective direction. Although simpler to implement, a significant disadvantage of running two separate fatigue tests is that this approach may miss defects or damage development in the blade due to combined loading present on the turbine. In addition, certification testing imposes economic costs on the turbine development cycle, and the development of methods to reduce the total testing time is advantageous. By applying the flap and lead-lag test loads simultaneously, it may be possible to reduce the total testing time compared to running separate fatigue tests sequentially. Therefore, significant research effort over the last decade has been focused on developing techniques for biaxial fatigue testing of these large structures. Most of these research techniques have only been demonstrated on relatively small stiff blades in comparison to modern 50+ meter blade designs. A challenge in these research efforts has been adequately demonstrating how the techniques can be scaled up to a multimegawatt turbine blade certification test. This report provides data and insights that help to bridge that gap with the goal of encouraging the evaluation of biaxial fatigue options in commercial test programs carried out at the WTTC and other laboratories worldwide.

This report develops a fictional 60-m blade test specification based on extrapolating data from recent test programs to provide a realistic problem statement for evaluating biaxial fatigue test designs. Available test excitation equipment is assumed to be the Inertial Resonance EXciter (IREX) system and Ground-based Resonance EXcitation (GREX) servo hydraulic systems supplied by MTS Systems Corporation. A simple simulation technique, including the addition of virtual mass, is introduced that enables tuning of the frequency and moment curve in one direction independently of the other direction. This virtual mass tuning has been demonstrated at a smaller scale by installing mass on a slide table connected to the blade by a pushrod as in the Hybrid test program at the NWTC. Alternatively, virtual mass may be added —or in theory removed - using a hydraulic actuator with a force function that is in phase with the displacement. This has been demonstrated through alteration in the bending moment distribution applied to a blade at resonance by changing the test frequency. In practice, there are limits to the range of virtual mass that can be applied with this method because increasing the frequency very much beyond resonance tends to lead to control system instabilities. However, this method does work well for increasing the virtual mass and reducing the test frequency within the capacity of the available actuator.

Several testing scenarios are generated and compared to evaluate the new concepts against more traditional approaches. Single-axis tests in the lead-lag and flap direction are compared with a quantum test design where the frequencies in the flap and lead-lag directions are independent. The results show that some compromises are required in the accuracy of the bending moment curve for a quantum biaxial fatigue test, particularly if virtual mass is not used. Snowberg et al. (2014) previously demonstrated that there are drawbacks to quantum biaxial fatigue testing in practice because the moment amplitude in the lead-lag direction will not be constant amplitude, 
which could result in extending the duration of the fatigue testing to achieve the required damage equivalent loads. These observations along with the goal of matching the phase angle between the lead-lag and flap loading directions to those typically experienced by a blade on a turbine in operation motivates the consideration of phase-locked testing (D. White 2004). Options for phase-locked testing are currently under investigation at the NWTC, including a scaled prototype "Hybrid" test setup currently being conducted on a 12-m blade. Two scenarios are considered in this report for phase-locked testing of a $60-\mathrm{m}$ blade with a flap to lead-lag frequency ratio of 1:1 and a frequency ratio of 1:2. The 1:1 frequency offers the greatest opportunity to control the phase angle in fatigue testing and thus best represent the real loading on the turbine if phase information is available. However, this test scenario extends the total biaxial testing to last roughly as long as for separate single-axis tests and the large virtual masses make achieving the lead-lag target bending moment distribution a challenge. A 1:2 frequency ratio has an advantage of not requiring nearly as much virtual mass, and the total testing time is reduced to just the time of a traditional lead-lag test. The phase relationship between the loading directions is not necessarily representative of the loads seen on a turbine; however, some combined loading is achieved and the phase angles can in theory be adjusted to represent certain operating states of the turbine. For a 1:2 frequency ratio test, virtual masses are often required near the tip of the blade in the flap direction, which experiences large deflections (a range as much as $10 \mathrm{~m}$ ) and may be difficult to implement, particularly without adding mass in the lead-lag direction, which is undesirable as it reduces the lead-lag frequency. Future work in this area to develop and prototype systems capable of applying these virtual masses is recommended. 


\section{Table of Contents}

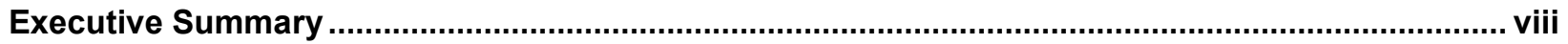

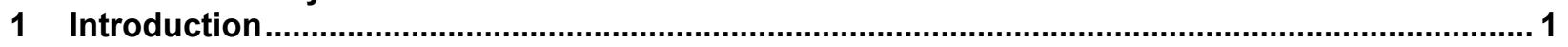

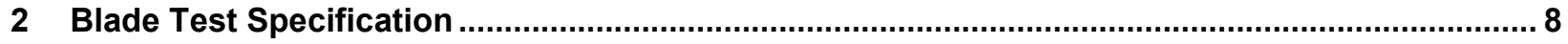

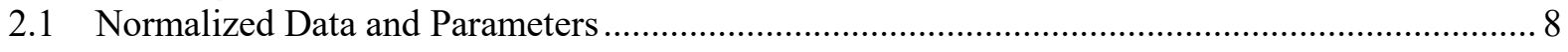

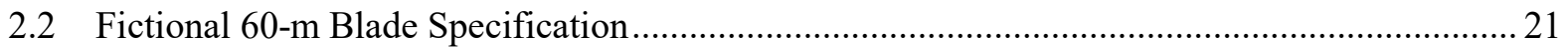

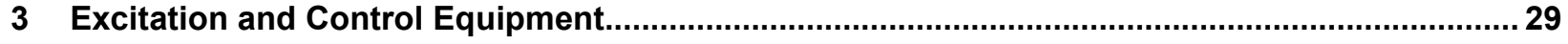

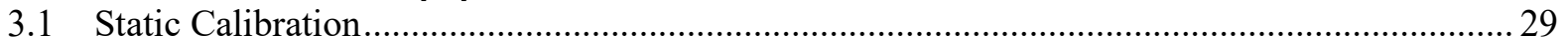

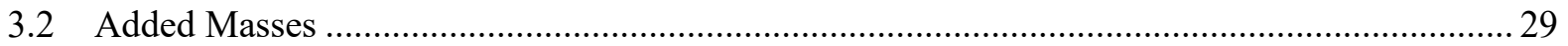

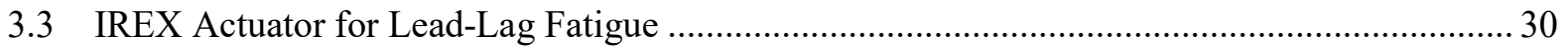

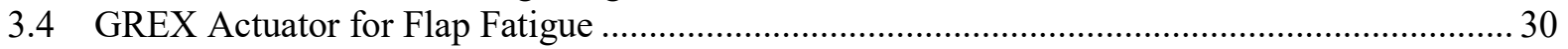

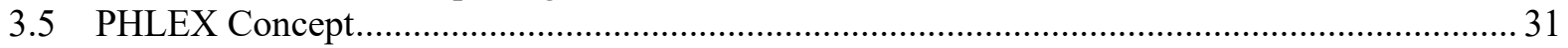

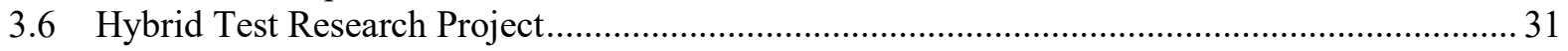

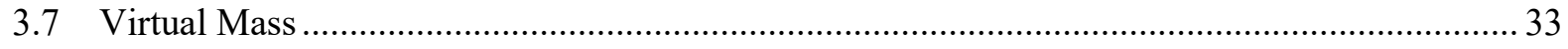

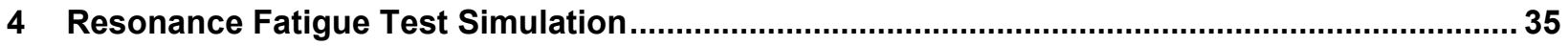

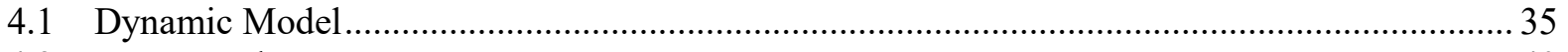

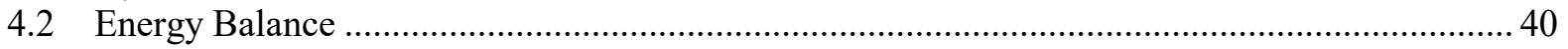

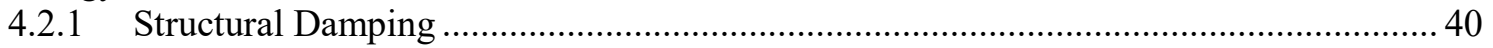

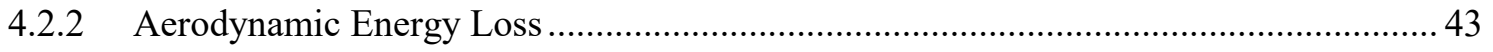

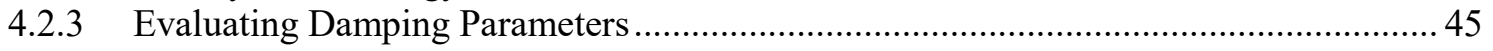

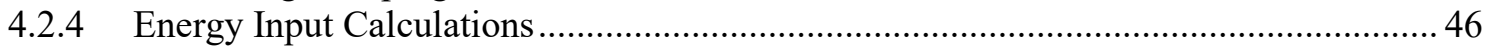

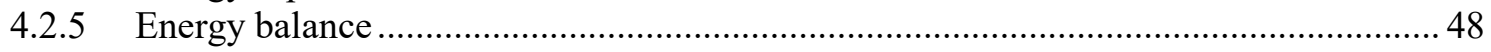

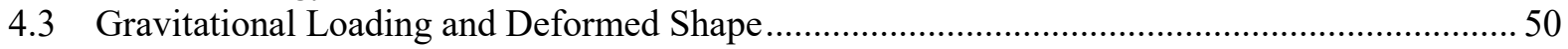

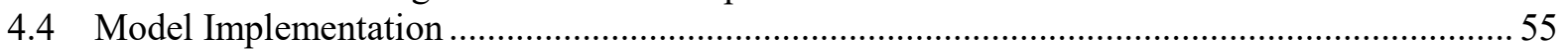

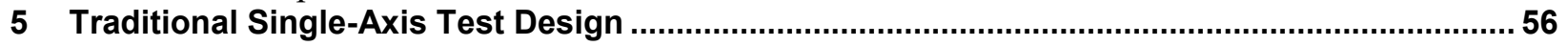

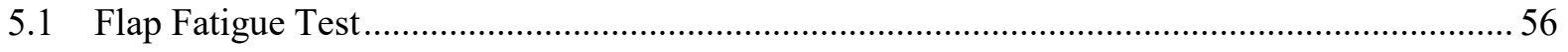

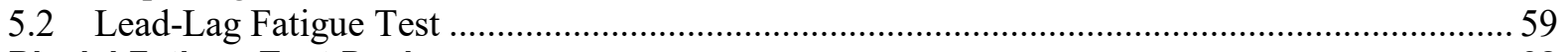

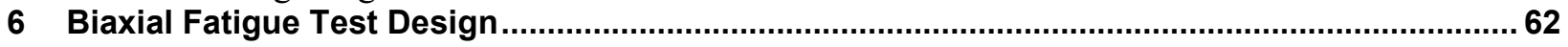

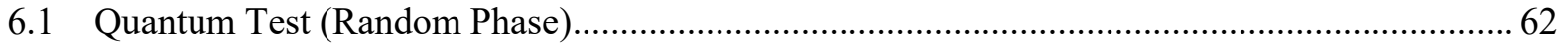

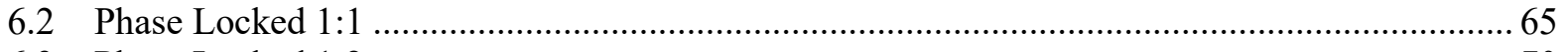

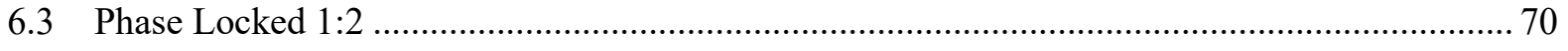

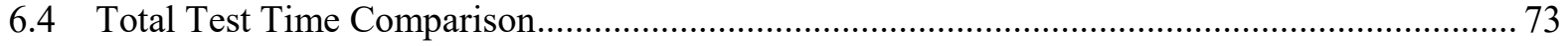

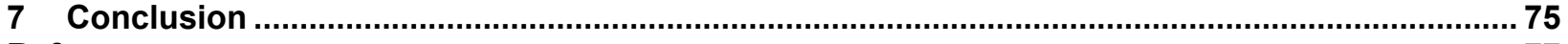

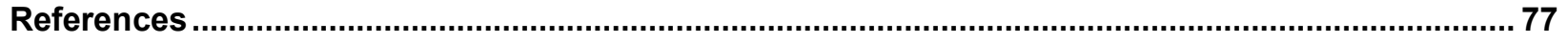




\section{List of Figures}

Figure 1. A biaxial force-displacement fatigue test on a wind turbine blade using two actuators and a bell crank conducted at NREL in 2002.

Figure 2. A prototype resonance fatigue shaker mounted on a $37-\mathrm{m}$ blade at NREL. The blue mass is moved up and down relative to the blade using a hydraulic actuator mounted on top of the device.

Figure 3. BREX fatigue test system combining a linear flap fatigue resonance shaker and a force-

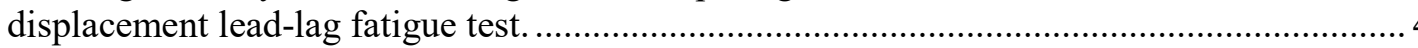

Figure 4. Prototype linear initial resonance excitation system in both the flap and lead-lag directions

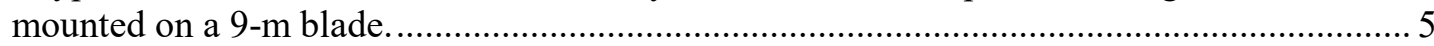

Figure 5. MTS IREXs installed on a turbine blade (viewed from root to tip) for conduction of a biaxial

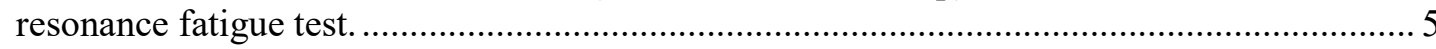

Figure 6. GREX 50 in operation on a flap fatigue test at the Wind Technology Testing Center............... 6

Figure 7. Normalized prebend based on maximum prebend ............................................................... 11

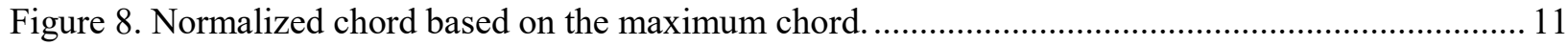

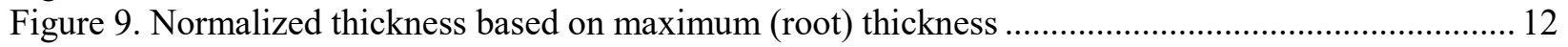

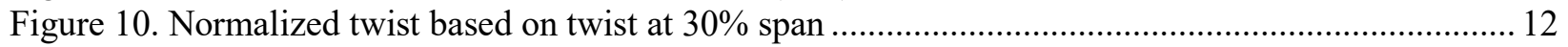

Figure 11. Normalized mass per unit length based on mass per until length at $30 \%$ span ..................... 13

Figure 12. Normalized flap direction stiffness (EI) based on EI at 30\% span........................................ 13

Figure 13. Normalized edge stiffness (EI) based on EI at 30\% span.................................................. 14

Figure 14. Normalized maximum flap static test target moment distribution ........................................ 14

Figure 15. Normalized minimum flap static test target moment distribution ......................................... 15

Figure 16. Normalized maximum edge static test target moment distribution ...................................... 15

Figure 17. Normalized minimum edge static test target moment distribution.......................................... 16

Figure 18. Normalized lead-lag fatigue target moment range distribution ............................................. 16

Figure 19. Normalized flap fatigue target moment range distribution.................................................... 17

Figure 20. Single actuator with fixed mass (black) and minimum moving mass (yellow)...................... 30

Figure 21. Hybrid concept for applying mass to the blade in the lead-lag direction but leaving the mass in the flap direction unchanged. In this case, the IREX is mounted off the blade as part of the

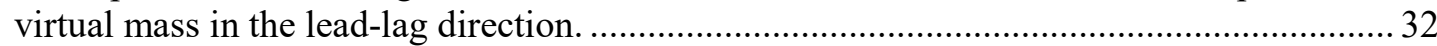

Figure 22. Hybrid configuration using IREX and GREX excitation systems attached to the same saddle.32 Figure 23. Addition of two sine wave force functions showing the result as a sine wave with shifted phase. Phase shifting is accomplished with a GREX-type device by modifying the excitation frequency, and a target phase can be set to include virtual mass in the forcing function for

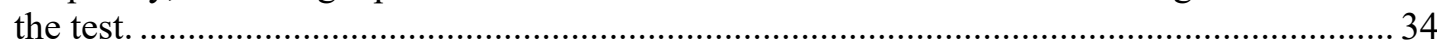

Figure 24. Modification of the bending moment by operating a GREX located at $43 \%$ span at different frequencies, effectively adding a virtual mass to this location as the frequency was decreased from $0.78 \mathrm{~Hz}$ to $0.75 \mathrm{~Hz}$. The force amplitude was adjusted to achieve the same strain

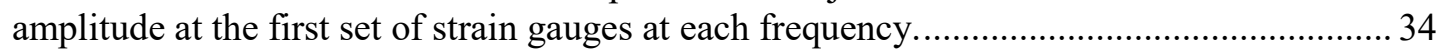

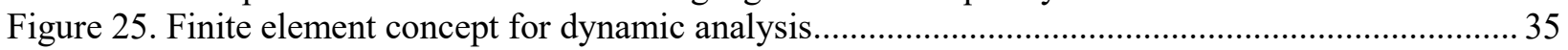

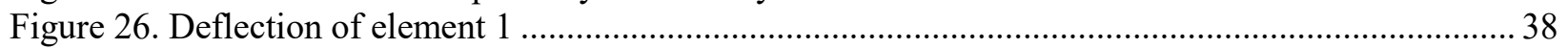

Figure 27. Example global coordinate system description referencing the test rig ..............................50

Figure 28. Deformation of element $i$ under shear and bending...................................................... 51

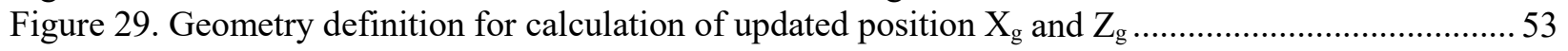

Figure 30. Free-body diagram of an element in deformed position..................................................... 54

Figure 31. Bare blade moment distribution at resonance in flap direction. Natural frequency is $0.56 \mathrm{~Hz} .57$

Figure 32. Flap fatigue test moment range achieved relative to target moment ..................................... 58

Figure 33. Bending moment extrema during flap fatigue test compared to static test target loads ............58

Figure 34. R-ratio (minimum moment/maximum moment) distribution for proposed flap fatigue test..... 59 
Figure 35. Bare blade moment distribution at resonance in lead-lag direction. Natural frequency is 1.01

$\mathrm{Hz}$

Figure 36. Lead-lag fatigue test moment range achieved relative to target moment.

Figure 37. Lead-lag fatigue moment relative to maximum and minimum edge static test target moment. 61

Figure 38. Quantum biaxial fatigue test flap direction moment distribution...

Figure 39. Quantum biaxial fatigue test lead-lag direction moment distribution .................................... 64

Figure 40. Motion pattern representing 30 seconds of test operation for quantum biaxial fatigue test ...... 65

Figure 41. Flap bending moment distribution achieved with 1:1 frequency ratio test setup ..................... 68

Figure 42. Lead-lag bending moment achieved with 1:1 frequency ratio test setup .............................. 69

Figure 43. Displacement representation for 1:1 frequency ratio with phase angle of $90 \mathrm{deg}$ (left), $45 \mathrm{deg}$ (center) and 0 deg (right). The mirror image of these is also possible..................................69

Figure 44. Flap bending moment distribution achieved with 1:2 frequency ratio test setup ................... 72

Figure 45. Lead-lag bending moment achieved with 1:2 frequency ratio test setup .............................. 72

Figure 46. Displacement representation for 1:2 frequency ratio with phase angle of $90 \mathrm{deg}$ (left), $45 \mathrm{deg}$ (center) and 0 deg (right). The mirror images of these are also possible............................... 73

Figure 47. Comparison of test time between different test methods...................................................... 74

\section{List of Tables}

Table 1. Blade Parameters and Normalization Parameters ….................................................................. 9

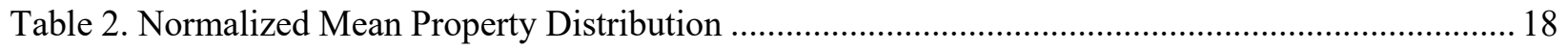

Table 3. Scaled 60-m Blade Geometry and Beam Element Properties.................................................... 22

Table 4. Scaled 60-m Test Target Loads Including All Design and Test Factors .....................................25

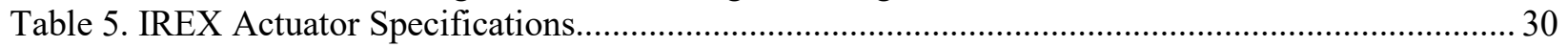

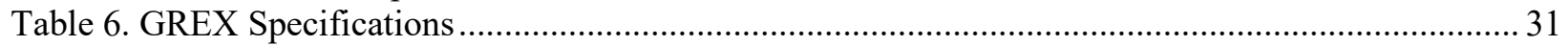

Table 7. Proposed Uniaxial Flap Fatigue Test Configuration and Dynamics at Each Saddle ................... 57

Table 8. Proposed Uniaxial Lead-Lag Fatigue Test Configuration and Dynamics at Each Saddle............ 60

Table 9. Mass Distribution for Quantum Biaxial Fatigue Test ...............................................................6 63

Table 10. Saddle Amplitudes and Forces from Quantum Biaxial Fatigue Test Simulation ....................... 63

Table 11. Mass Configuration for Phase-Locked Biaxial Test with 1:1 Frequency Ratio Using an IREX in the Lead-Lag Direction and a GREX in the Flap Direction to Excite the Blade .....................67

Table 12. Displacement, Acceleration, and Forces for Phase-Locked Biaxial Test with 1:1 Frequency

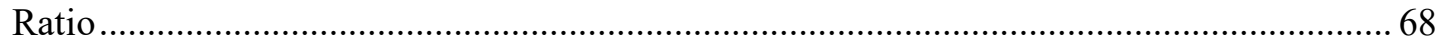

Table 13. Mass Configuration for Phase-Locked Biaxial Test with 1:2 Frequency Ratio ....................... 71

Table 14. Displacement, Acceleration, and Forces for Phase Locked Biaxial Test with 1:2 Frequency

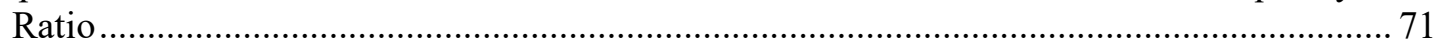




\section{Introduction}

This report presents a study of a biaxial fatigue test simulation for a fictional 60-meter (m) blade to better assess the future needs and potential for implementation of these techniques in certification and research and development testing of large wind turbine blades. The primary goal of structural testing of wind turbine blades is to demonstrate the performance of the structure under the anticipated lifetime loads. Advantages to biaxial testing include the potential for a reduction in total test time and possibly to apply test loads that are closer to the loading the blade will experience in operation on the turbine and thus are more realistic when compared with separate, single-axis fatigue tests. Reduced test time reduces the costs both of the testing itself and of the business uncertainty associated with having a production line ready to go prior to the completion of the test program. More realistic structural testing can better identify weaknesses in a design that could lead to failures once the turbine is deployed, therefore improving the turbine blade reliability. In both cases, these benefits can lead to reductions in the cost of wind energy. However, achieving these advantages in large-scale commercial certification testing has proven elusive due to a combination of technical challenges and industry momentum to continue with the current accepted practice rather than risk applying a potentially more severe biaxial loading condition. This report explores several concepts for biaxial testing to evaluate the design space of a multimegawatt biaxial fatigue test by defining the forces and displacements required for a typical certification test program under the IEC 61400-23 Standard (2014). These results also provide a design space scope for biaxial test systems with the goal of encouraging test labs and blade original equipment manufacturers to explore implementation of biaxial test techniques when planning a certification test.

Early structural tests of wind turbine blades were primarily performed in the flap direction. For relatively small blades, the flap fatigue loads are higher than the lead-lag loads, and these singleaxis tests thus represented the primary load the blades seen on the turbine. Fatigue loading was conducted using actuator(s) operating in a force-displacement mode with frequencies well below the first resonance frequency of the structure. A force-displacement mode test is defined as a test run well below the system resonance frequency where the applied force is in phase with the resulting displacement. This test method is similar to approaches used in other large-scale structural testing applications, for example, in aviation. Force-displacement enabled good control of the bending moment and load ratio (sometimes called the R-ratio) applied. As blades grew longer in the 1990s, the lead-lag direction fatigue loads became more significant due to the weight of the blades as the turbine rotor spins. Separate force-displacement lead-lag and flap tests were sometimes conducted, but it was recognized that these separate tests did not accurately represent the phase angle of the combined loading on the turbine. In 1999, the National Renewable Energy Laboratory (NREL) introduced a method for biaxial loading of a wind turbine blade using actuators and a bellcrank to simultaneously load the flap and lead-lag directions (Hughes, Musial and Stensland 1999). A photo depicting this type of fatigue test is shown in Figure 1. Because of the relatively large deflections seen in the blade test, an algorithm was developed for controlling the motion and thus the applied moment combinations and phase angle given the nonlinearity due to the test set-up geometry. 


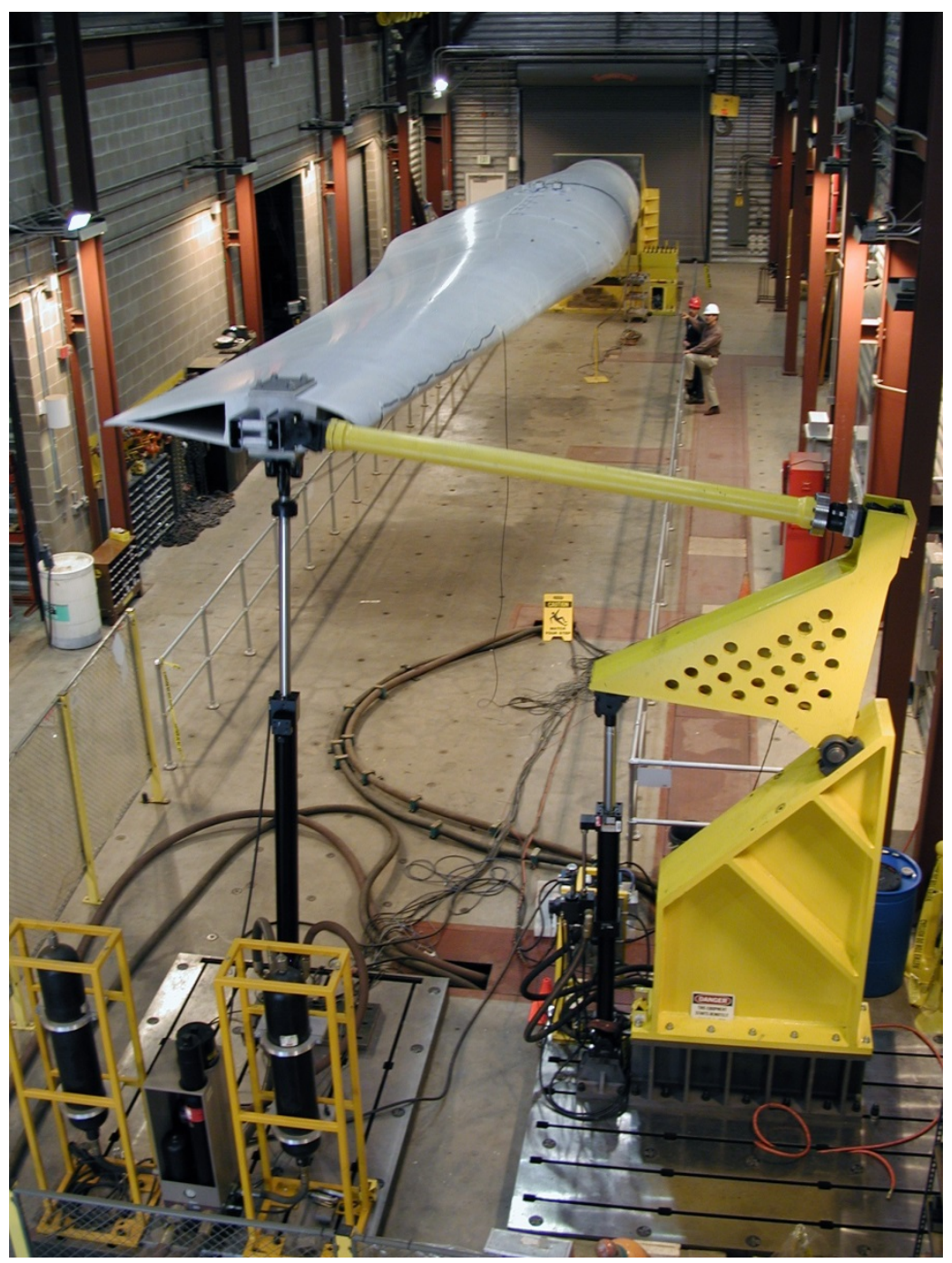

Figure 1. A biaxial force-displacement fatigue test on a wind turbine blade using two actuators and a bell crank conducted at NREL in 2002.

Photo by NREL 14825

However, as wind turbine blade size increased in the 2000 s, traditional force-displacement test techniques became expensive to implement and time consuming due to the large strokes and slow test speeds required to achieve the desired moments. Resonance fatigue testing was developed by several different laboratories, including NREL, to accelerate testing speeds and achieve more accurate bending moment distributions on the blade while using less energy to conduct the test. At NREL, early resonance fatigue testing involved a custom servo-hydraulic linear shaker with a mass attached to the end of an actuator mounted on the blade (Figure 2). The actuator would be operated in displacement control applying a sinusoidal motion to the mass. At the resonance frequency of the test system (turbine blade plus added the added test equipment), this will excite the blade. The exciter amplitude is increased until the target load level is achieved. A balance between the energy input and the energy loss due to structural and aerodynamic damping per cycle is maintained. A combination technique utilizing a forcedisplacement test in the lead-lag direction and a resonance fatigue test in the flap direction was developed by White et al. (2004) and is referred to as the Blade Resonance Excitation (BREX) 
system. This approach enabled control of the phase angle and has the advantages of resonance testing in the flap direction. The BREX was implemented successfully for the test of a 37-m wind turbine blade shown in Figure 3 (D. White 2004). However, the energy requirements and point loading for the lead-lag direction were substantial and achieving the desired bending moment curve in the lead-lag direction would likely require multiple loading points along the span. This further increases the energy requirement and becomes technically challenging on large blades (i.e., blades longer than $50 \mathrm{~m}$ ) that can have flap-fatigue tip displacement ranges greater than $10 \mathrm{~m}$. An additional drawback of this approach is that typically modern fatigue tests are designed with more cycles in the lead-lag direction than in the flap direction to avoid nearing the static strength of the blade during the accelerated fatigue test. Because the BREX requires testing the lead-lag frequency at the flap resonance frequency, the test time to achieve the leadlag damage equivalent loads may be significantly extended.

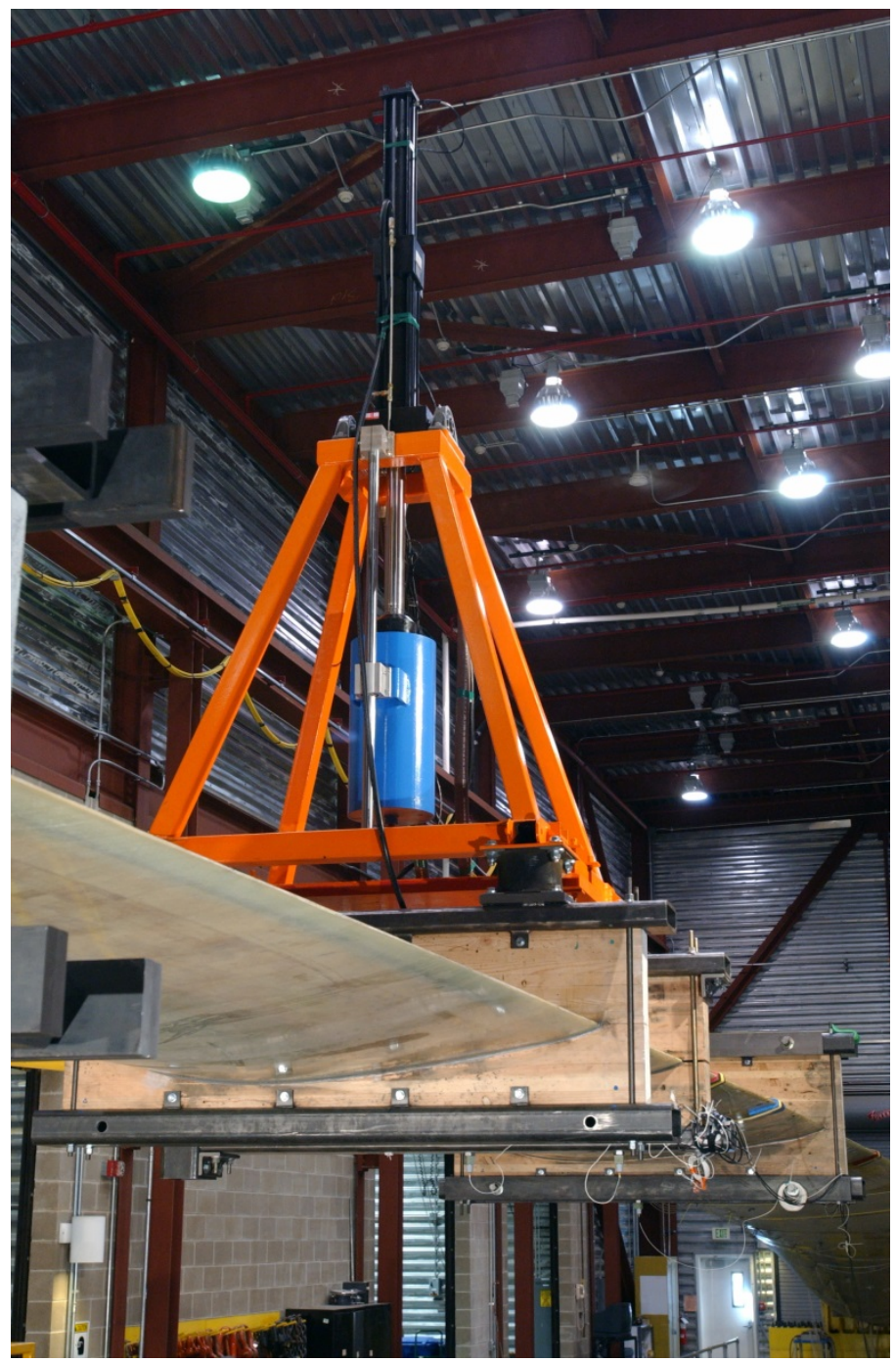

Figure 2. A prototype resonance fatigue shaker mounted on a 37-m blade at NREL. The blue mass is moved up and down relative to the blade using a hydraulic actuator mounted on top of the device.

Photo by Warren Gretz, NREL 12890 


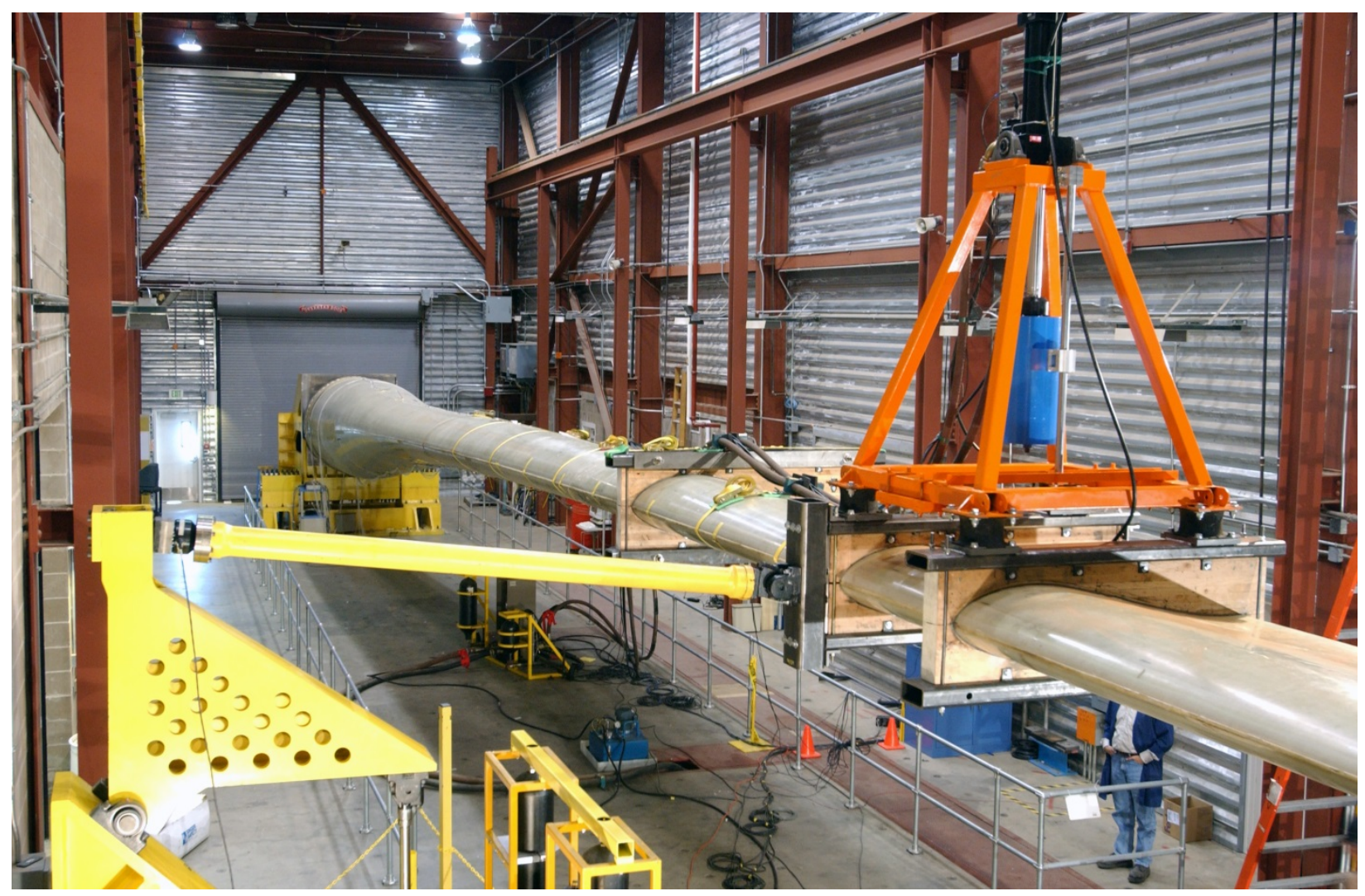

Figure 3. BREX fatigue test system combining a linear flap fatigue resonance shaker and a forcedisplacement lead-lag fatigue test.

Photo by Warren Gretz, NREL 12893

Following the development of the BREX, efforts were undertaken to design and demonstrate a system for biaxial resonance fatigue testing where the blade would be excited in both the flap and lead-lag directions at resonance. A smaller scale prototype system mounted on a 9-m blade is shown in Figure 4. This research resulted in an excitation technology (Hughes, Musial and White 2014) that has been licensed for manufacturing by MTS Systems Corporation (MTS) which created the Inertial Resonance Exciter (IREX) product - initially called the Universal Resonance Exciter (UREX) - to meet the requirements for this type of biaxial fatigue testing. The IREX technology was used to perform uniaxial fatigue tests on blades up to $50 \mathrm{~m}$ in length (Snowberg and Hughes 2013). In addition, a biaxial "quantum" fatigue test using IREX actuators in both the flap and lead-lag directions was successfully conducted and the required controls to maintain the desired test amplitude were demonstrated (Snowberg, et al. 2014). The hardware configuration for this test is shown in Figure 5. 


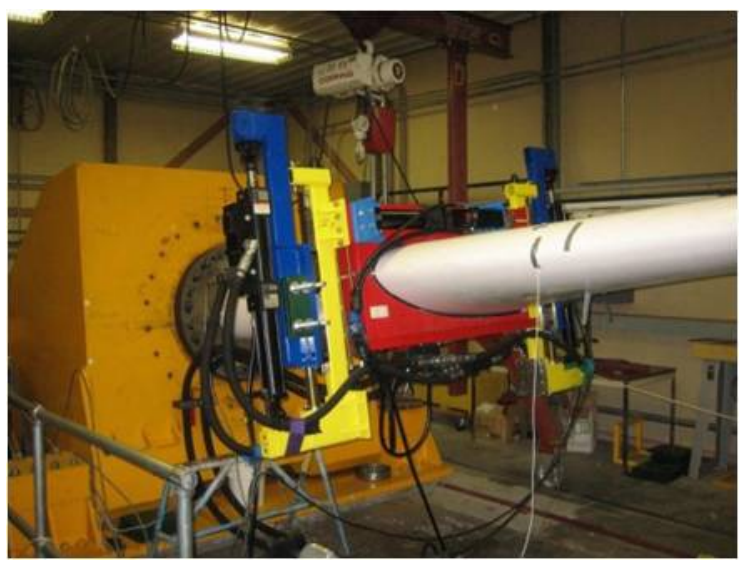

Figure 4. Prototype linear initial resonance excitation system in both the flap and lead-lag directions mounted on a 9-m blade.

Photo by Mike Jenks, NREL 17641

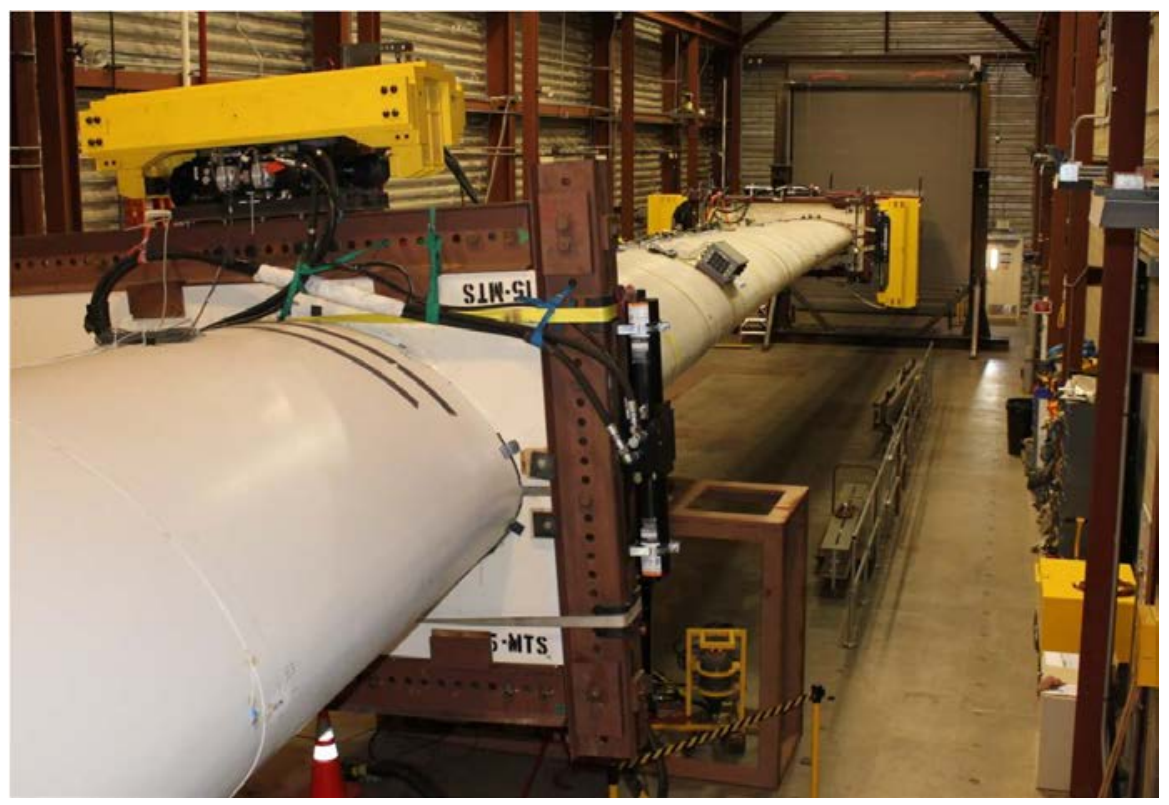

Figure 5. MTS IREXs installed on a turbine blade (viewed from root to tip) for conduction of a biaxial resonance fatigue test.

Photo by David Snowberg, NREL 28708

In 2008, the U.S. Department of Energy sought to expand the large-scale blade testing capability in the United States. The Massachusetts Clean Energy Center was selected to own and operate a new laboratory located in Boston, Massachusetts. This new laboratory, named the Wind Technology Testing Center (WTTC), was constructed to meet the growing need for commercial testing of large wind turbine blades. The WTTC opened in 2011. MTS IREX units were purchased as part of the initial test equipment and technology at the WTTC and are currently in use for lead-lag fatigue testing of multimegawatt-scale blades at the laboratory. However, limitations were identified in the MTS IREX to provide sufficient energy input in the flap direction to overcome the aerodynamic damping of flexible $50+\mathrm{m}$ blades. The problem was that to increase the energy input, more mass must be added to the blade, in turn decreasing the test 
frequency. A reduced test frequency reduces the energy input per cycle from an inertial massbased exciter, preventing the target flap moment range from being achieved with this hardware. While an IREX-like device with greater stroke will improve the possible energy input, all other things being equal, it would still be a challenge to design flap fatigue tests that meet the target bending moment distribution on a large blade using this type of exciter. A collaboration between NREL, MTS, and the WTTC to address these challenges in designing flap fatigue tests with existing hardware resulted in the development of the Ground-based Resonance Exciter (GREX) system, which was first implemented in 2013. In this approach to resonance fatigue testing, an actuator is connected between the blade and the ground and applies a forcing function to excite the structure at or near its fundamental resonance frequency. The GREX (Figure 6) enables significant greater energy input to a blade without requiring adding significant mass to the test system. This in turn results in typically achieving higher test frequencies compared with an IREX excitation system depending on the required additional mass to meet the target bending moment distribution. The GREX is operated at the first flap resonance frequency of the test system such that it applies an approximately sinusoidal forcing function to the blade that leads the displacement by a phase angle of roughly 90 degrees. In addition, the GREX technology enables adding or removing virtual mass, a concept that will be discussed in more detail later in this report, by running slightly off resonance so that part of the forcing function is in phase with displacement and part is out of phase.

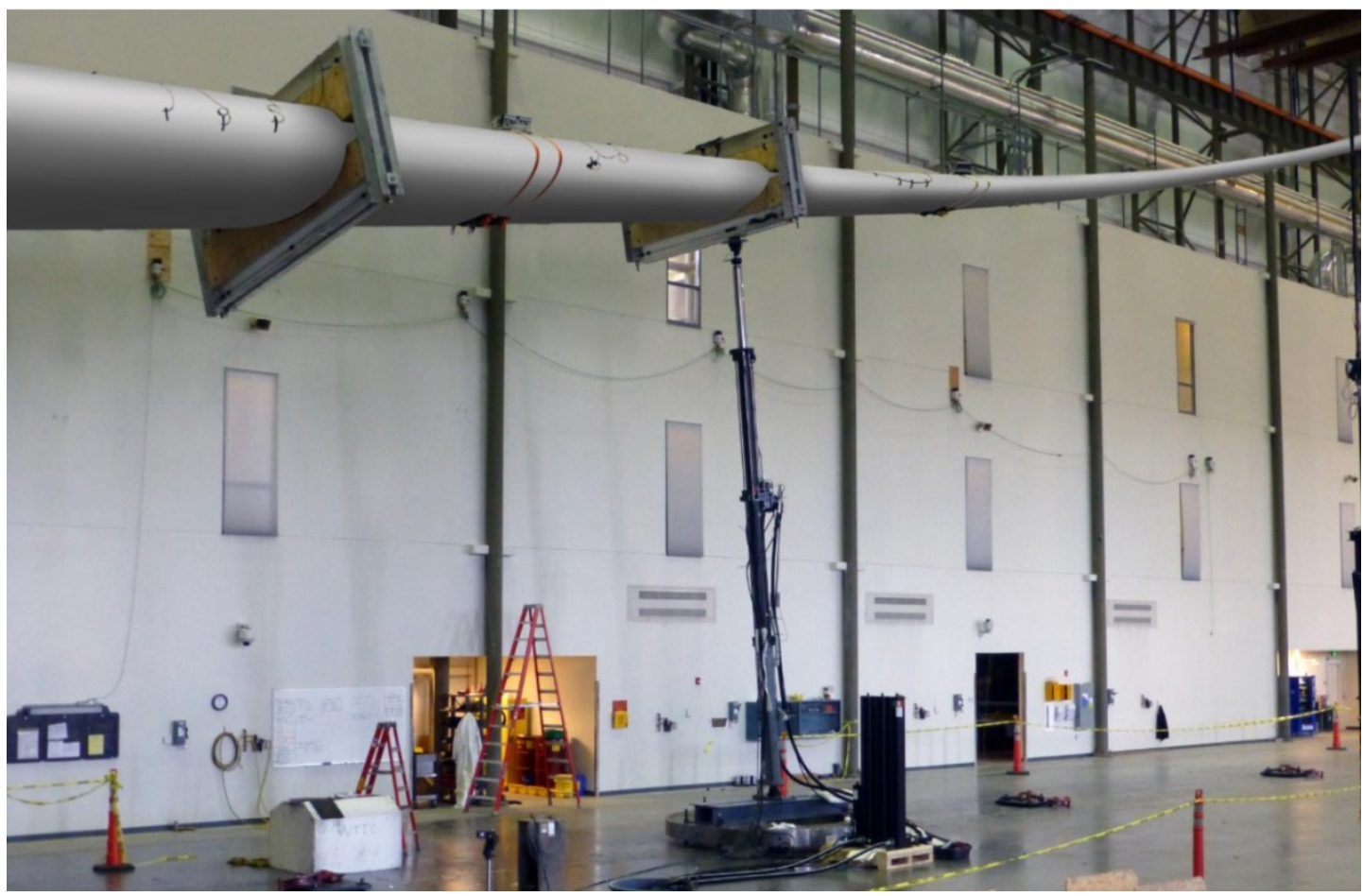

Figure 6. GREX 50 in operation on a flap fatigue test at the Wind Technology Testing Center.

Photo by Nathan Post, NREL 34756

This report considers the options for biaxial fatigue testing of a 60-m wind turbine blade at the WTTC using the IREX and GREX technology as well as estimating what additional hardware or technology might be required. Insight into the use of these test systems is gained through experience at the WTTC testing blades in the $50+\mathrm{m}$ length along with results from recent 
research undertaken at the National Wind Technology Center (NWTC) at NREL to prototype potential systems using smaller-scale test articles. In particular, this report will evaluate potential test systems that combine resonance loading with virtual masses - masses mounted to slide tables or other mechanical linkages so that they only act in one direction or forcing functions from hydraulic actuators - to enable phase-locked resonance or quasi-resonance testing. These research projects include the phase-locked excitation (PHLEX) approach (Beckwith, White and Barsotti 2013) where the concept is to increase the flap fatigue test frequency to match the leadlag resonance frequency and more recently the "Hybrid" test project that adds mass in one test direction without impacting the other test direction.

Unfortunately, the mechanical properties and test load levels for most commercial blades are considered company proprietary information and cannot be used in this type of public research study. Past blade scaling studies and research blade designs, such as the Sandia 61.5-megawatt (MW) blade model developed for the NREL 5-MW reference turbine (Resor 2013) are considerably stiffer and heavier in comparison with similar size commercial blades produced recently. This may be attributed to different design criteria: the Sandia 61.5 blade was designed for IEC class IB wind conditions while most of the blades currently tested in the US are designed for lower power output turbines in IEC wind class II and III conditions and therefore are subjected to lower wind speeds within their design envelope. Differences in mass and stiffness are critical in the design of a fatigue test where the larger deflections significantly increase the energy input requirements and change the natural frequencies and mode shapes. To provide as representative a test article as possible, the data from 17 different commercial turbine blades has been normalized and averaged to generate a single scalable blade used to provide the specifications for the $60-\mathrm{m}$ test article considered in this report.

To estimate the loading applied to a turbine blade, a simple fatigue modeling approach is presented that has been fit and verified against existing test data and provides good estimates of the required energy and force inputs during resonance fatigue testing. This model is similar to approaches taken by White (2004) and Desmond (2009), but separates the aerodynamic and structural damping to enable more accurate representation of the energy requirements as blades become larger and aerodynamic damping in fatigue testing dominates the total damping.

In addition to the phase-locked testing concept where the flap and lead-lag frequencies have a 1:1 ratio, this report also introduces the idea of using other simple Lissajous figures where a specific phase angle is maintained between the flap and lead-lag frequencies. This report specifically considers the ratio of 1:2 because many blades in the 50-60 m range have test frequencies that fall close to this ratio. 


\section{Blade Test Specification}

To provide a realistic assessment of a possible biaxial test configuration and the hardware required to excite and control that test, an accurate blade model is required. Several scaling studies in the past have developed reference wind turbine blade models that are publicly available and have been used for turbine simulation and cost studies. One example is the Sandia National Laboratories (Sandia) 61.5-m reference blade created by Sandia for the NREL offshore 5-MW baseline wind turbine (Resor 2013). Unfortunately, these fictional blades have proven to be insufficient for modeling structural test requirements due to significantly overpredicting the stiffness and mass of the blades in comparison to the present day commercial blade designs. Several factors for this include the continuous improvement in blade design, materials, and manufacturing technology as well as an industry trend to design larger rotors optimized for lower wind speed conditions. Most utility-scale wind turbine blades currently under certification testing in the United States have lengths in the 50- to 60-m range and are designed for 1.6- to about 3MW turbines. These blades are typically designed for wind class II or III turbines although this information is not available for all of the blades included in this study. As longer blades have been designed for smaller-capacity turbines and lower wind conditions, the corresponding stiffness and mass of the blade have not increased as much as might have been predicted from scaling earlier designs.

Rather than attempt the design of a blade, this study relies on curve fitting and extrapolating the geometry, mass, stiffness, and applied test loads based on data from commercial blade tests conducted over the past 4 years. This enables us to provide a realistic example blade without compromising proprietary information. The blade test article specifications and target loads from 17 different test articles in the 44-m to 57-m length range have been normalized, combined, and slightly extrapolated to generate a realistic fictional test article whose properties can be released in the public domain. The process used for normalizing the data is described here along with the final results; however, to keep the source data confidential, the precursor data cannot be provided. Reasonable extrapolation of these data to a fictional blade exceeding the length of any of the blades studied was made possible by considering each normalizing parameter as a function of blade length. Although there is always some risk of nonlinearities impacting the accuracy when extrapolating a data set, the small extrapolation from a 57-m length to a $60-\mathrm{m}$ length limits the risk of a gross error in the predicted blade properties. A $60-\mathrm{m}$ blade length was selected because it is desirable to consider how proposed test methods will apply to larger blades.

\subsection{Normalized Data and Parameters}

The fatigue test simulation to be conducted for this study requires the data necessary to assemble a beam element model of the blade. The parameters that are included in this scaling study are listed in Table 1. The undeformed geometry, global stiffness parameters, and applied target loading are considered. The fatigue test design for the blades used as input in this study varied from 1 million to 9 million cycles. In each case, the test target was scaled to 2 million cycles for lead-lag fatigue and 1 million cycles for flap fatigue using the S-N curve inverse slope parameter provided by the customer, if available, or assumed to be an inverse slope of 9 if not available. Not all information was available for all blades. In some cases, multiple blades used in the study had the same external geometry, so to develop a representation of each parameter only the subset of blades with unique information is used. To define the final curve fit blade, several parameters must be arbitrarily selected, including the blade length, maximum chord, and prebend. 
The following process was performed to normalize and combine the data. First, the respective data for each blade were interpolated for 101 equally spaced nodes between the blade root and the blade tip from data provided by the blade manufacturer or turbine original equipment manufacturer to the test laboratory. Then, the resulting values were normalized based on the values at a specific normalization location, as indicated in Table 1. For target loading, it was reasonable to use the root moments. However, different blade designers and blade designs state widely varying unit mass and stiffness properties near the root of the blade, so a point farther out where results were more consistent was selected for normalization, in this case, using the values at $30 \%$ span. Likewise, the twist reported for the root of a blade where it is round varies widely; again, the twist at $30 \%$ span was used for normalization of the data. Geometric data were normalized by the maximum value of the chord, thickness, and prebend regardless of where they occurred.

Table 1. Blade Parameters and Normalization Parameters

\begin{tabular}{|c|c|c|c|}
\hline Property & $\begin{array}{l}\text { Normalization } \\
\text { location }\end{array}$ & $\begin{array}{l}\text { Parameter slope } \\
\text { linear fit of } \\
\text { normalization value } \\
\text { vs. span }(\mathrm{m})\end{array}$ & $\begin{array}{l}\text { Parameter offset } \\
\text { linear fit of } \\
\text { normalization value } \\
\text { vs. span }(\mathrm{m})\end{array}$ \\
\hline \multicolumn{4}{|l|}{ Geometry } \\
\hline Prebend & Tip (max prebend) & & \\
\hline Chord & Max Chord & & \\
\hline Thickness & Max Thickness & & \\
\hline Twist & $30 \%$ span & $0.1583 \mathrm{deg} / \mathrm{m}$ & $0.5212 \mathrm{deg}$ \\
\hline \multicolumn{4}{|l|}{ FEA beam properties } \\
\hline Mass/unit length & $30 \%$ span & $4.298(\mathrm{~kg} / \mathrm{m}) / \mathrm{m}$ & $-6.443 \mathrm{~kg} / \mathrm{m}$ \\
\hline Stiffness El-Flap & $30 \%$ span & $32,118 \mathrm{kN}-\mathrm{m}^{2} / \mathrm{m}$ & $-1,061,000 \mathrm{kN}-\mathrm{m}^{2}$ \\
\hline Stiffness El-Lead-lag & $30 \%$ span & $125,886 \mathrm{kN}-\mathrm{m}^{2} / \mathrm{m}$ & $-4,449,000 \mathrm{kN}-\mathrm{m}^{2}$ \\
\hline \multicolumn{4}{|c|}{ Test target moment including all test factors } \\
\hline Static Max Flap & Root & $484.4 \mathrm{kNm} / \mathrm{m}$ & $-15,780 \mathrm{kNm}$ \\
\hline Static Max Edge & Root & $269.0 \mathrm{kNm} / \mathrm{m}$ & $-8,689 \mathrm{kNm}$ \\
\hline Static Min Flap & Root & $458.3 \mathrm{kNm} / \mathrm{m}$ & $-16,630 \mathrm{kNm}$ \\
\hline Static Min Edge & Root & $266.9 \mathrm{kNm} / \mathrm{m}$ & $-9,221 \mathrm{kNm}$ \\
\hline $\begin{array}{l}\text { Fatigue lead-lag bending } \\
\text { moment range for } 2 \text { million } \\
\text { cycles }\end{array}$ & Root & $409.7 \mathrm{kNm} / \mathrm{m}$ & $-13,970 \mathrm{kNm}$ \\
\hline $\begin{array}{l}\text { Fatigue flap bending moment } \\
\text { range for } 1 \text { million cycles }\end{array}$ & Root & $252.2 \mathrm{kNm} / \mathrm{m}$ & $-6,394 \mathrm{kNm}$ \\
\hline
\end{tabular}


The normalized blade properties along with \pm 2 standard deviations are presented in Figure 7 through Figure 13 to demonstrate the range of variability observed in each parameter. Prebend shape is relatively inconsistent between different blades; however, as this has limited impact on the fatigue tests, the exact shape of the prebend is not critical. The mean distribution of the normalized prebend provides a smooth curve and is considered acceptable for this study. Normalized chord and thickness distributions are relatively consistent among the blades surveyed. As previously mentioned, twist shows wide variability near the root but is reasonably consistent past 30\% span and again will have no impact on the fatigue simulations undertaken in this study. Mass per unit length, flap, and lead-lag stiffness all vary widely in the root portion of the blade but are reasonably consistent and provide a smooth curve past the $30 \%$ span normalization point. Results are consistent across the blades surveyed for the shape of the normalized target test loads as shown in Figure 14 through Figure 19, so the test specification developed for the fictional blade will be fairly representative of the typical target load distribution required.

Once the results are normalized, the mean, median, and standard deviation of these normalized values can be found as a function of percent span. The mean values reported in Table 2 are used to calculate the distribution of the reference blade. For most properties, the normalizing parameter is approximately linear as a function of blade span. The slope and offset for this normalizing parameter as a function of blade span in meters are presented in Table 1. Thus, once the blade length, prebend, and maximum chord are selected, the rest of the test specification information can be generated as follows:

1. Determine normalizing parameter
A. Chord normalization is maximum chord, prebend normalization is the prebend.
B. Thickness normalization is the root chord from chord distribution to provide a round root.
C. All others-select length of blade to be generated, then:

Normalizing parameter $=$ slope $*$ blade length in meters + of $f$ set

2. Multiply normalized distribution (Table 2) by normalizing parameter.

3. Multiply span fraction by selected blade length. 


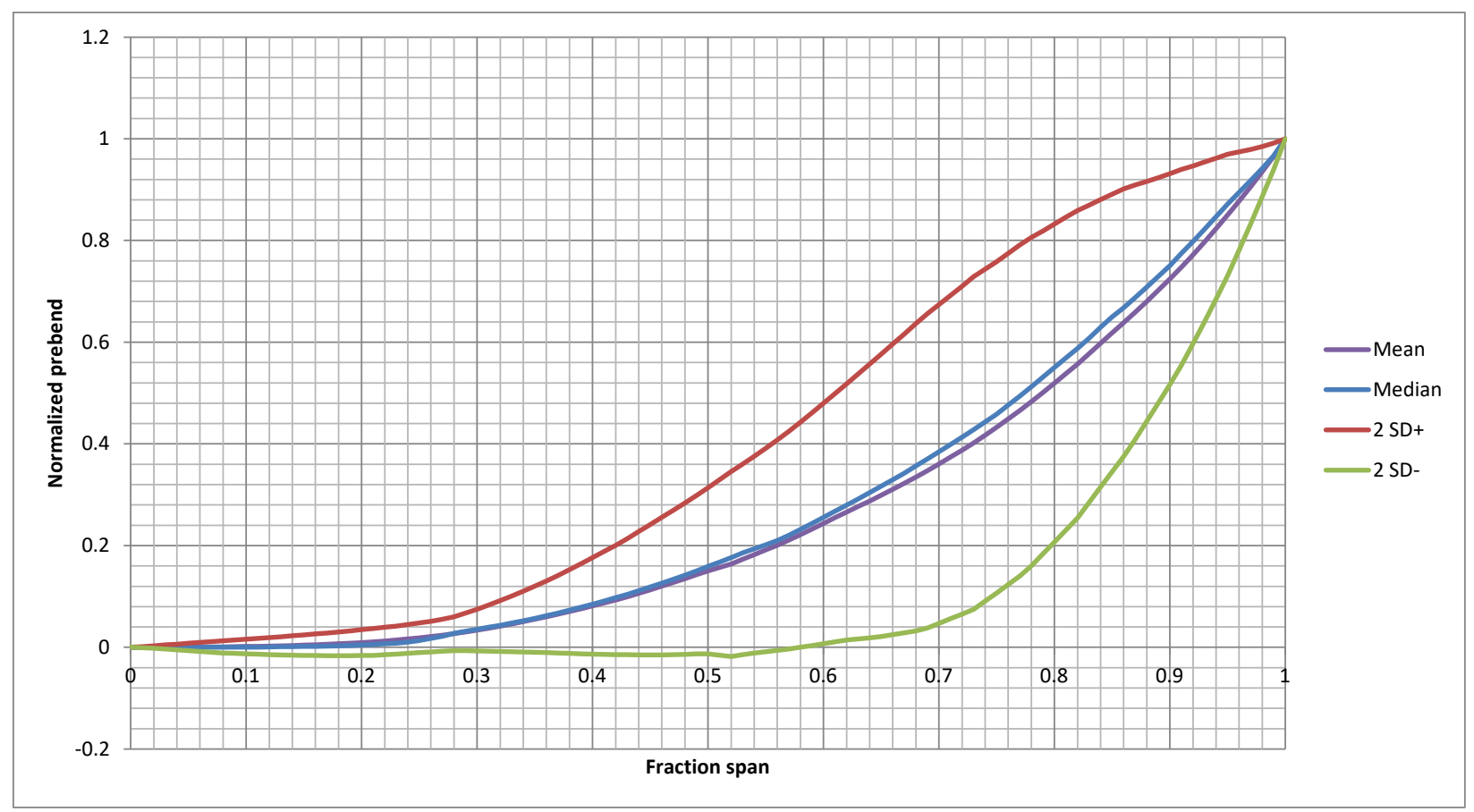

Figure 7. Normalized prebend based on maximum prebend

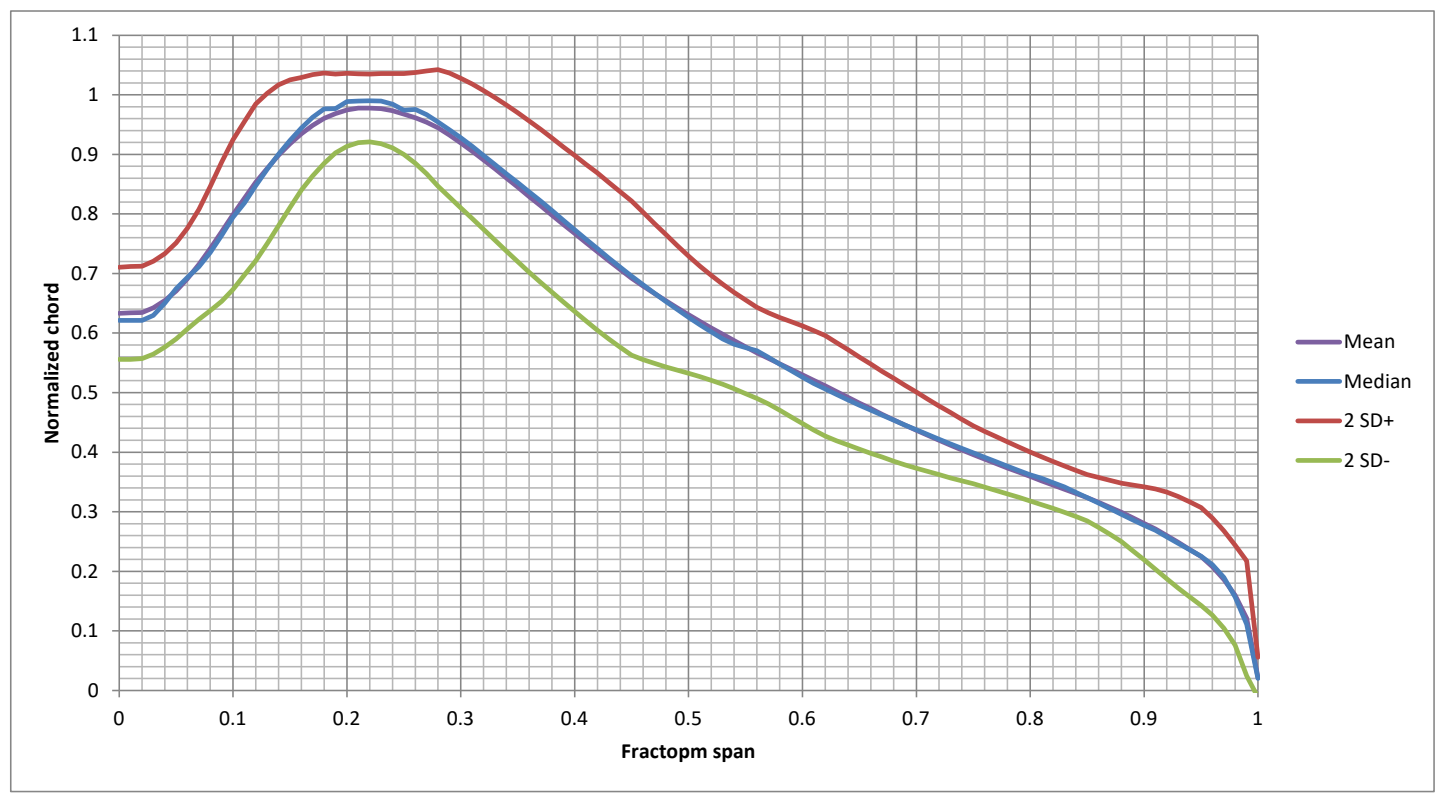

Figure 8. Normalized chord based on the maximum chord.

Note: because the data for each blade as normalized is based on that blade's maximum chord and the maximum chord occurs at different fractional spans for different blades, the mean and median values do not quite reach 1.0. 


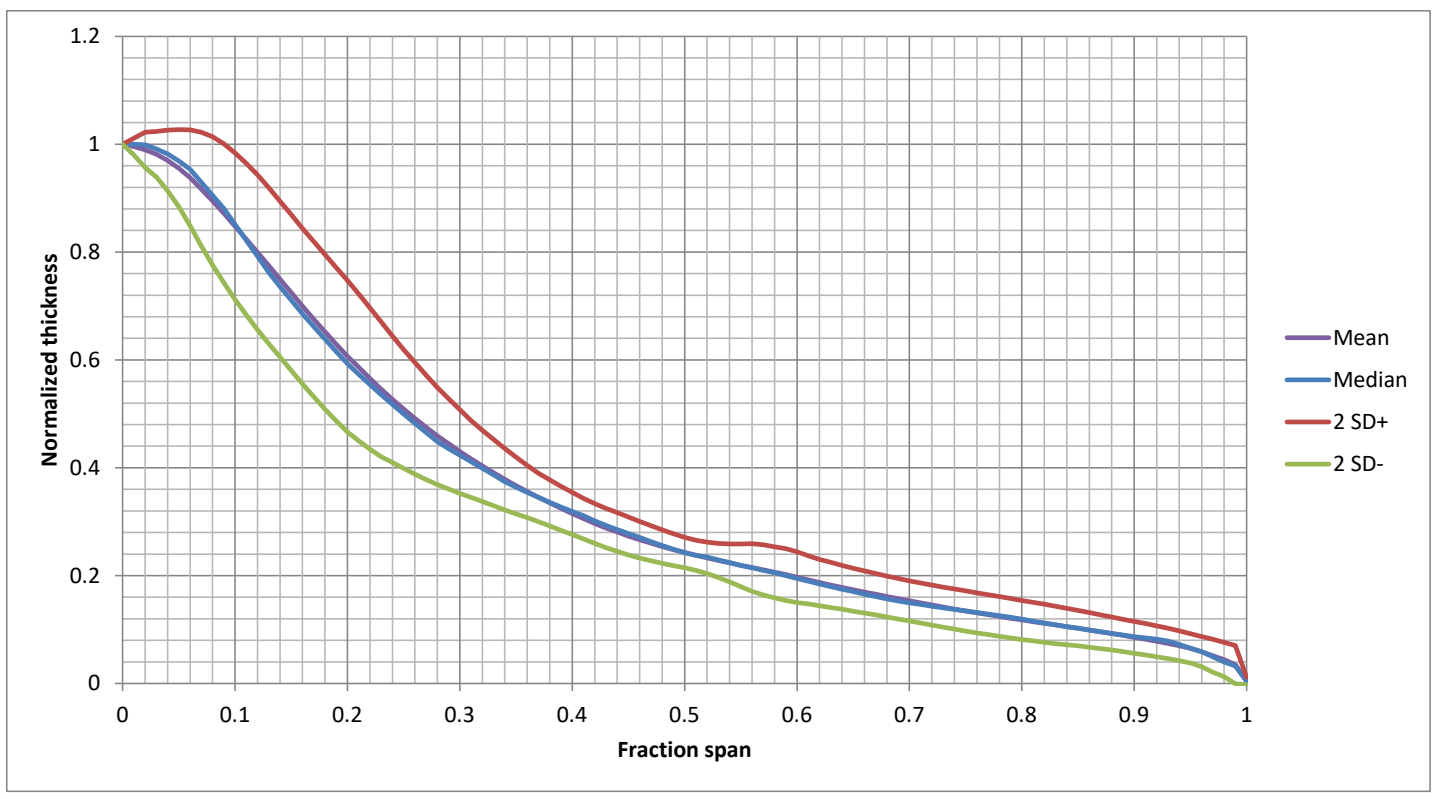

Figure 9. Normalized thickness based on maximum (root) thickness

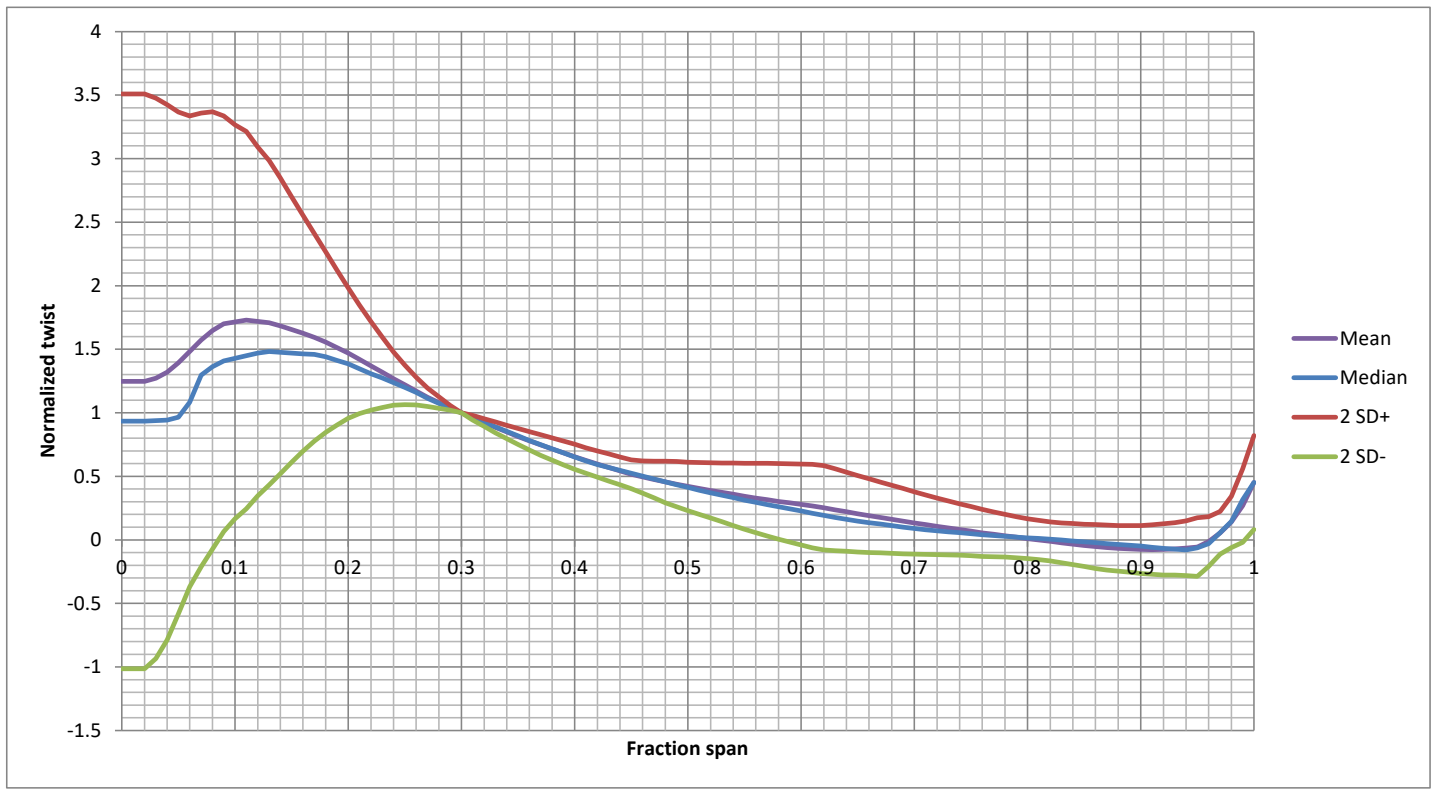

Figure 10. Normalized twist based on twist at $30 \%$ span 


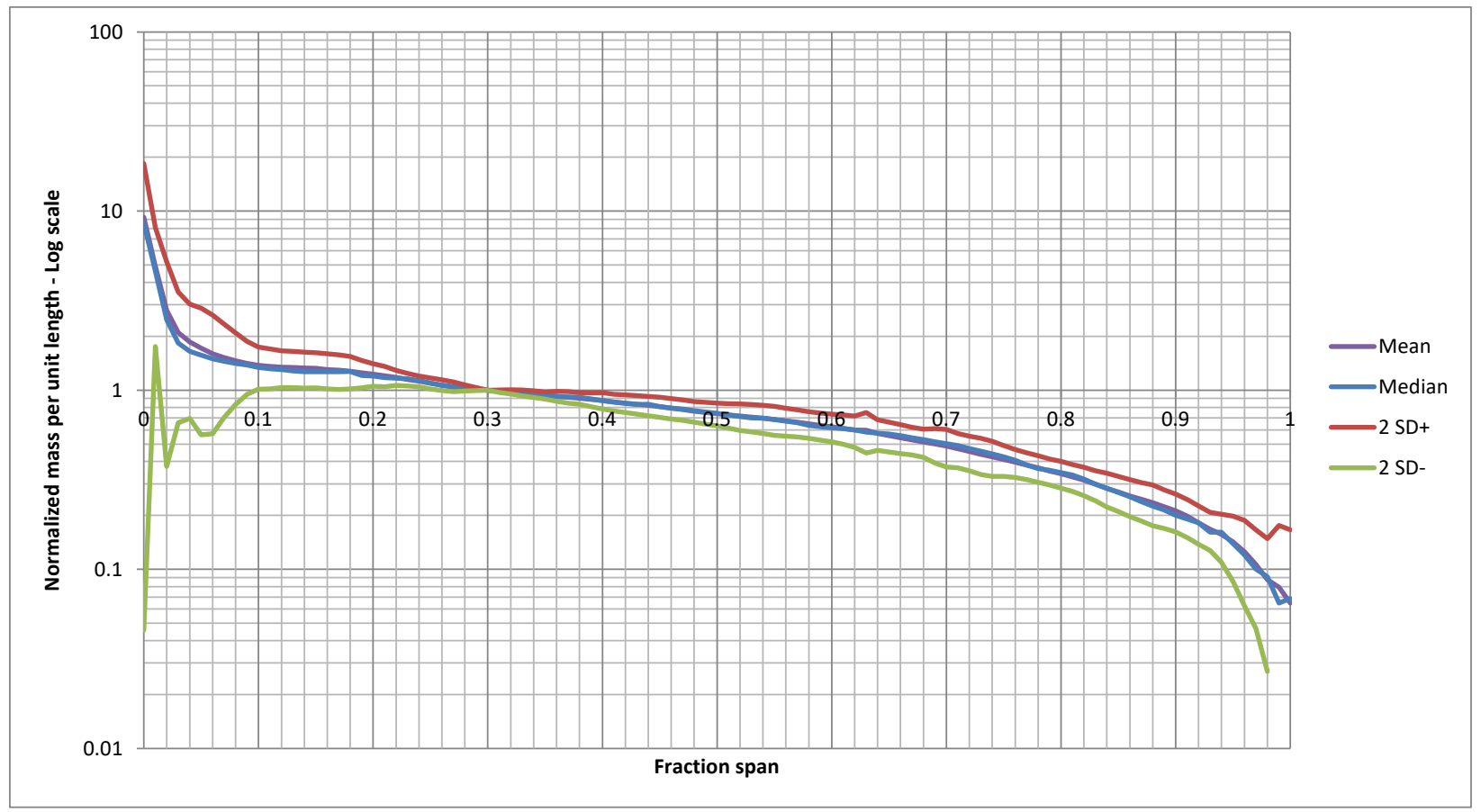

Figure 11. Normalized mass per unit length based on mass per until length at $30 \%$ span

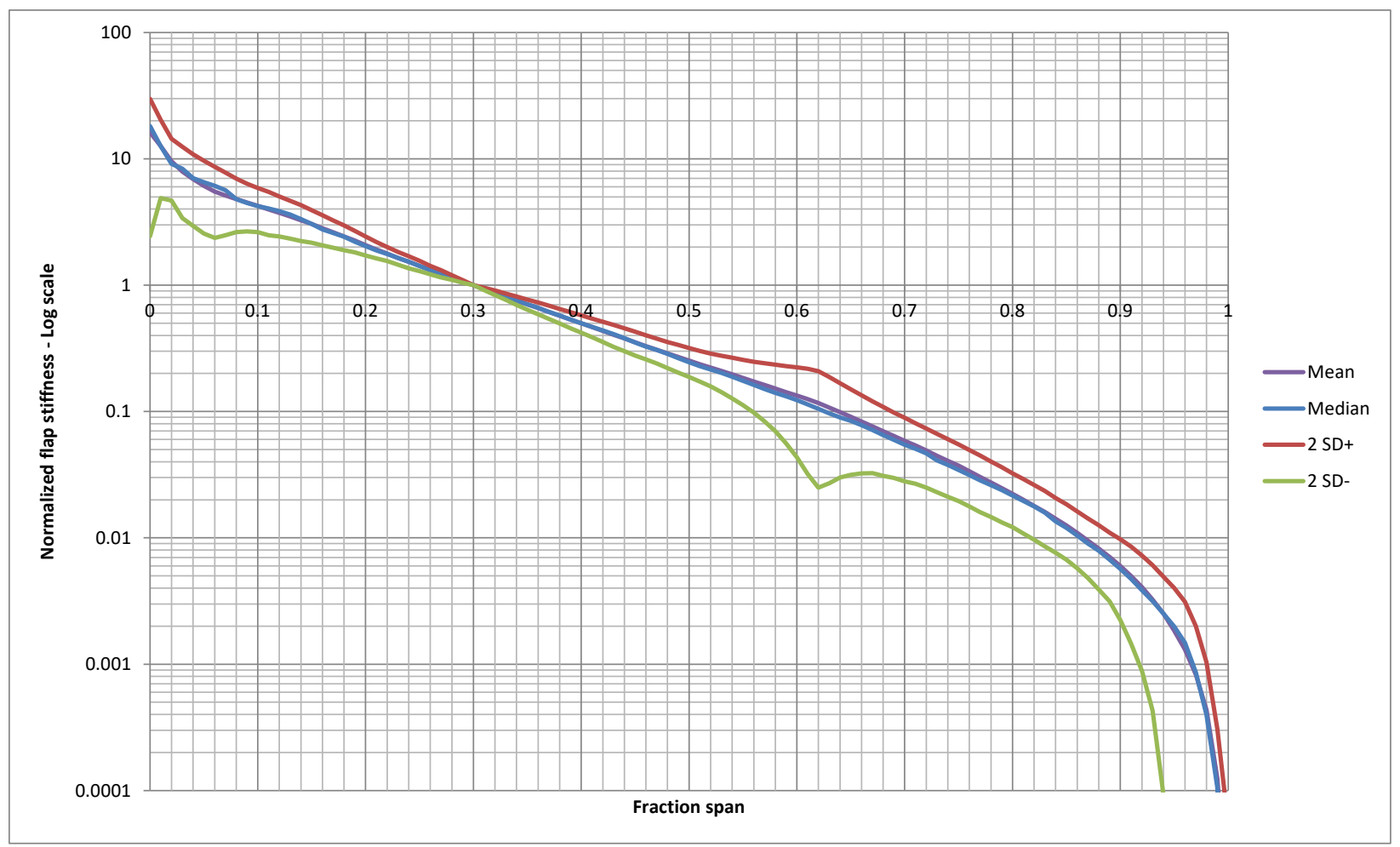

Figure 12. Normalized flap direction stiffness (EI) based on El at $30 \%$ span 


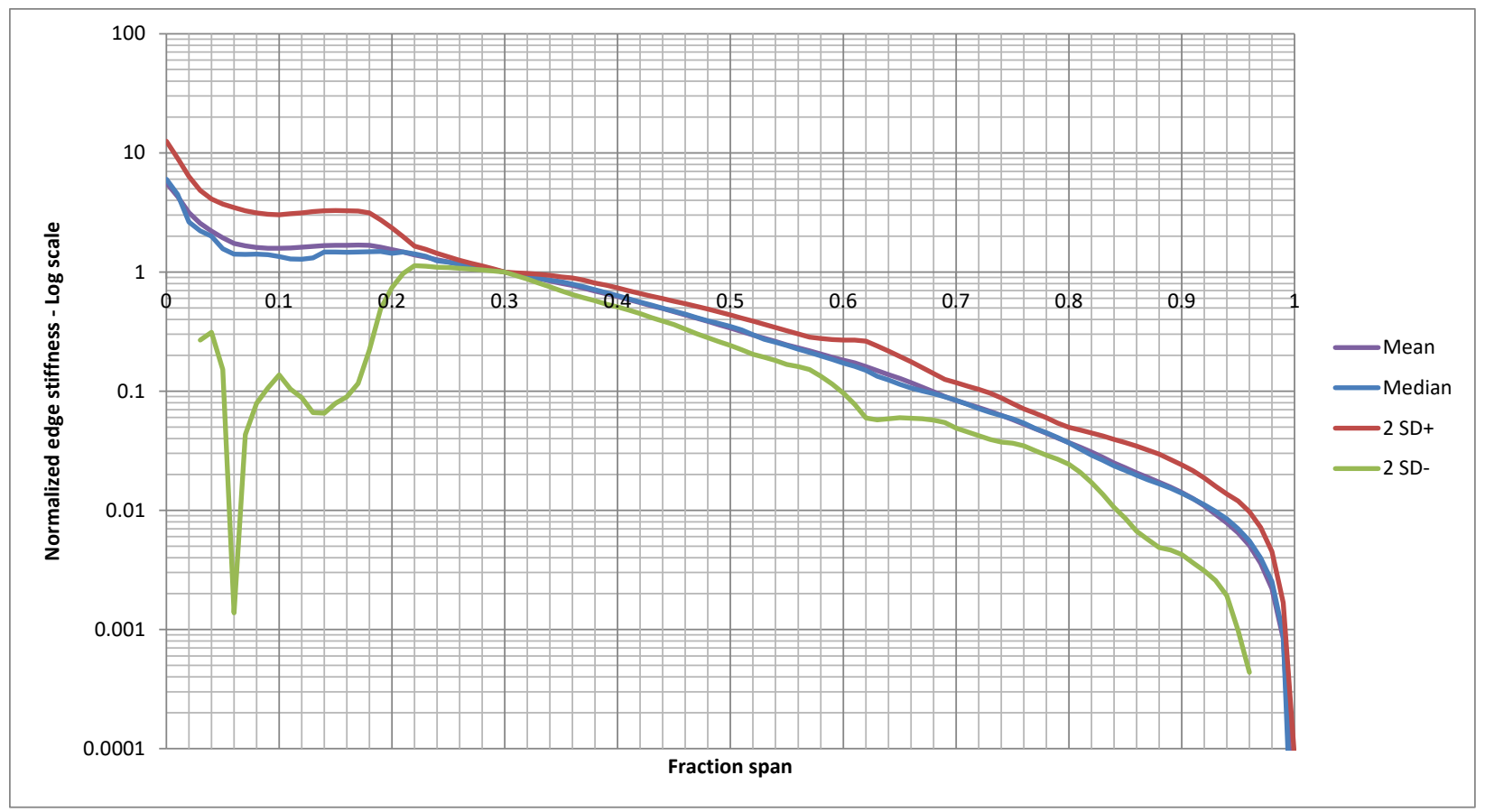

Figure 13. Normalized edge stiffness (EI) based on El at $30 \%$ span

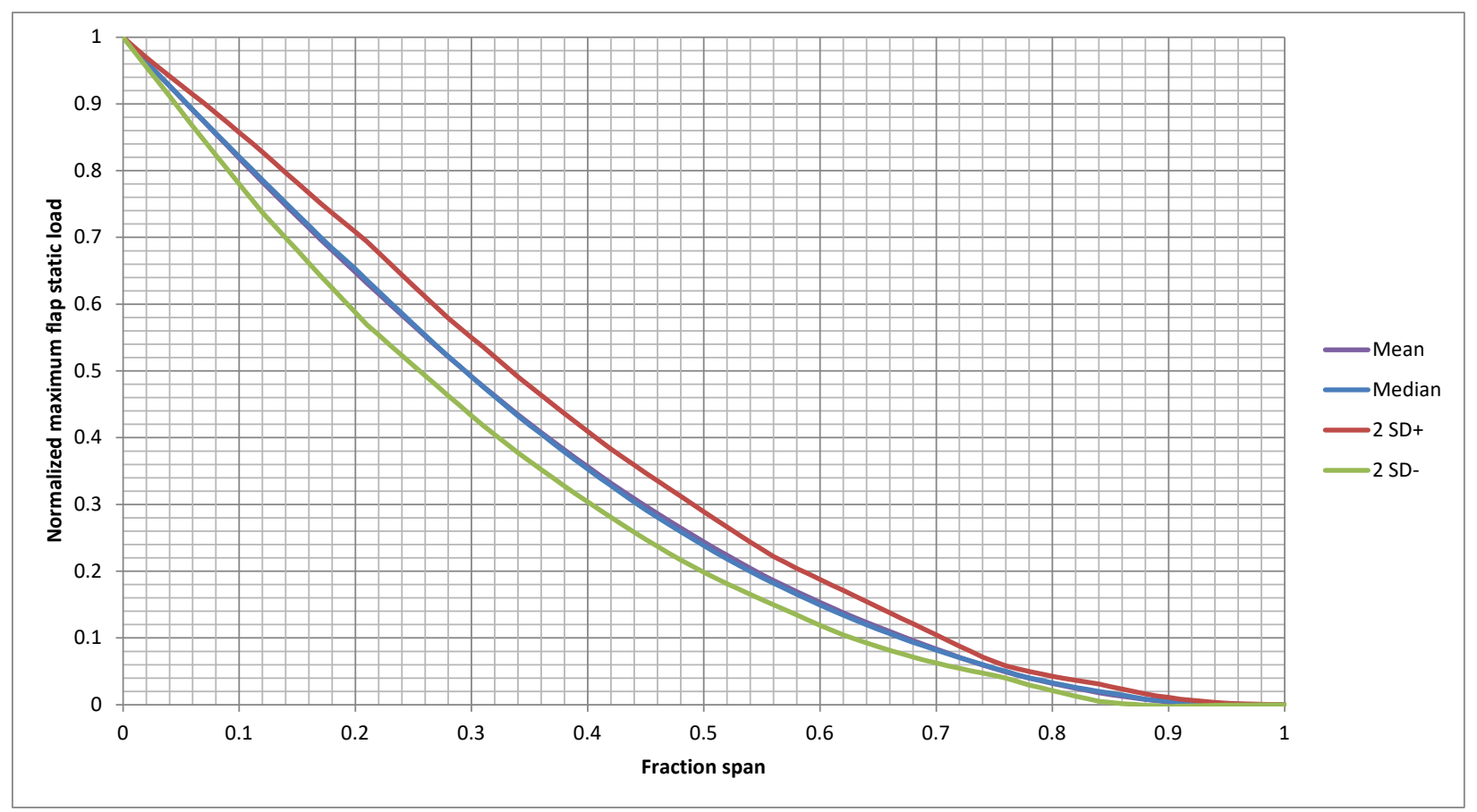

Figure 14. Normalized maximum flap static test target moment distribution 


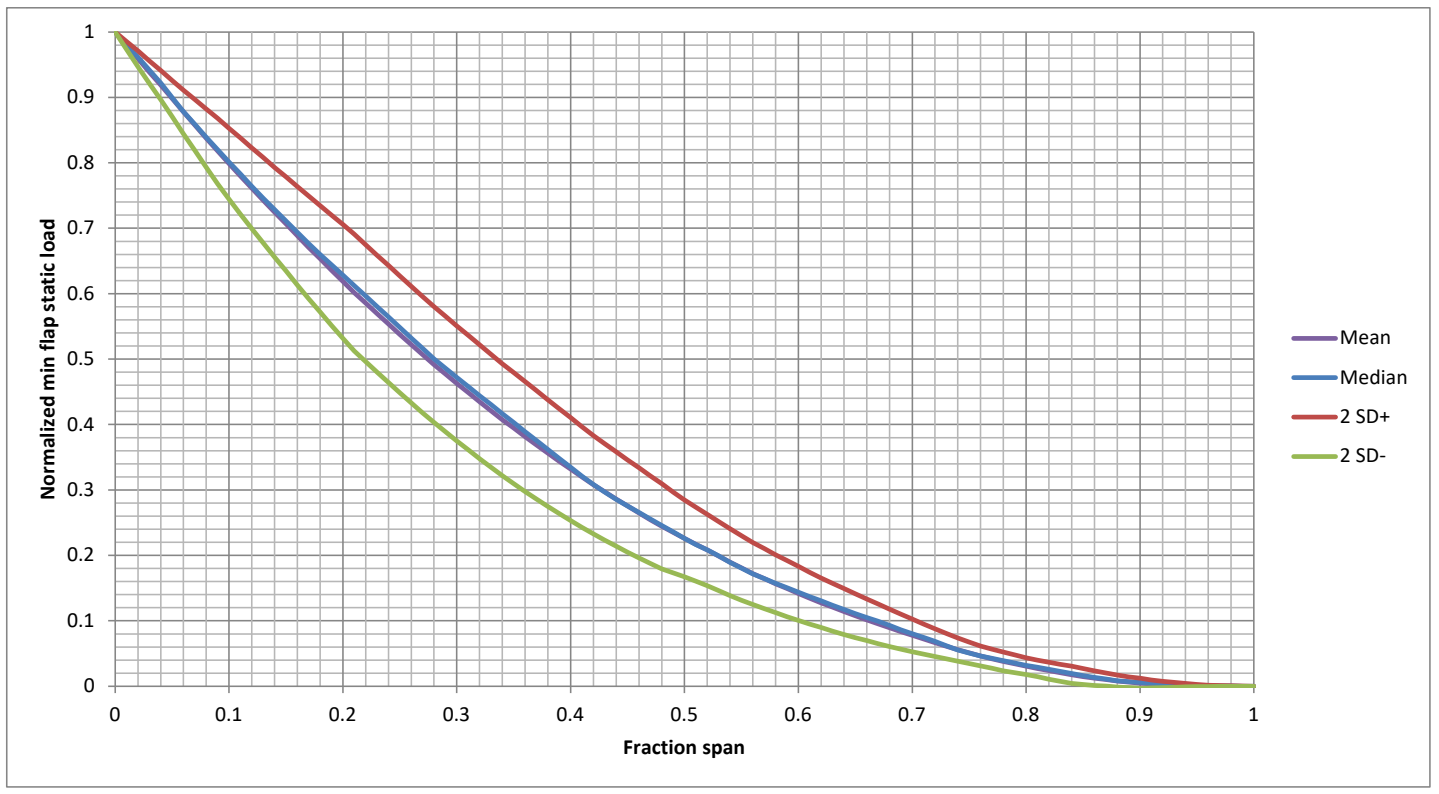

Figure 15. Normalized minimum flap static test target moment distribution

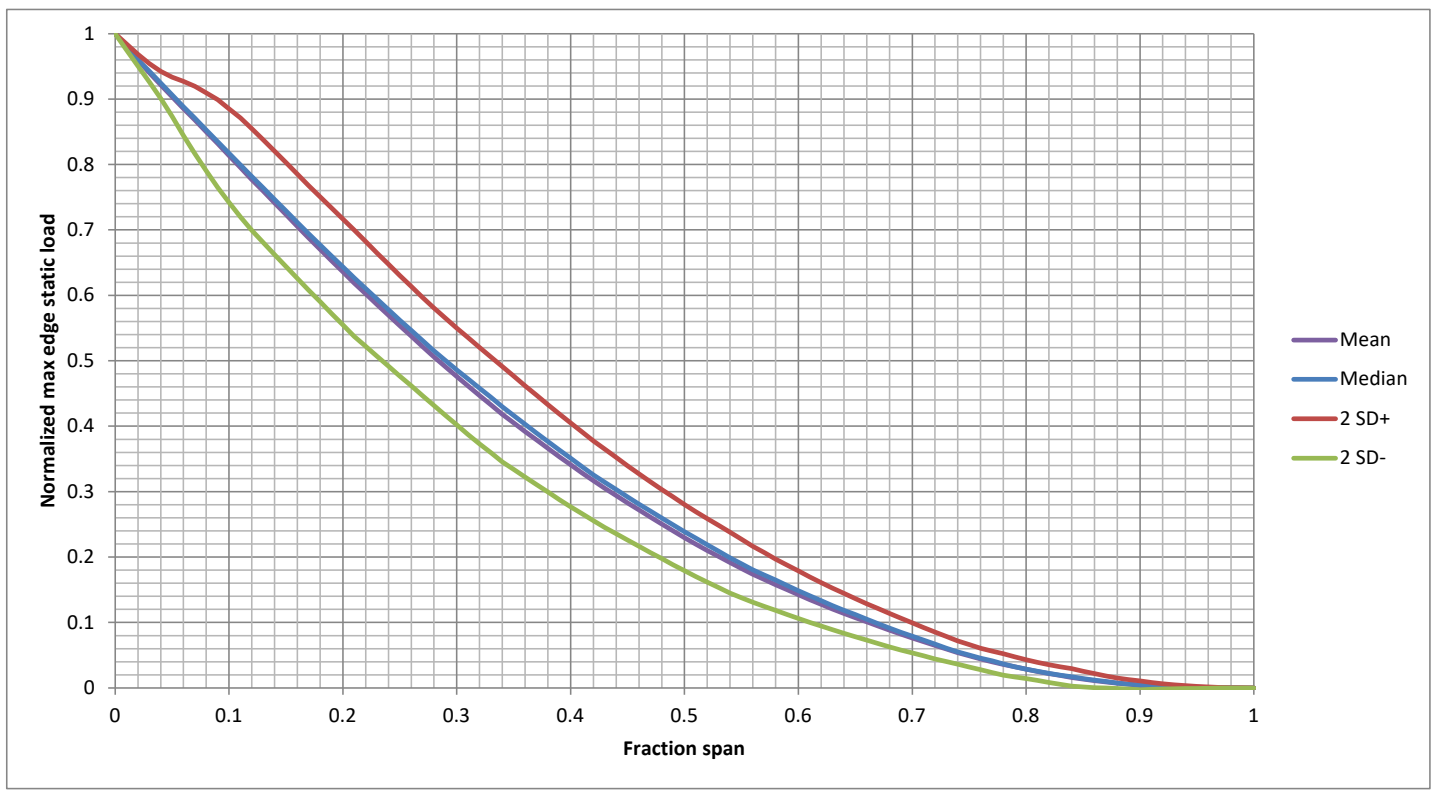

Figure 16. Normalized maximum edge static test target moment distribution 


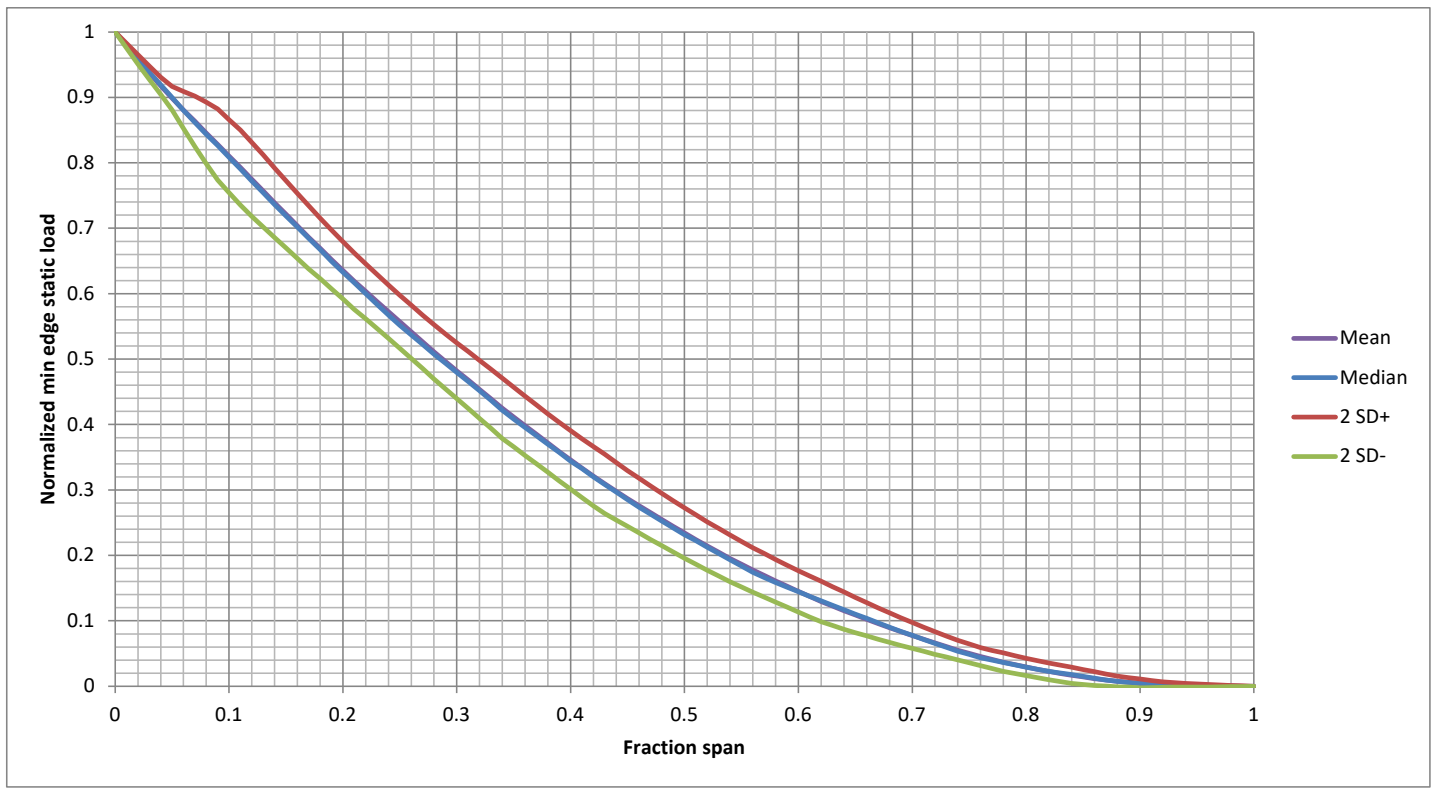

Figure 17. Normalized minimum edge static test target moment distribution

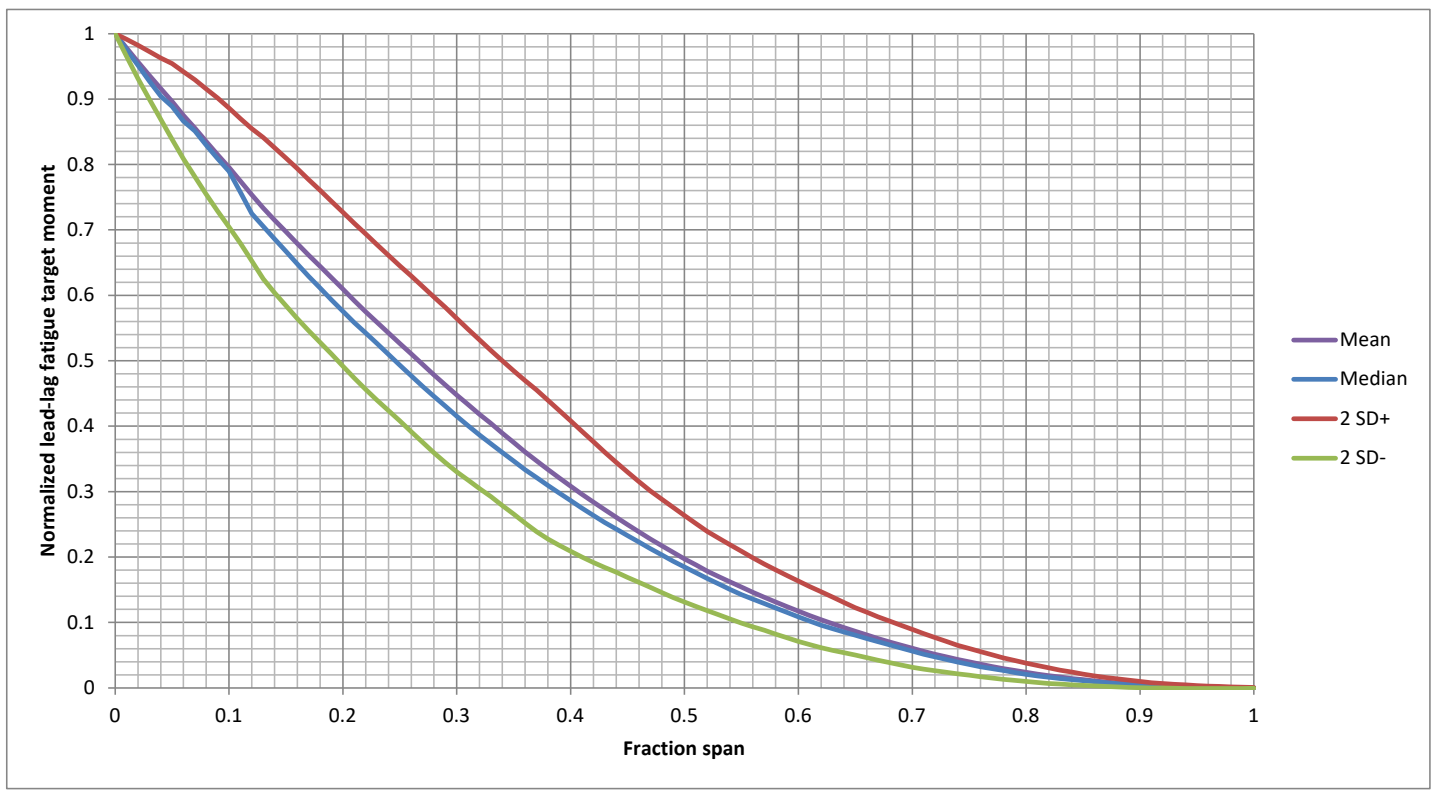

Figure 18. Normalized lead-lag fatigue target moment range distribution 


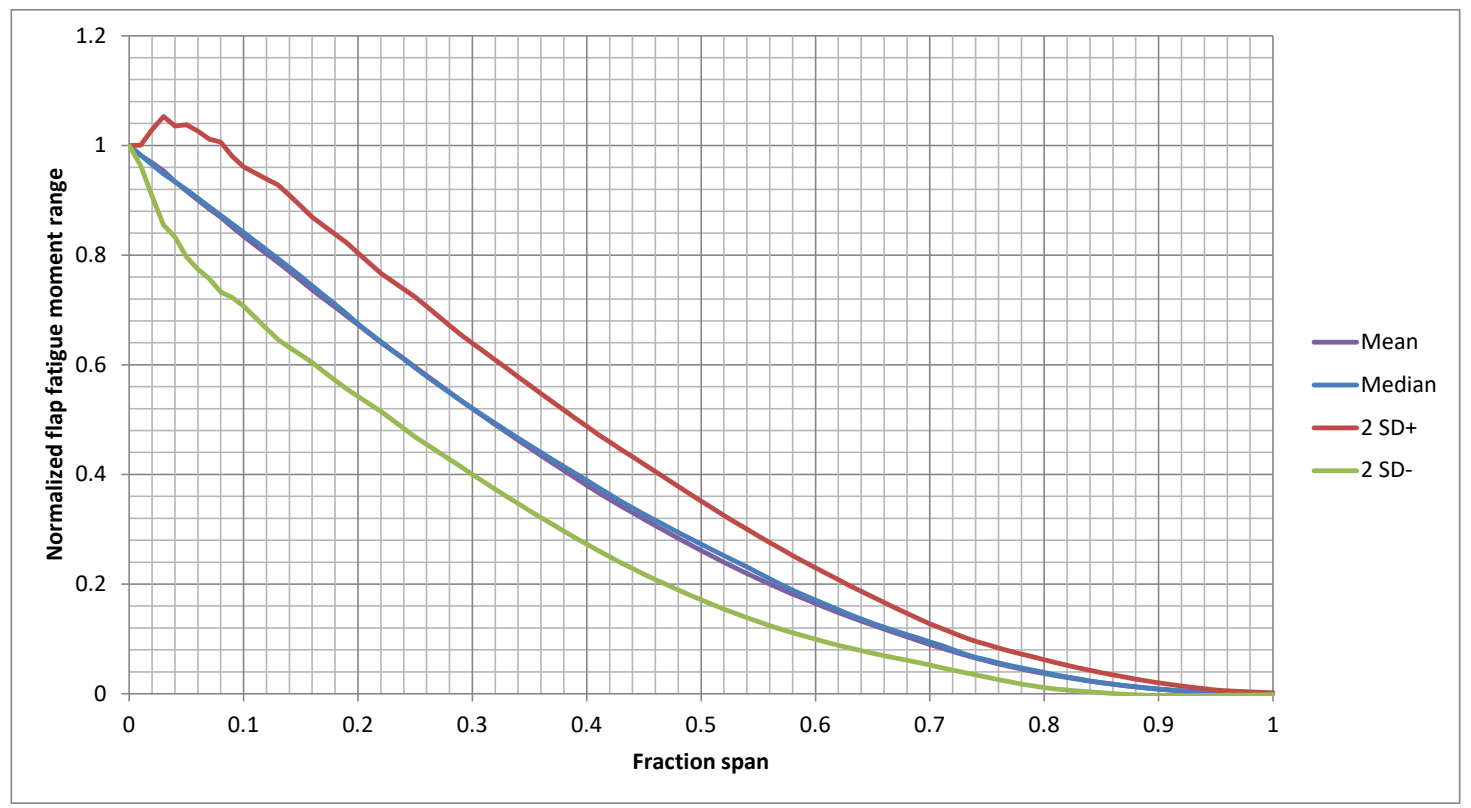

Figure 19. Normalized flap fatigue target moment range distribution 
Table 2. Normalized Mean Property Distribution

\begin{tabular}{|c|c|c|c|c|c|c|c|c|c|c|c|c|c|}
\hline 竞 & $\begin{array}{l}\frac{0}{0} \\
\frac{0}{0} \\
\frac{0}{0} \\
\frac{1}{2} \\
\end{array}$ & $\begin{array}{l}\frac{0}{0} \\
\text { 은 }\end{array}$ & 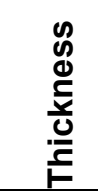 & $\stackrel{\vec{n}}{\underline{\underline{n}}}$ & 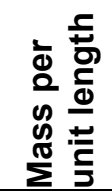 & 은 & 旁导 & 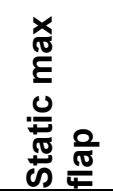 & 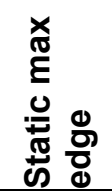 & 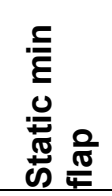 & 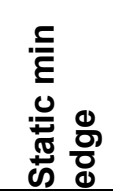 & 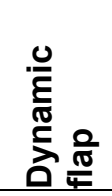 & 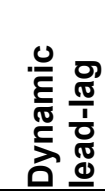 \\
\hline 0.00 & 0.000 & 0.633 & 1.000 & 1.247 & 9.245 & 16.160 & 5.593 & 1.000 & 1.000 & 1.000 & 1.000 & 1.000 & 1.000 \\
\hline 0.01 & 0.000 & 0.634 & 0.996 & 1.247 & 4.920 & 12.633 & 4.283 & 0.981 & 0.980 & 0.979 & 0.979 & 0.982 & 0.978 \\
\hline 0.02 & 0.000 & 0.635 & 0.990 & 1.247 & 2.791 & 9.540 & 3.147 & 0.963 & 0.959 & 0.959 & 0.958 & 0.968 & 0.957 \\
\hline 0.03 & 0.001 & 0.642 & 0.981 & 1.271 & 2.094 & 7.903 & 2.555 & 0.945 & 0.940 & 0.939 & 0.938 & 0.954 & 0.93 \\
\hline 0.04 & 0.001 & 0.655 & 0.970 & 1.319 & 1.857 & 6.903 & 2.202 & 0.927 & 0.922 & 0.919 & 0.918 & 0.934 & 0.916 \\
\hline 0.05 & 0.001 & 0.671 & 0.955 & 1.393 & 1.717 & 6.112 & 1.937 & 0.909 & 0.904 & 0.898 & 0.899 & 0.917 & 0.896 \\
\hline 0.06 & 0.001 & 0.691 & 0.938 & 1.483 & 1.599 & 5.495 & 1.733 & 0.891 & 0.886 & 0.878 & 0.881 & 0.900 & 0.875 \\
\hline 0.07 & 0.001 & 0.715 & 0.917 & 1.573 & 1.521 & 5.125 & 1.654 & 0.873 & 0.868 & 0.858 & 0.863 & 0.884 & 0.855 \\
\hline 0.08 & 0.001 & 0.742 & 0.895 & 1.647 & 1 & 4.802 & 7 & 0.855 & 350 & 38 & .846 & .869 & .835 \\
\hline 0.09 & 0.001 & 0.770 & 0.872 & 1.701 & .410 & 4.511 & 1.582 & 0.837 & 0.832 & 0.818 & .828 & .852 & .815 \\
\hline 0.10 & 0.002 & 0.799 & 0.848 & 716 & .378 & 4.250 & 1.582 & 0.819 & 0.814 & 0.799 & 0.810 & 0.834 & 0.79 \\
\hline 0.11 & 0.002 & 0.827 & 0.824 & 730 & 359 & 3.975 & .590 & 0.801 & 0.795 & 0.780 & 0.793 & 0.818 & 0.77 \\
\hline 0.12 & 0.002 & 0.853 & 0.799 & 1.718 & 1.346 & 3.734 & 1.612 & 0.783 & 0.777 & 0.761 & 0.775 & 0.802 & 0.754 \\
\hline 0.13 & 0.003 & 0.877 & 0.775 & 1.708 & 1.340 & 3.495 & 1.639 & 0.765 & 0.759 & 0.743 & 0.757 & 0.787 & 0.733 \\
\hline 0.14 & 0.004 & 0.899 & 0.750 & 1.683 & 1.329 & 3.261 & 1.663 & 0.748 & 0.741 & 0.725 & 0.739 & 0.770 & 0.715 \\
\hline 0.15 & 0.004 & 0.918 & 0.725 & 1.655 & 1.325 & 3.046 & 1.676 & 0.731 & 0.723 & 0.707 & 0.721 & 0.753 & 0.697 \\
\hline 0.16 & 0.005 & 0.934 & 0.700 & 1.625 & 1.305 & 2.819 & 1.674 & 0.714 & 0.706 & 0.689 & 0.704 & 0.737 & 0.679 \\
\hline 0.17 & 0.006 & 0.949 & 0.676 & 1.594 & 1.293 & 2.615 & 1.681 & 0.697 & 0.688 & 0.671 & 0.686 & 0.721 & 0.662 \\
\hline 0.18 & 0.007 & 0 & 0.652 & 1.556 & 8 & 2. & 7 & 0 & 0 & 3 & 0 & 05 & 0.644 \\
\hline 0. & 0 & 9 & 9 & 1.513 & 49 & 2 & 4 & 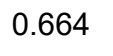 & 3 & 0.636 & 2 & 9 & $.0<$ \\
\hline 0.20 & 0.009 & 0.975 & 0.607 & 1.469 & 1.228 & 2.074 & 1.543 & 0.648 & 0.636 & 0.619 & 0.636 & 0.673 & 0.609 \\
\hline 0.21 & 0.011 & 0.977 & 0.586 & 1.420 & 1.202 & 1.913 & 1.475 & 0.631 & 0.619 & 0.602 & 0.619 & 0.657 & 0.592 \\
\hline 0.22 & 0.012 & 0.978 & 0.565 & 1.370 & 1.177 & 1.776 & 1.392 & 0.615 & 0.602 & 0.585 & 0.604 & 0.641 & 0.575 \\
\hline 0.23 & 0.014 & 0.977 & 0.545 & 1.319 & 1.148 & 1.643 & 1.335 & 0.600 & 0.586 & 0.569 & 0.588 & 0.626 & 0.559 \\
\hline 0.24 & 0.016 & 0.973 & 0.527 & 1.268 & 1.122 & 1.530 & 1.265 & 0.584 & 0.569 & 0.553 & 0.572 & 0.611 & 0.543 \\
\hline 0.25 & 0.019 & 0.968 & 0.509 & 1.220 & 093 & 1.422 & 5 & 0.568 & 3 & 0.538 & 0.557 & 0.596 & 0.527 \\
\hline 0.26 & 21 & 0.961 & 0.492 & 71 & 68 & 1.3 & 3 & 52 & 38 & 22 & 42 & 581 & 0 \\
\hline 0.27 & 0.024 & 0.954 & 0.475 & 1.122 & 047 & 1.231 & 120 & 0.537 & 22 & 0.507 & .526 & 0.565 & 0.40 \\
\hline 0.28 & 0.027 & 0.945 & 0.459 & 1.080 & 1.030 & 1.150 & 1.081 & 0.521 & 0.506 & 0.492 & 0.511 & 0.550 & 0.478 \\
\hline 0.29 & 0.030 & 0.932 & 0.444 & 1.039 & 1.014 & 1.071 & 1.041 & 0.506 & 0.491 & 0.477 & 0.497 & 0.535 & 0.463 \\
\hline 0.30 & 0.034 & 0.919 & 0.430 & 1.000 & 1.000 & 1.000 & 1.000 & 0.492 & 0.476 & 0.463 & 0.482 & 0.520 & 0.448 \\
\hline 0.31 & 0.038 & 0.905 & 0.416 & 0.960 & 0.988 & 0.933 & 0.960 & 0.477 & 0.461 & 0.449 & 0.468 & 0.505 & 0.433 \\
\hline 0.32 & 0.042 & 0.890 & 0.403 & 0.922 & .978 & 0.871 & .922 & 0.463 & 0.447 & 0.435 & 0.454 & .491 & 0.418 \\
\hline 0.33 & 0.046 & 0.876 & 0.391 & 885 & 966 & 0.81 & 0.883 & 0.449 & .432 & 1 & 9 & 77 & ד. \\
\hline 0.34 & 0.050 & 0.860 & 379 & 849 & 952 & 0.756 & 843 & 0.434 & 0.418 & 0.407 & .425 & 0.463 & 0.389 \\
\hline
\end{tabular}




\begin{tabular}{|c|c|c|c|c|c|c|c|c|c|c|c|c|c|}
\hline 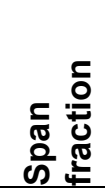 & $\begin{array}{l}\frac{0}{0} \\
\frac{0}{0} \\
\frac{0}{0} \\
0\end{array}$ & $\frac{\text { 음 }}{\frac{0}{0}}$ & 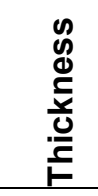 & $\stackrel{\stackrel{n}{n}}{\underline{E}}$ & 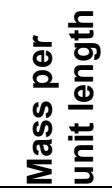 & 鱼峦 & 总 & 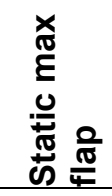 & 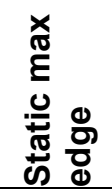 & 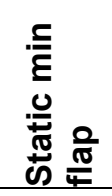 & 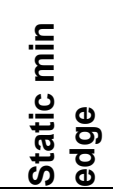 & $\begin{array}{l}\frac{0}{E} \\
\stackrel{\frac{1}{\pi}}{\frac{1}{\lambda}} \frac{0}{\pi} \\
\frac{\pi}{4}\end{array}$ & 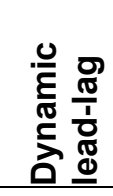 \\
\hline 0.35 & 0.055 & 0.845 & 0.367 & 0.814 & 0.936 & 0.704 & 0.803 & 0.421 & 0.405 & 0.394 & 0.411 & 0.448 & 0.375 \\
\hline 0.36 & 0.060 & 0.829 & 0.356 & 0.779 & 0.927 & 0.658 & 0.769 & 0.408 & 0.392 & 0.382 & 0.398 & 0.435 & 0.361 \\
\hline 0.37 & 0.065 & 0.814 & 0.345 & 0.746 & 0.914 & 0.614 & 0.731 & 0.395 & 0.379 & 0.369 & 0.385 & 0.421 & .347 \\
\hline 0.38 & 0.070 & 0.798 & 0.335 & 0.715 & 0.901 & 0.572 & 0.691 & 0.382 & 0.366 & 0.356 & 0.372 & 0.407 & 0.334 \\
\hline 0.39 & 0.076 & 0.783 & 0.325 & 0.684 & 0.888 & 0.533 & 0.655 & 0.369 & 0.354 & 0.344 & 0.359 & 0.394 & 0.321 \\
\hline 0.40 & 0.081 & 0.767 & 0.315 & 0.654 & 0.876 & 0.499 & 0.622 & 0.357 & 0.341 & 0.332 & 0.346 & 0.380 & 0.308 \\
\hline 0.41 & 0.087 & 0.752 & 0.306 & 0.625 & 0.858 & 0.465 & 0.586 & 0.344 & 0.329 & 0.320 & 0.333 & 0.367 & 0.296 \\
\hline 0.42 & 0.093 & 0.736 & 0.297 & 0.597 & 0.846 & 0.434 & 0.554 & 0.332 & 0.317 & 0.308 & 0.321 & 0.355 & 0.284 \\
\hline 0.43 & 0.100 & 0.721 & 288 & 0.570 & 834 & 0.404 & 0.521 & 0.320 & .305 & 0.297 & .309 & .342 & .272 \\
\hline 0.44 & 0.106 & 0.707 & 281 & 0.543 & .822 & 0.378 & 0.493 & 0.309 & 0.294 & 0.286 & .298 & .330 & .261 \\
\hline 0.45 & 0.113 & 0.692 & 0.273 & 0.517 & 0.808 & 0.353 & 0.465 & 0.297 & 0.283 & 0.275 & 0.287 & 0.319 & .249 \\
\hline 0.46 & 0.120 & 0.679 & 0.267 & 0.495 & 0.795 & 0.330 & 0.436 & 0.286 & 0.272 & 0.265 & 0.276 & 0.307 & 0.238 \\
\hline 0.47 & 0.128 & 0.666 & 0.260 & 0.475 & 0.780 & 0.308 & 0.409 & 0.275 & 0.261 & 0.255 & 0.265 & 0.295 & 0.227 \\
\hline 0.48 & 0.135 & 0.654 & 0.254 & 0.455 & 0.763 & 0.288 & 0.385 & 0.265 & 0.250 & 0.244 & 0.255 & 0.284 & 0.217 \\
\hline 0.49 & 0.143 & 0.642 & 0.248 & 0.438 & 0.751 & 0.270 & 0.361 & 0.254 & 0.240 & 0.235 & 0.245 & 0.272 & 0.207 \\
\hline 0.50 & 0. & 0.631 & 0.243 & 0. & 39 & 0.253 & 8 & 44 & 0 & 26 & 4 & 261 & 197 \\
\hline 0. & & 0.620 & 38 & & 28 & 年 & 17 & 0.204 & & 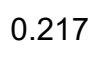 & $2+$ & .250 & 0 \\
\hline 0.52 & 0.164 & 0.609 & 33 & 0.389 & 717 & 0.223 & 296 & 0.224 & 10 & 0.208 & 4 & .240 & 179 \\
\hline 0.53 & 0.173 & 0.598 & 0.228 & 0.374 & 0.708 & 0.209 & 0.278 & 0.214 & 0.201 & 0.199 & .205 & .230 & 0.170 \\
\hline 0.54 & 0.182 & 0.587 & 0.224 & 0.359 & 0.698 & 0.197 & 0.261 & 0.204 & 0.192 & 0.190 & 0.195 & 0.220 & 0.162 \\
\hline 0.55 & 0.191 & 0.577 & 0.219 & 0.344 & 0.686 & 0.184 & 0.245 & 0.195 & 0.182 & 0.181 & 0.186 & 0.210 & 0.154 \\
\hline 0.56 & 0.201 & 0.567 & 0.215 & 0.329 & 0.674 & 0.173 & 0.231 & 0.186 & 0.174 & 0.172 & 0.178 & 0.200 & 0.146 \\
\hline 0.57 & 0.211 & 0.557 & 0.211 & 0.315 & 0.663 & 0.162 & 0.218 & 0.178 & 0.166 & 0.164 & 0.169 & 0.191 & 0.139 \\
\hline 0.58 & 0.222 & 0.548 & 0.206 & 0.303 & 0.649 & 0.152 & 0.205 & 0.169 & 0.158 & 0.157 & 0.161 & 0.182 & 0.131 \\
\hline 0.59 & 0.232 & 0.539 & 0.202 & 0.29 & 336 & 0.142 & 3 & 0.1 & 0 & 49 & 3 & 0.173 & 121 \\
\hline 0.60 & 0.243 & 0.530 & 0.197 & 0.27 & 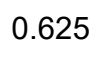 & 0.13 & 2 & 0.153 & 0.142 & 2 & 3 & 65 & 7 \\
\hline 0.61 & 0.255 & 0.521 & 0.192 & 0.266 & 0.613 & 0.125 & 0.173 & 0.146 & 0.135 & 0.135 & 0.137 & 56 & 11 \\
\hline 0.62 & 0.266 & 0.511 & 0.187 & 0.25 & 0.599 & 0.117 & 161 & 0.138 & 8 & 28 & 0.130 & 0.148 & .104 \\
\hline 0.63 & 0.277 & 0.502 & 0.183 & 0.237 & 0.598 & 0.107 & 0.149 & 0.131 & 0.121 & 0.121 & 0.122 & 0.140 & 0.098 \\
\hline 0.64 & 0.288 & 0.492 & 0.178 & 0.221 & 0.572 & 0.099 & 138 & 0.123 & 114 & 0.114 & .115 & 0.133 & 0.092 \\
\hline 0.65 & 0.299 & 0.482 & 0.174 & 0.206 & .558 & 0.091 & 8 & 0.116 & 7 & 08 & 109 & 125 & 0.086 \\
\hline 0.66 & 0.311 & 0.473 & 0.170 & 0.191 & 542 & 0.083 & 118 & 0.110 & 101 & 0.102 & 102 & 18 & .081 \\
\hline 0.67 & 0.322 & 0 & 16 & 0.17 & 0.527 & 0.076 & 8 & 3 & 5 & 5 & 6 & 1 & 0.076 \\
\hline 0.68 & 0.334 & 0.454 & 0.161 & 0.162 & 14 & 0.070 & 99 & 0.096 & 88 & 0.089 & 90 & 104 & 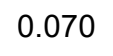 \\
\hline 0.69 & 0.347 & 0.445 & 0.157 & 0.147 & 0.502 & 0.064 & 0.090 & 0.090 & 0.082 & 0.083 & 0.083 & 0.097 & 0.065 \\
\hline 0.70 & 0.360 & 0.437 & 0.153 & 0.133 & 0.488 & 0.059 & 0.083 & 0.084 & 0.076 & 0.078 & 0.078 & 0.090 & 0.060 \\
\hline
\end{tabular}




\begin{tabular}{|c|c|c|c|c|c|c|c|c|c|c|c|c|c|}
\hline 竞 & 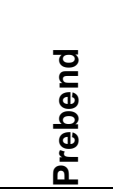 & $\frac{\overline{0}}{\frac{0}{0}}$ & 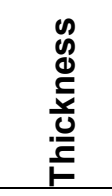 & $\stackrel{\Delta}{\underline{n}}$ & 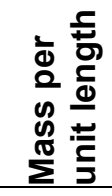 & 量 & 㚔 & 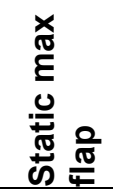 & 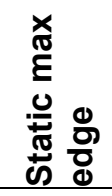 & 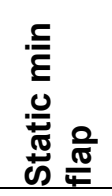 & 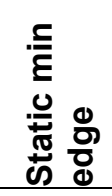 & 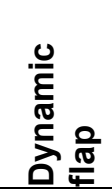 & 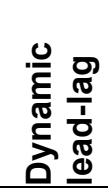 \\
\hline 0.71 & 0.374 & 0.428 & 0.149 & 0.120 & 0.471 & 0.054 & 0.078 & 0.077 & 0.071 & 0.072 & 0.072 & 0.084 & 0.056 \\
\hline 0.72 & 0.388 & $0.7<v$ & (170 & 101 & 454 & 0.049 & .073 & 101 & 065 & .067 & .066 & 377 & 052 \\
\hline 0.73 & 0.402 & 0.412 & 0.142 & 0.094 & 0.438 & 0.045 & 0.068 & .065 & 59 & .061 & 061 & 0.071 & 047 \\
\hline 0.74 & 0.417 & 0.404 & 0.138 & 0.082 & 0.424 & 0.041 & 0.063 & 0.059 & 0.054 & 0.056 & 0.055 & 0.065 & 0.043 \\
\hline 0.75 & 0.433 & 0.396 & 0.134 & 0.068 & 0.411 & 0.037 & 0.058 & 0.054 & 0.049 & 0.051 & 0.050 & 0.060 & 0.040 \\
\hline 0.76 & 0.449 & 0.388 & 0.131 & 56 & 96 & 0.034 & 0.053 & .049 & 44 & 046 & 45 & .055 & 0.036 \\
\hline 0.77 & 0 & 0 & 0.128 & 0.044 & 2 & 0.030 & 0.048 & 0.044 & 0.040 & 0.042 & .041 & 0.050 & 0.033 \\
\hline 0.78 & 0.483 & . & o. & 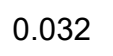 & 0.000 & 0.027 & 0.044 & 0.040 & 0.036 & 0.038 & .037 & 0.045 & 0.030 \\
\hline 0.79 & 0.501 & 0.366 & 0.121 & 021 & 0.354 & 0.025 & 0.040 & 0.036 & 0.032 & 0.034 & 0.033 & 0.041 & 0.027 \\
\hline 0.80 & 0.519 & 0.359 & 0.118 & 010 & 0.342 & 0.022 & 0.037 & 0.032 & 0.029 & 0.031 & .029 & 0.037 & 0.024 \\
\hline 0.81 & 0.538 & 0.352 & 0.115 & -0.001 & 0.328 & 0.020 & 0.034 & 0.028 & 0.025 & 0.027 & 0.026 & 0.033 & 0.021 \\
\hline 0.82 & 0.557 & 0.345 & 0.112 & -0.012 & 0.314 & 0.018 & 0.031 & 0.025 & 0.022 & 0.024 & 0.023 & 0.029 & 0.019 \\
\hline 0.83 & 0.577 & 0.338 & 0.109 & -0.023 & 0.298 & 0.016 & 0.028 & 0.021 & 0.019 & 0.021 & 0.020 & 0.026 & 0.017 \\
\hline 0.84 & 0.598 & 0.331 & 0.106 & -0.033 & 0.283 & 0.014 & 0.025 & 0.018 & 0.016 & 0.017 & 0.017 & 0.023 & 0.014 \\
\hline 0.85 & 0.618 & 0.324 & 0.102 & -0.043 & 0.270 & 0.013 & 0.023 & 0.015 & 0.014 & 0.015 & 14 & 0.020 & 0.013 \\
\hline 0.86 & 0.638 & 16 & 0.099 & -0.052 & 0.257 & 0 & 0 & 0.013 & 0.011 & 0.012 & & 7 & 0.011 \\
\hline - & 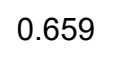 & 0.308 & 0.096 & ( & 0.246 & 0.010 & 0.019 & 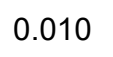 & & 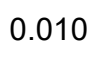 & 9 & $\zeta$ & 0.009 \\
\hline 0.88 & 0. & 0 & 3 & -5 & 5 & 0 & 7 & 8 & 7 & 8 & 7 & 2 & .000 \\
\hline 0.89 & 0.702 & 0.290 & 0.089 & $-C$ & 0.224 & 0.007 & 0.016 & 0.006 & 0.005 & 0.006 & 006 & 0.010 & 0.006 \\
\hline 0.90 & 0.724 & 0.280 & 0.086 & -0.075 & 0.212 & 0.006 & 0.014 & 0.004 & 0.004 & 0.005 & 0.004 & 0.008 & 0.005 \\
\hline 0.91 & 0.747 & 0.271 & 0.082 & -0.077 & 0.198 & 0.005 & 0.013 & 0.003 & 0.003 & 0.004 & 0.003 & 0.007 & 0.004 \\
\hline 0.92 & 0.772 & 0.260 & 0.078 & -0.076 & 0.182 & 0.004 & 0.011 & 0.002 & 0.002 & 0.003 & 0.003 & 0.005 & 0.003 \\
\hline 0.93 & 0.797 & 0.249 & 0.074 & -0.071 & 0.167 & 0.003 & 0.009 & 0.002 & 0.002 & 0.002 & 0.002 & .004 & 0.003 \\
\hline Or & 0.823 & 0.237 & 0.070 & -0.065 & .156 & 0.003 & .008 & 0.001 & .001 & .002 & 2 & 03 & 0.002 \\
\hline 0.95 & 0.850 & 0.225 & 0.065 & -0.056 & 0.142 & 0.002 & 0.006 & 0.001 & 0.001 & 0.001 & 0.001 & 0.002 & 0.001 \\
\hline 0.96 & 0.878 & 0.208 & 0.059 & -0.013 & 0.125 & 0.001 & 0.005 & 0.001 & 0.001 & 0.001 & 0.001 & 0.001 & 0.001 \\
\hline 0.97 & 0.906 & 0.186 & 0.051 & 0.056 & 0.106 & 0.001 & 0.004 & 0.000 & 0.000 & 0.000 & 0.000 & 0.001 & 0.001 \\
\hline 0.98 & 0.936 & 0.160 & 0.044 & 0.142 & 0.087 & 0.000 & 0.002 & 0.000 & 0.000 & 0.000 & 0.000 & 0.001 & 0.000 \\
\hline 0.99 & 0.966 & 0.121 & 0.035 & 0.270 & 0.079 & 0.000 & 0.001 & 0.000 & 0.000 & 0.000 & 0.000 & 0.000 & 0.000 \\
\hline 1.00 & 1.000 & 0.022 & 05 & 2 & 65 & 0. & 0 & 000 & 0.0 & 0 & 0 & 00 & an \\
\hline
\end{tabular}




\subsection{Fictional 60-m Blade Specification}

Using the normalized average blade and scaling parameters, a fictional $60-\mathrm{m}$ test article specification was defined. The length of the blade was selected because it represents the upper end of blades that are typically manufactured in the United States at present and does not overly extrapolate the data set it is based on. The maximum chord selected is $3.8 \mathrm{~m}$, and the prebend is $3.5 \mathrm{~m}$. These parameters are similar to those for blades in the 50-60 m span and are typically constrained by transportation restrictions for truck transit. The resulting blade has a root diameter of $2.406 \mathrm{~m}$, a total mass of $13,117 \mathrm{~kg}$, and a center of gravity at a span of $18.3 \mathrm{~m}$, all of which are within line of typical blades of this size. The resulting distribution of blade properties is provided in Table 3.

The target test loads are given in Table 4 . These loads are defined by the selected blade length and the corresponding normalization parameter slope and offset in Table 1. The resulting normalization parameters calculated in this way represent the root target moments for each test type and loading direction. Thus, the loads specified for this fictional blade test represent a typical or average target load based on the test specifications for the blades studied extrapolated for a $60-\mathrm{m}$ blade. 
Table 3. Scaled 60-m Blade Geometry and Beam Element Properties

\begin{tabular}{|c|c|c|c|c|c|c|c|}
\hline $\begin{array}{l}\text { Span } \\
\text { (m) }\end{array}$ & $\begin{array}{l}\text { Prebend } \\
\text { (m) }\end{array}$ & $\begin{array}{l}\text { Chord } \\
\text { (m) }\end{array}$ & $\begin{array}{l}\text { Thickness } \\
\text { (m) }\end{array}$ & $\begin{array}{l}\text { Twist } \\
\text { (deg) }\end{array}$ & $\begin{array}{l}\text { Unit Mass } \\
(\mathrm{kg} / \mathrm{m})\end{array}$ & $\begin{array}{l}\text { El } \\
\text { Flapwise } \\
\left(\mathrm{Nm}^{2}\right)\end{array}$ & $\begin{array}{l}\text { El } \\
\text { Lead-Lag } \\
\left(\mathrm{Nm}^{2}\right)\end{array}$ \\
\hline 0.00 & 0.000 & 2.406 & 2.406 & 12.50 & 2325.1 & $1.40 \mathrm{E}+10$ & $1.74 \mathrm{E}+10$ \\
\hline 0.60 & -0.001 & 2.408 & 2.395 & 12.50 & 1237.4 & $1.09 \mathrm{E}+10$ & $1.33 E+10$ \\
\hline 1.20 & -0.002 & 2.411 & 2.381 & 12.50 & 701.9 & $8.26 \mathrm{E}+09$ & $9.77 \mathrm{E}+09$ \\
\hline 1.80 & -0.002 & 2.441 & 2.362 & 12.74 & 526.7 & $6.84 \mathrm{E}+09$ & $7.93 E+09$ \\
\hline 2.40 & -0.002 & 2.488 & 2.333 & 13.22 & 467.1 & $5.98 \mathrm{E}+09$ & $6.84 \mathrm{E}+09$ \\
\hline 3.00 & -0.002 & 2.548 & 2.299 & 13.95 & 431.8 & $5.29 \mathrm{E}+09$ & $6.01 \mathrm{E}+09$ \\
\hline 3.60 & -0.002 & 2.627 & 2.256 & 14.86 & 402.2 & $4.76 \mathrm{E}+09$ & $5.38 \mathrm{E}+09$ \\
\hline 4.20 & -0.003 & 2.718 & 2.206 & 15.76 & 382.5 & $4.44 \mathrm{E}+09$ & $5.14 \mathrm{E}+09$ \\
\hline 4.80 & -0.003 & 2.818 & 2.154 & 16.51 & 367.3 & $4.16 \mathrm{E}+09$ & $4.99 E+09$ \\
\hline 5.40 & -0.004 & 2.926 & 2.099 & 17.05 & 354.6 & $3.91 \mathrm{E}+09$ & $4.91 \mathrm{E}+09$ \\
\hline 6.00 & -0.006 & 3.036 & 2.041 & 17.19 & 346.6 & $3.68 E+09$ & $4.91 \mathrm{E}+09$ \\
\hline 6.60 & -0.007 & 3.141 & 1.982 & 17.33 & 341.8 & $3.44 \mathrm{E}+09$ & $4.94 \mathrm{E}+09$ \\
\hline 7.20 & -0.009 & 3.242 & 1.923 & 17.21 & 338.4 & $3.23 E+09$ & $5.00 \mathrm{E}+09$ \\
\hline 7.80 & -0.011 & 3.331 & 1.864 & 17.11 & 336.9 & $3.03 E+09$ & $5.09 E+09$ \\
\hline 8.40 & -0.013 & 3.415 & 1.804 & 16.86 & 334.2 & $2.82 \mathrm{E}+09$ & $5.16 \mathrm{E}+09$ \\
\hline 9.00 & -0.015 & 3.488 & 1.744 & 16.58 & 333.2 & $2.64 \mathrm{E}+09$ & $5.20 \mathrm{E}+09$ \\
\hline 9.60 & -0.017 & 3.551 & 1.684 & 16.29 & 328.1 & $2.44 \mathrm{E}+09$ & $5.20 \mathrm{E}+09$ \\
\hline 10.20 & -0.020 & 3.605 & 1.626 & 15.97 & 325.3 & $2.26 \mathrm{E}+09$ & $5.22 \mathrm{E}+09$ \\
\hline 10.80 & -0.024 & 3.650 & 1.569 & 15.59 & 321.5 & $2.10 \mathrm{E}+09$ & $5.20 \mathrm{E}+09$ \\
\hline 11.40 & -0.028 & 3.681 & 1.514 & 15.16 & 314.2 & $1.95 E+09$ & $5.01 \mathrm{E}+09$ \\
\hline 12.00 & -0.032 & 3.704 & 1.460 & 14.72 & 308.8 & $1.80 E+09$ & $4.79 E+09$ \\
\hline 12.60 & -0.037 & 3.714 & 1.410 & 14.23 & 302.4 & $1.66 \mathrm{E}+09$ & $4.58 \mathrm{E}+09$ \\
\hline 13.20 & -0.043 & 3.716 & 1.361 & 13.72 & 296.1 & $1.54 \mathrm{E}+09$ & $4.32 \mathrm{E}+09$ \\
\hline 13.80 & -0.050 & 3.712 & 1.313 & 13.22 & 288.7 & $1.42 E+09$ & $4.14 \mathrm{E}+09$ \\
\hline 14.40 & -0.057 & 3.699 & 1.268 & 12.71 & 282.3 & $1.32 \mathrm{E}+09$ & $3.93 E+09$ \\
\hline 15.00 & -0.065 & 3.677 & 1.225 & 12.22 & 274.8 & $1.23 E+09$ & $3.77 \mathrm{E}+09$ \\
\hline 15.60 & -0.074 & 3.653 & 1.183 & 11.73 & 268.6 & $1.14 \mathrm{E}+09$ & $3.61 \mathrm{E}+09$ \\
\hline 16.20 & -0.083 & 3.624 & 1.143 & 11.24 & 263.4 & $1.07 \mathrm{E}+09$ & $3.48 \mathrm{E}+09$ \\
\hline 16.80 & -0.094 & 3.590 & 1.105 & 10.82 & 259.1 & $9.95 E+08$ & $3.35 E+09$ \\
\hline 17.40 & -0.106 & 3.543 & 1.069 & 10.41 & 255.0 & $9.27 E+08$ & $3.23 E+09$ \\
\hline 18.00 & -0.118 & 3.492 & 1.035 & 10.02 & 251.5 & $8.66 \mathrm{E}+08$ & $3.10 E+09$ \\
\hline 18.60 & -0.132 & 3.439 & 1.002 & 9.62 & 248.4 & $8.08 E+08$ & $2.98 \mathrm{E}+09$ \\
\hline 19.20 & -0.146 & 3.384 & 0.971 & 9.24 & 246.0 & $7.54 \mathrm{E}+08$ & $2.86 \mathrm{E}+09$ \\
\hline 19.80 & -0.161 & 3.327 & 0.941 & 8.86 & 243.0 & $7.03 E+08$ & $2.74 \mathrm{E}+09$ \\
\hline 20.40 & -0.177 & 3.269 & 0.912 & 8.51 & 239.4 & $6.54 \mathrm{E}+08$ & $2.62 E+09$ \\
\hline 21.00 & -0.193 & 3.210 & 0.884 & 8.15 & 235.4 & $6.10 \mathrm{E}+08$ & $2.49 \mathrm{E}+09$ \\
\hline
\end{tabular}




\begin{tabular}{|c|c|c|c|c|c|c|c|}
\hline $\begin{array}{l}\text { Span } \\
\text { (m) }\end{array}$ & $\begin{array}{l}\text { Prebend } \\
\text { (m) }\end{array}$ & $\begin{array}{l}\text { Chord } \\
\text { (m) }\end{array}$ & $\begin{array}{l}\text { Thickness } \\
\text { (m) }\end{array}$ & $\begin{array}{l}\text { Twist } \\
\text { (deg) }\end{array}$ & $\begin{array}{l}\text { Unit Mass } \\
(\mathrm{kg} / \mathrm{m})\end{array}$ & $\begin{array}{l}\text { El } \\
\text { Flapwise } \\
\left(\mathrm{Nm}^{2}\right)\end{array}$ & $\begin{array}{l}\text { El } \\
\text { Lead-Lag } \\
\left(\mathrm{Nm}^{2}\right)\end{array}$ \\
\hline 21.60 & -0.210 & 3.151 & 0.856 & 7.81 & 233.1 & $5.70 \mathrm{E}+08$ & $2.39 E+09$ \\
\hline 22.20 & -0.227 & 3.092 & 0.830 & 7.47 & 229.9 & $5.31 \mathrm{E}+08$ & $2.27 E+09$ \\
\hline 22.80 & -0.246 & 3.033 & 0.806 & 7.16 & 226.5 & $4.95 E+08$ & $2.15 E+09$ \\
\hline 23.40 & -0.265 & 2.974 & 0.782 & 6.86 & 223.3 & $4.62 \mathrm{E}+08$ & $2.03 E+09$ \\
\hline 24.00 & -0.285 & 2.915 & 0.758 & 6.55 & 220.2 & $4.32 \mathrm{E}+08$ & $1.93 \mathrm{E}+09$ \\
\hline 24.60 & -0.305 & 2.856 & 0.735 & 6.26 & 215.7 & $4.03 E+08$ & $1.82 E+09$ \\
\hline 25.20 & -0.326 & 2.799 & 0.714 & 5.98 & 212.7 & $3.76 \mathrm{E}+08$ & $1.72 E+09$ \\
\hline 25.80 & -0.348 & 2.741 & 0.694 & 5.71 & 209.8 & $3.50 \mathrm{E}+08$ & $1.62 E+09$ \\
\hline 26.40 & -0.372 & 2.685 & 0.676 & 5.44 & 206.8 & $3.28 \mathrm{E}+08$ & $1.53 E+09$ \\
\hline 27.00 & -0.396 & 2.630 & 0.658 & 5.18 & 203.3 & $3.06 \mathrm{E}+08$ & $1.44 \mathrm{E}+09$ \\
\hline 27.60 & -0.421 & 2.580 & 0.642 & 4.96 & 199.9 & $2.86 \mathrm{E}+08$ & $1.35 \mathrm{E}+09$ \\
\hline 28.20 & -0.447 & 2.532 & 0.626 & 4.75 & 196.2 & $2.67 E+08$ & $1.27 \mathrm{E}+09$ \\
\hline 28.80 & -0.473 & 2.486 & 0.611 & 4.56 & 192.0 & $2.49 E+08$ & $1.19 \mathrm{E}+09$ \\
\hline 29.40 & -0.500 & 2.441 & 0.597 & 4.39 & 188.8 & $2.34 \mathrm{E}+08$ & $1.12 E+09$ \\
\hline 30.00 & -0.526 & 2.397 & 0.584 & 4.22 & 185.8 & $2.19 \mathrm{E}+08$ & $1.05 \mathrm{E}+09$ \\
\hline 30.60 & -0.549 & 2.354 & 0.572 & 4.05 & 183.1 & $2.05 \mathrm{E}+08$ & $9.83 E+08$ \\
\hline 31.20 & -0.573 & 2.313 & 0.560 & 3.90 & 180.4 & $1.93 \mathrm{E}+08$ & $9.18 \mathrm{E}+08$ \\
\hline 31.80 & -0.605 & 2.272 & 0.549 & 3.75 & 178.0 & $1.81 \mathrm{E}+08$ & $8.63 E+08$ \\
\hline 32.40 & -0.638 & 2.232 & 0.538 & 3.59 & 175.6 & $1.70 \mathrm{E}+08$ & $8.11 E+08$ \\
\hline 33.00 & -0.670 & 2.192 & 0.527 & 3.44 & 172.5 & $1.59 \mathrm{E}+08$ & $7.60 \mathrm{E}+08$ \\
\hline 33.60 & -0.702 & 2.154 & 0.517 & 3.30 & 169.4 & $1.49 \mathrm{E}+08$ & $7.17 \mathrm{E}+08$ \\
\hline 34.20 & -0.738 & 2.118 & 0.507 & 3.16 & 166.6 & $1.40 \mathrm{E}+08$ & $6.77 \mathrm{E}+08$ \\
\hline 34.80 & -0.775 & 2.083 & 0.496 & 3.03 & 163.2 & $1.32 E+08$ & $6.35 \mathrm{E}+08$ \\
\hline 35.40 & -0.813 & 2.049 & 0.485 & 2.91 & 159.9 & $1.23 E+08$ & $5.98 \mathrm{E}+08$ \\
\hline 36.00 & -0.852 & 2.014 & 0.474 & 2.79 & 157.1 & $1.16 \mathrm{E}+08$ & $5.66 \mathrm{E}+08$ \\
\hline 36.60 & -0.892 & 1.979 & 0.462 & 2.66 & 154.2 & $1.08 \mathrm{E}+08$ & $5.36 \mathrm{E}+08$ \\
\hline 37.20 & -0.932 & 1.943 & 0.451 & 2.53 & 150.7 & $1.01 \mathrm{E}+08$ & $5.00 \mathrm{E}+08$ \\
\hline 37.80 & -0.969 & 1.906 & 0.440 & 2.37 & 150.4 & $9.30 \mathrm{E}+07$ & $4.61 \mathrm{E}+08$ \\
\hline 38.40 & -1.007 & 1.870 & 0.429 & 2.22 & 143.9 & $8.55 E+07$ & $4.27 \mathrm{E}+08$ \\
\hline 39.00 & -1.046 & 1.833 & 0.418 & 2.06 & 140.3 & $7.87 \mathrm{E}+07$ & $3.97 \mathrm{E}+08$ \\
\hline 39.60 & -1.087 & 1.797 & 0.408 & 1.91 & 136.3 & $7.22 \mathrm{E}+07$ & $3.66 \mathrm{E}+08$ \\
\hline 40.20 & -1.128 & 1.762 & 0.398 & 1.77 & 132.7 & $6.61 \mathrm{E}+07$ & $3.35 \mathrm{E}+08$ \\
\hline 40.80 & -1.171 & 1.727 & 0.388 & 1.62 & 129.2 & $6.06 \mathrm{E}+07$ & $3.06 \mathrm{E}+08$ \\
\hline 41.40 & -1.215 & 1.693 & 0.378 & 1.48 & 126.1 & $5.53 E+07$ & $2.80 \mathrm{E}+08$ \\
\hline 42.00 & -1.262 & 1.660 & 0.369 & 1.34 & 122.8 & $5.07 E+07$ & $2.59 E+08$ \\
\hline 42.60 & -1.309 & 1.627 & 0.359 & 1.20 & 118.5 & $4.66 \mathrm{E}+07$ & $2.42 \mathrm{E}+08$ \\
\hline 43.20 & -1.357 & 1.596 & 0.350 & 1.07 & 114.3 & $4.25 \mathrm{E}+07$ & $2.26 \mathrm{E}+08$ \\
\hline
\end{tabular}




\begin{tabular}{|c|c|c|c|c|c|c|c|}
\hline $\begin{array}{l}\text { Span } \\
\text { (m) }\end{array}$ & $\begin{array}{l}\text { Prebend } \\
\text { (m) }\end{array}$ & $\begin{array}{l}\text { Chord } \\
\text { (m) }\end{array}$ & $\begin{array}{l}\text { Thickness } \\
\text { (m) }\end{array}$ & $\begin{array}{l}\text { Twist } \\
\text { (deg) }\end{array}$ & $\begin{array}{l}\text { Unit Mass } \\
(\mathrm{kg} / \mathrm{m})\end{array}$ & $\begin{array}{l}\text { EI } \\
\text { Flapwise } \\
\left(\mathrm{Nm}^{2}\right)\end{array}$ & $\begin{array}{l}\text { El } \\
\text { Lead-Lag } \\
\left(\mathrm{Nm}^{2}\right)\end{array}$ \\
\hline 43.80 & -1.406 & 1.564 & 0.341 & 0.94 & 110.3 & $3.87 \mathrm{E}+07$ & $2.10 \mathrm{E}+08$ \\
\hline 44.40 & -1.460 & 1.534 & 0.332 & 0.82 & 106.7 & $3.53 \mathrm{E}+07$ & $1.94 E+08$ \\
\hline 45.00 & -1.514 & 1.504 & 0.323 & 0.69 & 103.3 & $3.22 E+07$ & $1.79 E+08$ \\
\hline 45.60 & -1.571 & 1.475 & 0.315 & 0.56 & 99.6 & $2.91 \mathrm{E}+07$ & $1.64 \mathrm{E}+08$ \\
\hline 46.20 & -1.630 & 1.447 & 0.307 & 0.44 & 96.0 & $2.63 \mathrm{E}+07$ & $1.50 E+08$ \\
\hline 46.80 & -1.691 & 1.420 & 0.299 & 0.33 & 92.6 & $2.37 \mathrm{E}+07$ & $1.38 \mathrm{E}+08$ \\
\hline 47.40 & -1.754 & 1.392 & 0.291 & 0.21 & 89.1 & $2.15 \mathrm{E}+07$ & $1.26 \mathrm{E}+08$ \\
\hline 48.00 & -1.818 & 1.365 & 0.284 & 0.10 & 85.9 & $1.93 \mathrm{E}+07$ & $1.15 E+08$ \\
\hline 48.60 & -1.883 & 1.338 & 0.276 & -0.01 & 82.6 & $1.74 \mathrm{E}+07$ & $1.05 E+08$ \\
\hline 49.20 & -1.949 & 1.311 & 0.269 & -0.12 & 79.0 & $1.55 \mathrm{E}+07$ & $9.57 \mathrm{E}+07$ \\
\hline 49.80 & -2.021 & 1.284 & 0.261 & -0.23 & 75.0 & $1.39 \mathrm{E}+07$ & $8.66 \mathrm{E}+07$ \\
\hline 50.40 & -2.093 & 1.257 & 0.254 & -0.33 & 71.2 & $1.23 \mathrm{E}+07$ & $7.76 \mathrm{E}+07$ \\
\hline 51.00 & -2.164 & 1.230 & 0.247 & -0.43 & 67.9 & $1.09 \mathrm{E}+07$ & $7.05 \mathrm{E}+07$ \\
\hline 51.60 & -2.234 & 1.200 & 0.239 & -0.52 & 64.6 & $9.49 \mathrm{E}+06$ & $6.39 \mathrm{E}+07$ \\
\hline 52.20 & -2.307 & 1.169 & 0.231 & -0.60 & 61.8 & $8.24 \mathrm{E}+06$ & $5.85 E+07$ \\
\hline 52.80 & -2.381 & 1.136 & 0.223 & -0.67 & 59.2 & $7.13 E+06$ & $5.35 E+07$ \\
\hline 53.40 & -2.458 & 1.101 & 0.214 & -0.71 & 56.2 & $6.11 \mathrm{E}+06$ & $4.85 \mathrm{E}+07$ \\
\hline 54.00 & -2.534 & 1.066 & 0.206 & -0.76 & 53.4 & $5.19 E+06$ & $4.39 E+07$ \\
\hline 54.60 & -2.615 & 1.029 & 0.198 & -0.77 & 49.8 & $4.31 \mathrm{E}+06$ & $3.90 \mathrm{E}+07$ \\
\hline 55.20 & -2.702 & 0.989 & 0.188 & -0.76 & 45.8 & $3.52 E+06$ & $3.38 \mathrm{E}+07$ \\
\hline 55.80 & -2.790 & 0.945 & 0.178 & -0.71 & 42.1 & $2.81 E+06$ & $2.87 E+07$ \\
\hline 56.40 & -2.882 & 0.900 & 0.168 & -0.66 & 39.4 & $2.17 \mathrm{E}+06$ & $2.43 E+07$ \\
\hline 57.00 & -2.975 & 0.854 & 0.157 & -0.56 & 35.7 & $1.60 \mathrm{E}+06$ & $2.01 \mathrm{E}+07$ \\
\hline 57.60 & -3.071 & 0.790 & 0.142 & -0.13 & 31.5 & $1.13 E+06$ & $1.58 \mathrm{E}+07$ \\
\hline 58.20 & -3.172 & 0.707 & 0.123 & 0.56 & 26.8 & $7.16 \mathrm{E}+05$ & $1.11 \mathrm{E}+07$ \\
\hline 58.80 & -3.275 & 0.608 & 0.107 & 1.42 & 22.0 & $3.77 \mathrm{E}+05$ & $6.79 E+06$ \\
\hline 59.40 & -3.381 & 0.460 & 0.084 & 2.70 & 20.0 & $1.08 \mathrm{E}+05$ & $2.60 E+06$ \\
\hline 60.00 & -3.500 & 0.083 & 0.011 & 4.53 & 16.3 & $8.52 E+03$ & $5.51 E+04$ \\
\hline
\end{tabular}


Table 4. Scaled 60-m Test Target Loads Including All Design and Test Factors

\begin{tabular}{|c|c|c|c|c|c|c|}
\hline $\begin{array}{l}\text { Span } \\
\text { (m) }\end{array}$ & $\begin{array}{l}\text { Static } \\
\text { Max Flap } \\
(\mathrm{kNm})\end{array}$ & $\begin{array}{l}\text { Static } \\
\text { Max Edge } \\
(\mathrm{kNm})\end{array}$ & $\begin{array}{l}\text { Static } \\
\text { Min Flap } \\
(\mathrm{kNm})\end{array}$ & $\begin{array}{l}\text { Static } \\
\text { Min Edge } \\
(\mathrm{kNm})\end{array}$ & $\begin{array}{l}\text { Fatigue } \\
\text { Flap } \\
\text { Range } \\
\text { (kNm) }\end{array}$ & $\begin{array}{l}\text { Fatigue } \\
\text { Lead-lag } \\
\text { Range } \\
\text { (kNm) }\end{array}$ \\
\hline 0.00 & 13,032 & 7,297 & 10,642 & 6,652 & 8,741 & 10,500 \\
\hline 0.60 & 12,784 & 7,146 & 10,419 & 6,509 & 8,582 & 10,272 \\
\hline 1.20 & 12,545 & 7,004 & 10,200 & 6,372 & 8,462 & 10,047 \\
\hline 1.80 & 12,306 & 6,865 & 9,981 & 6,235 & 8,337 & 9,831 \\
\hline 2.40 & 12,067 & 6,730 & 9,761 & 6,107 & 8,165 & 9,616 \\
\hline 3.00 & 11,829 & 6,598 & 9,538 & 5,987 & 8,016 & 9,410 \\
\hline 3.60 & 11,592 & 6,466 & 9,320 & 5,868 & 7,868 & 9,191 \\
\hline 4.20 & 11,351 & 6,332 & 9,102 & 5,747 & 7,728 & 8,982 \\
\hline 4.80 & 11,112 & 6,198 & 8,887 & 5,627 & 7,600 & 8,767 \\
\hline 5.40 & 10,872 & 6,061 & 8,680 & 5,507 & 7,443 & 8,556 \\
\hline 6.00 & 10,633 & 5,925 & 8,474 & 5,387 & 7,291 & 8,353 \\
\hline 6.60 & 10,396 & 5,788 & 8,271 & 5,265 & 7,152 & 8,133 \\
\hline 7.20 & 10,165 & 5,655 & 8,071 & 5,143 & 7,013 & 7,914 \\
\hline 7.80 & 9,936 & 5,521 & 7,873 & 5,022 & 6,878 & 7,699 \\
\hline 8.40 & 9,709 & 5,388 & 7,677 & 4,902 & 6,732 & 7,506 \\
\hline 9.00 & 9,483 & 5,255 & 7,481 & 4,782 & 6,586 & 7,317 \\
\hline 9.60 & 9,259 & 5,124 & 7,289 & 4,664 & 6,440 & 7,129 \\
\hline 10.20 & 9,038 & 4,994 & 7,099 & 4,548 & 6,301 & 6,946 \\
\hline 10.80 & 8,820 & 4,865 & 6,910 & 4,434 & 6,163 & 6,765 \\
\hline 11.40 & 8,603 & 4,735 & 6,722 & 4,320 & 6,026 & 6,584 \\
\hline 12.00 & 8,386 & 4,609 & 6,537 & 4,209 & 5,884 & 6,398 \\
\hline 12.60 & 8,174 & 4,485 & 6,362 & 4,102 & 5,742 & 6,216 \\
\hline 13.20 & 7,962 & 4,363 & 6,187 & 3,997 & 5,602 & 6,036 \\
\hline 13.80 & 7,751 & 4,242 & 6,014 & 3,890 & 5,470 & 5,865 \\
\hline 14.40 & 7,541 & 4,123 & 5,843 & 3,786 & 5,340 & 5,696 \\
\hline 15.00 & 7,332 & 4,004 & 5,674 & 3,681 & 5,210 & 5,529 \\
\hline 15.60 & 7,126 & 3,887 & 5,507 & 3,577 & 5,076 & 5,360 \\
\hline 16.20 & 6,921 & 3,770 & 5,343 & 3,474 & 4,941 & 5,191 \\
\hline 16.80 & 6,724 & 3,658 & 5,185 & 3,375 & 4,806 & 5,024 \\
\hline 17.40 & 6,528 & 3,546 & 5,030 & 3,277 & 4,672 & 4,858 \\
\hline 18.00 & 6,336 & 3,436 & 4,877 & 3,181 & 4,543 & 4,699 \\
\hline 18.60 & 6,145 & 3,328 & 4,726 & 3,083 & 4,416 & 4,544 \\
\hline
\end{tabular}




\begin{tabular}{|c|c|c|c|c|c|c|}
\hline $\begin{array}{l}\text { Span } \\
\text { (m) }\end{array}$ & $\begin{array}{l}\text { Static } \\
\text { Max Flap } \\
(\mathrm{kNm})\end{array}$ & $\begin{array}{l}\text { Static } \\
\text { Max Edge } \\
(\mathrm{kNm})\end{array}$ & $\begin{array}{l}\text { Static } \\
\text { Min Flap } \\
(\mathbf{k N m})\end{array}$ & $\begin{array}{l}\text { Static } \\
\text { Min Edge } \\
(\mathrm{kNm})\end{array}$ & $\begin{array}{l}\text { Fatigue } \\
\text { Flap } \\
\text { Range } \\
(\mathrm{kNm})\end{array}$ & $\begin{array}{l}\text { Fatigue } \\
\text { Lead-lag } \\
\text { Range } \\
(\mathrm{kNm})\end{array}$ \\
\hline 19.20 & 5,957 & 3,222 & 4,576 & 2,985 & 4,291 & 4,392 \\
\hline 19.80 & 5,769 & 3,116 & 4,427 & 2,888 & 4,167 & 4,242 \\
\hline 20.40 & 5,593 & 3,017 & 4,286 & 2,796 & 4,043 & 4,088 \\
\hline 21.00 & 5,417 & 2,919 & 4,146 & 2,705 & 3,920 & 3,937 \\
\hline 21.60 & 5,242 & 2,823 & 4,007 & 2,615 & 3,798 & 3,788 \\
\hline 22.20 & 5,072 & 2,727 & 3,872 & 2,526 & 3,677 & 3,642 \\
\hline 22.80 & 4,904 & 2,633 & 3,738 & 2,437 & 3,558 & 3,504 \\
\hline 23.40 & 4,736 & 2,540 & 3,606 & 2,350 & 3,440 & 3,371 \\
\hline 24.00 & 4,571 & 2,449 & 3,475 & 2,265 & 3,323 & 3,238 \\
\hline 24.60 & 4,408 & 2,358 & 3,347 & 2,181 & 3,208 & 3,108 \\
\hline 25.20 & 4,253 & 2,273 & 3,227 & 2,102 & 3,099 & 2,982 \\
\hline 25.80 & 4,100 & 2,189 & 3,109 & 2,025 & 2,993 & 2,859 \\
\hline 26.40 & 3,949 & 2,106 & 2,993 & 1,950 & 2,888 & 2,738 \\
\hline 27.00 & 3,802 & 2,025 & 2,878 & 1,876 & 2,784 & 2,619 \\
\hline 27.60 & 3,657 & 1,944 & 2,766 & 1,804 & 2,682 & 2,502 \\
\hline 28.20 & 3,514 & 1,864 & 2,654 & 1,732 & 2,580 & 2,388 \\
\hline 28.80 & 3,376 & 1,788 & 2,554 & 1,662 & 2,480 & 2,279 \\
\hline 29.40 & 3,239 & 1,712 & 2,455 & 1,592 & 2,381 & 2,174 \\
\hline 30.00 & 3,105 & 1,637 & 2,358 & 1,524 & 2,285 & 2,073 \\
\hline 30.60 & 2,973 & 1,565 & 2,263 & 1,457 & 2,189 & 1,973 \\
\hline 31.20 & 2,843 & 1,496 & 2,161 & 1,392 & 2,096 & 1,875 \\
\hline 31.80 & 2,714 & 1,426 & 2,060 & 1,328 & 2,007 & 1,787 \\
\hline 32.40 & 2,590 & 1,359 & 1,964 & 1,267 & 1,920 & 1,701 \\
\hline 33.00 & 2,469 & 1,294 & 1,871 & 1,207 & 1,833 & 1,616 \\
\hline 33.60 & 2,358 & 1,234 & 1,787 & 1,151 & 1,750 & 1,534 \\
\hline 34.20 & 2,248 & 1,175 & 1,703 & 1,095 & 1,668 & 1,455 \\
\hline 34.80 & 2,141 & 1,117 & 1,621 & 1,039 & 1,588 & 1,379 \\
\hline 35.40 & 2,036 & 1,061 & 1,541 & 985 & 1,513 & 1,304 \\
\hline 36.00 & 1,934 & 1,006 & 1,463 & 932 & 1,438 & 1,231 \\
\hline 36.60 & 1,832 & 951 & 1,386 & 880 & 1,366 & 1,162 \\
\hline 37.20 & 1,734 & 899 & 1,312 & 832 & 1,295 & 1,095 \\
\hline 37.80 & 1,639 & 848 & 1,240 & 785 & 1,227 & 1,031 \\
\hline 38.40 & 1,547 & 799 & 1,172 & 740 & 1,160 & 969 \\
\hline
\end{tabular}




\begin{tabular}{|c|c|c|c|c|c|c|}
\hline $\begin{array}{l}\text { Span } \\
\text { (m) }\end{array}$ & $\begin{array}{l}\text { Static } \\
\text { Max Flap } \\
(\mathrm{kNm})\end{array}$ & $\begin{array}{l}\text { Static } \\
\text { Max Edge } \\
(\mathrm{kNm})\end{array}$ & $\begin{array}{l}\text { Static } \\
\text { Min Flap } \\
(\mathbf{k N m})\end{array}$ & $\begin{array}{l}\text { Static } \\
\text { Min Edge } \\
(\mathrm{kNm})\end{array}$ & $\begin{array}{l}\text { Fatigue } \\
\text { Flap } \\
\text { Range } \\
(\mathrm{kNm})\end{array}$ & $\begin{array}{l}\text { Fatigue } \\
\text { Lead-lag } \\
\text { Range } \\
(\mathrm{kNm})\end{array}$ \\
\hline 39.00 & 1,456 & 751 & 1,103 & 695 & 1,095 & 908 \\
\hline 39.60 & 1,367 & 704 & 1,036 & 652 & 1,031 & 850 \\
\hline 40.20 & 1,279 & 657 & 970 & 609 & 969 & 793 \\
\hline 40.80 & 1,193 & 612 & 906 & 567 & 907 & 739 \\
\hline 41.40 & 1,109 & 568 & 844 & 527 & 846 & 685 \\
\hline 42.00 & 1,027 & 525 & 783 & 488 & 787 & 635 \\
\hline 42.60 & 946 & 483 & 723 & 449 & 730 & 587 \\
\hline 43.20 & 866 & 442 & 664 & 411 & 675 & 542 \\
\hline 43.80 & 789 & 402 & 608 & 375 & 621 & 497 \\
\hline 44.40 & 719 & 366 & 555 & 342 & 570 & 456 \\
\hline 45.00 & 649 & 330 & 503 & 308 & 522 & 417 \\
\hline 45.60 & 588 & 297 & 456 & 278 & 477 & 380 \\
\hline 46.20 & 528 & 266 & 411 & 250 & 434 & 344 \\
\hline 46.80 & 476 & 239 & 371 & 225 & 394 & 311 \\
\hline 47.40 & 425 & 213 & 332 & 200 & 357 & 280 \\
\hline 48.00 & 377 & 188 & 295 & 177 & 321 & 250 \\
\hline 48.60 & 329 & 164 & 258 & 154 & 288 & 223 \\
\hline 49.20 & 284 & 141 & 224 & 134 & 258 & 197 \\
\hline 49.80 & 239 & 119 & 189 & 113 & 229 & 173 \\
\hline 50.40 & 203 & 101 & 162 & 96 & 201 & 151 \\
\hline 51.00 & 166 & 83 & 134 & 79 & 176 & 132 \\
\hline 51.60 & 134 & 68 & 110 & 64 & 152 & 113 \\
\hline 52.20 & 103 & 53 & 87 & 50 & 129 & 96 \\
\hline 52.80 & 79 & 41 & 68 & 39 & 109 & 80 \\
\hline 53.40 & 54 & 29 & 49 & 28 & 90 & 66 \\
\hline 54.00 & 42 & 22 & 39 & 22 & 73 & 54 \\
\hline 54.60 & 33 & 17 & 30 & 18 & 58 & 43 \\
\hline 55.20 & 25 & 13 & 23 & 14 & 46 & 34 \\
\hline 55.80 & 18 & 9 & 17 & 10 & 36 & 26 \\
\hline 56.40 & 11 & 6 & 11 & 7 & 28 & 20 \\
\hline 57.00 & 7 & 4 & 7 & 5 & 18 & 14 \\
\hline 57.60 & 4 & 2 & 4 & 3 & 12 & 9 \\
\hline 58.20 & 2 & 1 & 2 & 2 & 8 & 6 \\
\hline
\end{tabular}




\begin{tabular}{|c|c|c|c|c|c|c|}
\hline $\begin{array}{l}\text { Span } \\
\text { (m) }\end{array}$ & $\begin{array}{l}\text { Static } \\
\text { Max Flap } \\
(\mathrm{kNm})\end{array}$ & $\begin{array}{l}\text { Static } \\
\text { Max Edge } \\
(\mathrm{kNm})\end{array}$ & $\begin{array}{l}\text { Static } \\
\text { Min Flap } \\
(\mathrm{kNm})\end{array}$ & $\begin{array}{l}\text { Static } \\
\text { Min Edge } \\
(\mathrm{kNm})\end{array}$ & $\begin{array}{l}\text { Fatigue } \\
\text { Flap } \\
\text { Range } \\
(\mathrm{kNm})\end{array}$ & $\begin{array}{l}\text { Fatigue } \\
\text { Lead-lag } \\
\text { Range } \\
(\mathbf{k N m})\end{array}$ \\
\hline 58.80 & 1 & 0 & 1 & 1 & 5 & 4 \\
\hline 59.40 & 0 & 0 & 0 & 0 & 3 & 2 \\
\hline 60.00 & 0 & 0 & 0 & 0 & 2 & 1 \\
\hline
\end{tabular}




\section{Excitation and Control Equipment}

The test configuration and excitation systems considered in this study are based on equipment and standard certification test practices in use at the WTTC laboratory. Typically, for a resonance fatigue test the blade will be mounted on the test stand in a high pressure up configuration with the zero pitch line horizontal. Flap fatigue tests are excited using a GREX; whereas edge tests are excited using an IREX. The proposed biaxial test design will use a combination of a GREX in the flap direction and either an IREX or a GREX type device (possibly including a bell crank) in the lead-lag direction.

The bending moment curve is adjusted to best fit the target load by placing masses along the blade as needed. As little mass as possible is used to reduce the mean bending moment in the flap direction and keep the test frequency as high as possible as is typically requested by the manufacturer or turbine OEM. The required input energy is calculated based on estimates of the structural and aerodynamic damping. Additionally, "virtual" mass may be conceptually added in one direction, but not in the other by either using a physical mass connected to the blade via a pushrod or by adjusting the frequency so that the GREX type actuator applies a force that is in phase with the blade movement.

Fatigue tests are controlled by an MTS FlexTest 200 controller using amplitude control to maintain the desired strain level corresponding to the desired bending moment by adjusting the amount of input energy (IREX stroke or GREX force). This results in a nearly constant amplitude test even as temperature and other environmental effects change. In addition, to keep the blade at resonance as the ambient temperature changes, the controller is typically configured to use a resonance tracking algorithm. This software enables the controller to continuously measure the phase angle between the excitation command and the response of the blade and adjust the test frequency to keep the test at a constant phase angle at or near the resonance frequency.

\subsection{Static Calibration}

Static calibrations are conducted in either the horizontal (lead-lag) or vertical (flapwise) direction pulling on the blade to a nominal load at an outboard saddle and measuring the strain response. Unlike for a static test, the loading cable is configured to be approximately perpendicular to the span axis of the blade during the static calibration test. Then, the bending moment at each strain gauge is simply the product of the difference in span between that gauge and the loaded saddle and the force applied (neglecting geometric nonlinearity due to blade deformation). For a biaxial fatigue test, cross talk matrix compensation will be required and is typically applied in a similar way to the method described in the IEC 61400-13 technical specification for wind turbine measurements (IEC_61400-13 2001).

\subsection{Added Masses}

The bending moment curve may be adjusted by adding masses to the blade to better match the target test load distribution along the blade span. The acceleration of the mass as the blade moves creates a point load that is in phase with the displacement and increases the applied bending moment amplitude linearly between the mass and the root of the blade. The applied masses also modify the mean bending moment in the flap direction. Large masses on the order of 1,000 
$3,000 \mathrm{~kg}$ are sometimes required between $20 \%$ and $50 \%$ of the span to increase the root bending moment. Smaller masses may also be required outboard on the blade. Typically, either a saddle or parts of a saddle are used if the mass required is between 100 and $400 \mathrm{~kg}$. If a small tip mass is required, then small steel plates may be attached directly to the blade tip using straps and adhesively bonded aluminum angles.

\subsection{IREX Actuator for Lead-Lag Fatigue}

The primary method of lead-lag fatigue excitation for a WTTC fatigue test is the IREX system with specifications shown in Table 5. In general, for a lead-lag fatigue test, a single IREX actuator (Figure 5) is placed on a saddle at approximately mid-span of the blade. The moving mass oscillates linearly with a sinusoidal displacement command. The MTS controller tracks the resonance frequency of the blade to keep the system operating at optimum efficiency and simultaneously adjusts the displacement amplitude to achieve the target fatigue strain amplitude.

Table 5. IREX Actuator Specifications

\begin{tabular}{|c|c|}
\hline Maximum Stroke Range ${ }^{a}$ & $0.300 \mathrm{~m}$ \\
\hline Moving Mass & $160-1,525 \mathrm{~kg}$ \\
\hline Fixed Mass ${ }^{b}$ & $320 \mathrm{~kg}$ \\
\hline
\end{tabular}

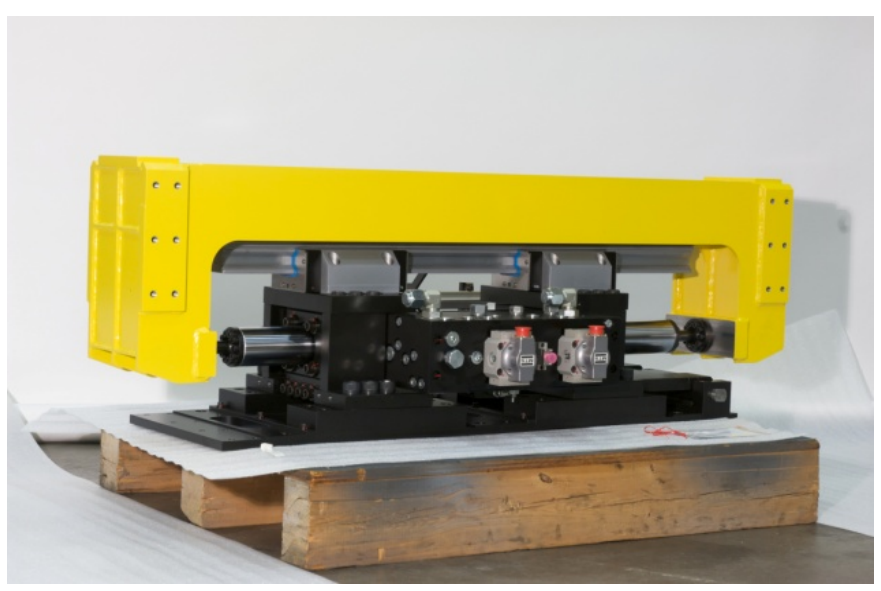

Figure 20. Single actuator with fixed mass (black) and minimum moving mass (yellow). NREL 17637

\subsection{GREX Actuator for Flap Fatigue}

The GREX actuator is designed to connect to a saddle on the blade, and the applied force is reacted by a base plate mass on the laboratory floor. During normal operation, the MTS controller is configured to excite the blade at resonance using a sinusoidal force command. Maximum forces that can be applied by the actuator are limited by two sets of valves, one electronic and one mechanical. The electronic valves are designed to open on an interlock or other sudden stop event allowing the blade to keep moving and the motion to damp out gradually without damaging the test article or actuator. The mechanical valves will relieve pressure in the 
actuator if the force exceeds a preset value. In combination, these valves provide redundant protection to ensure that the actuator and test article are not damaged due to the high energy stored in the test article during excitation. During demonstration testing, it was found that during a normal interlock the maximum force applied to the blade never exceeded the target force amplitude.

Two versions of the GREX are available at the WTTC: GREX 50 and GREX 100. The capabilities of each actuator are listed in Table 6.

Table 6. GREX Specifications

\begin{tabular}{lll}
\hline Specification & GREX 50 & GREX 100 \\
\hline Max static force rating & $50 \mathrm{kN}$ & $100 \mathrm{kN}$ \\
Max dynamic force & $\sim 30 \mathrm{kN}$ & $\sim 60 \mathrm{kN}$ \\
Max stroke amplitude & $875 \mathrm{~mm}$ & $875 \mathrm{~mm}$ \\
Max velocity & $2.5 \mathrm{~m} / \mathrm{s}$ & $2.5 \mathrm{~m} / \mathrm{s}$ \\
Max horizontal acceleration at & $1.0 \mathrm{~g}$ & $1.0 \mathrm{~g}$ \\
top pivot & 12 degrees & 12 degrees \\
Max angle of actuator from & $5,692 \mathrm{~mm}$ & $5,795 \mathrm{~mm}$ \\
vertical & $8,687 \mathrm{~mm}$ & $8,790 \mathrm{~mm}$ \\
Minimum mean stroke length & $75 \mathrm{~mm}$ & $75 \mathrm{~mm}$ \\
Maximum mean stroke length & $600 \mathrm{~mm}$ & $215 \mathrm{~mm}$ \\
with extension tube & & \\
Length adjustment increment & & \\
Base height (typical) & &
\end{tabular}

\subsection{PHLEX Concept}

The PHLEX is a concept for increasing the flap frequency until it equals the lead-lag frequency by providing real or virtual (hydraulic actuator) springs in the flap direction. If successfully implemented, this concept has the advantage that the test can be run relatively quickly at the higher lead-lag frequency. Experiments were conducted to implement this on a 9-m blade using a hydraulic actuator mounted at $7 \mathrm{~m}$, relatively close to the blade tip. See White et al. (2011) and Beckwith et al. (2013) for more details on these test simulations and experiments.

\subsection{Hybrid Test Research Project}

The hybrid test research project is an ongoing set of experiments to evaluate methods for elliptical phase-locked testing using different energy input approaches. Experiments are conducted using inertial mass excitation (IREX), direct forcing (GREX) and base excitation where the plate where the blade is mounted is moved by actuators. Different geometry and linkage mechanisms are also considered. One incarnation of this experimental program achieves a phase-locked resonance testing using a mass mounted on a slide table to reduce the lead-lag frequency to match that of the flap frequency. This concept is shown in Figure 21 and may be combined with a GREX-type flap exciter as shown in Figure 22. At the present time, experiments have demonstrated successful excitation of the blade at matching flap and lead-lag 
frequencies using this test configuration installed on a 12-m blade. Further results of this project will be published after its conclusion.

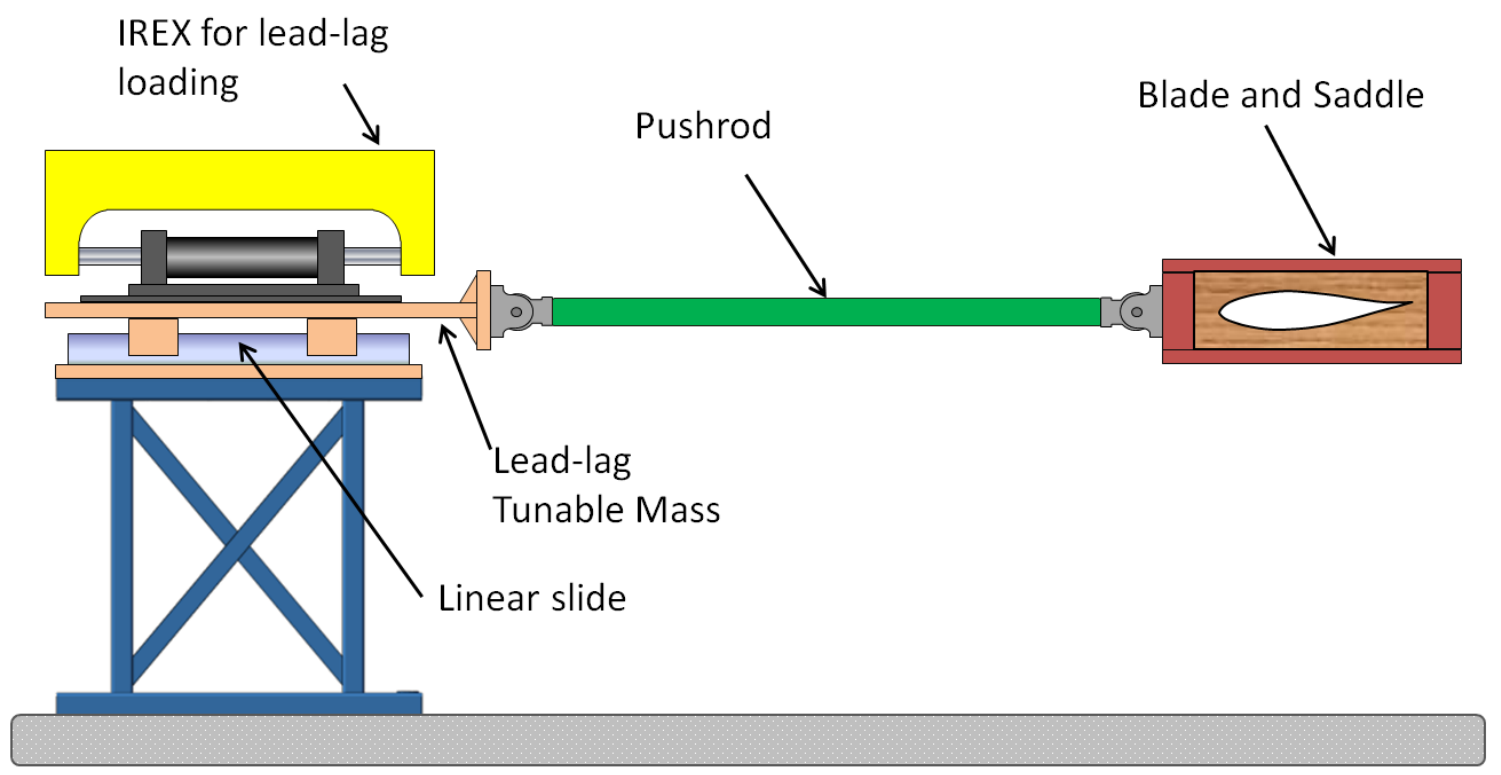

Figure 21. Hybrid concept for applying mass to the blade in the lead-lag direction but leaving the mass in the flap direction unchanged. In this case, the IREX is mounted off the blade as part of the virtual mass in the lead-lag direction.

Image credit: Scott Hughes, NREL

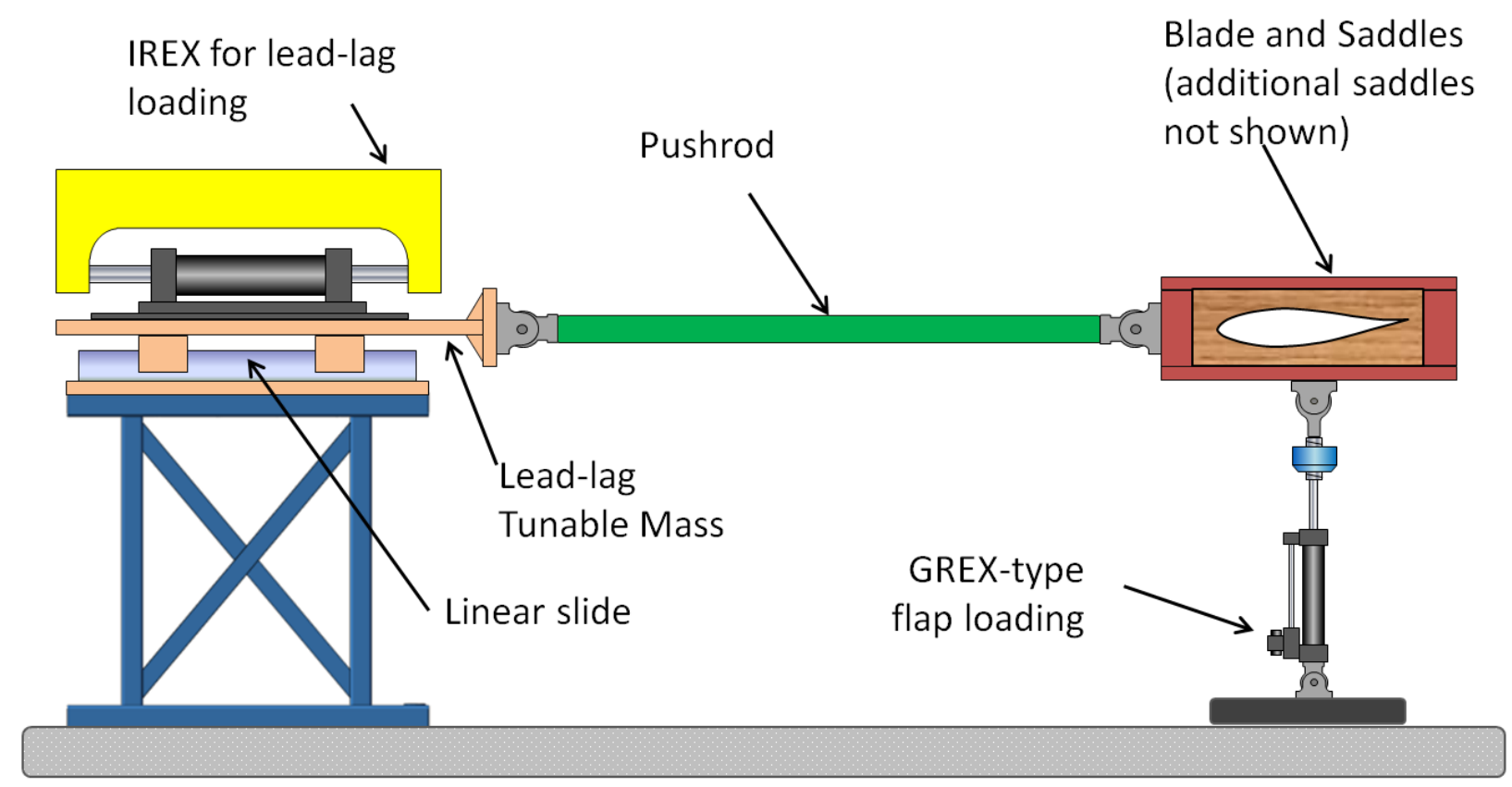

Figure 22. Hybrid configuration using IREX and GREX excitation systems attached to the same saddle.

Image credit: Scott Hughes, NREL 


\subsection{Virtual Mass}

This study uses the term virtual mass to refer to a force applied to the blade that behaves like a mass acting in just one direction from a numerical standpoint. Virtual mass may be implemented as real mass that is connected through some type of mechanical linkage such that it only acts in one of the primary directions of motion — lead-lag or flap — as demonstrated in the hybrid test research project.

Alternatively, a virtual mass may be implemented using a servo hydraulic actuator to apply a sinusoidal force in phase with the displacement that is the equivalent to the virtual mass times the blade acceleration in that direction. The same actuator could be used to simultaneously apply the excitation for resonance. The sum of the two applied sine waves is simply another sine wave with a shifted phase (Figure 23). In essence, the virtual mass is created by modifying the phase angle between the force and displacement, which in turn modifies the resonance frequency of the system. This concept has successfully been demonstrated using a GREX actuator to both excite a blade in the flap direction and by modifying the command frequency, and thus the phase angle between the force and displacement, the bending moment distribution was changed (Figure 24). The bending moment curve will be modified just as if a mass was added to the blade at the exciter saddle. However, the mean load and the resonance mode shape in the other direction (lead-lag vs. flap) will remain unchanged.

By increasing the excitation test frequency above resonance, it is also possible to apply "negative virtual mass." In this case the actuator is applying a force that is 180 degrees out of phase with the displacement. Essentially, the actuator is carrying some of the saddle and blade rather than relying on the blade to accelerate that mass. Small amounts of negative virtual mass are possible; however, experimentally control instabilities tend to occur if the test frequency with a GREX is increased very far above the system resonance frequency. Numerically the simulation eigenvector analysis described in the next section also becomes unstable if more mass is removed than is present at that saddle location. Other models that include actual dynamic timeseries approaches may be required to accurately simulate this type of test. This is a topic area for further investigation in the future.

The required force amplitude for a virtual mass is estimated by multiplying the virtual mass required in kilograms by the acceleration in meters per seconds squared at a given saddle location. Farther out on a blade where the acceleration is relatively high, large forces may be generated with relatively small masses. However, in the middle of the blade and closer to the root, a large mass of several thousand kilograms may be replaced with a reasonable force for an actuator in the $10-40 \mathrm{kN}$ range, and the strokes and velocities required are reasonable for a hydraulic actuator. Therefore, it is reasonable to consider actuators be used for virtual mass in about the first $50 \%$ of a blade span and a system with actual masses attached to the blade through mechanical linkage be developed for outboard stations. 


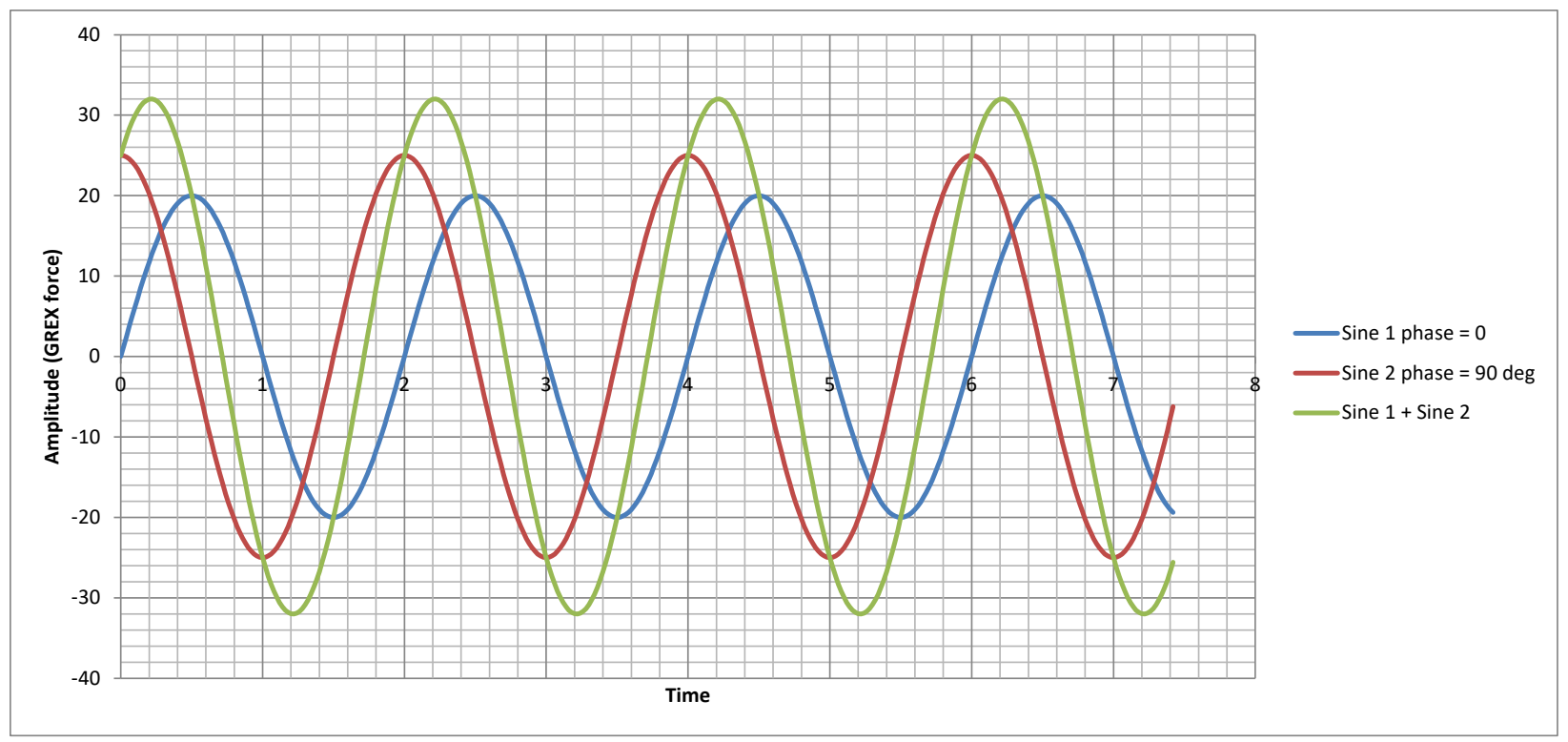

Figure 23. Addition of two sine wave force functions showing the result as a sine wave with shifted phase. Phase shifting is accomplished with a GREX-type device by modifying the excitation frequency, and a target phase can be set to include virtual mass in the forcing function for the test.

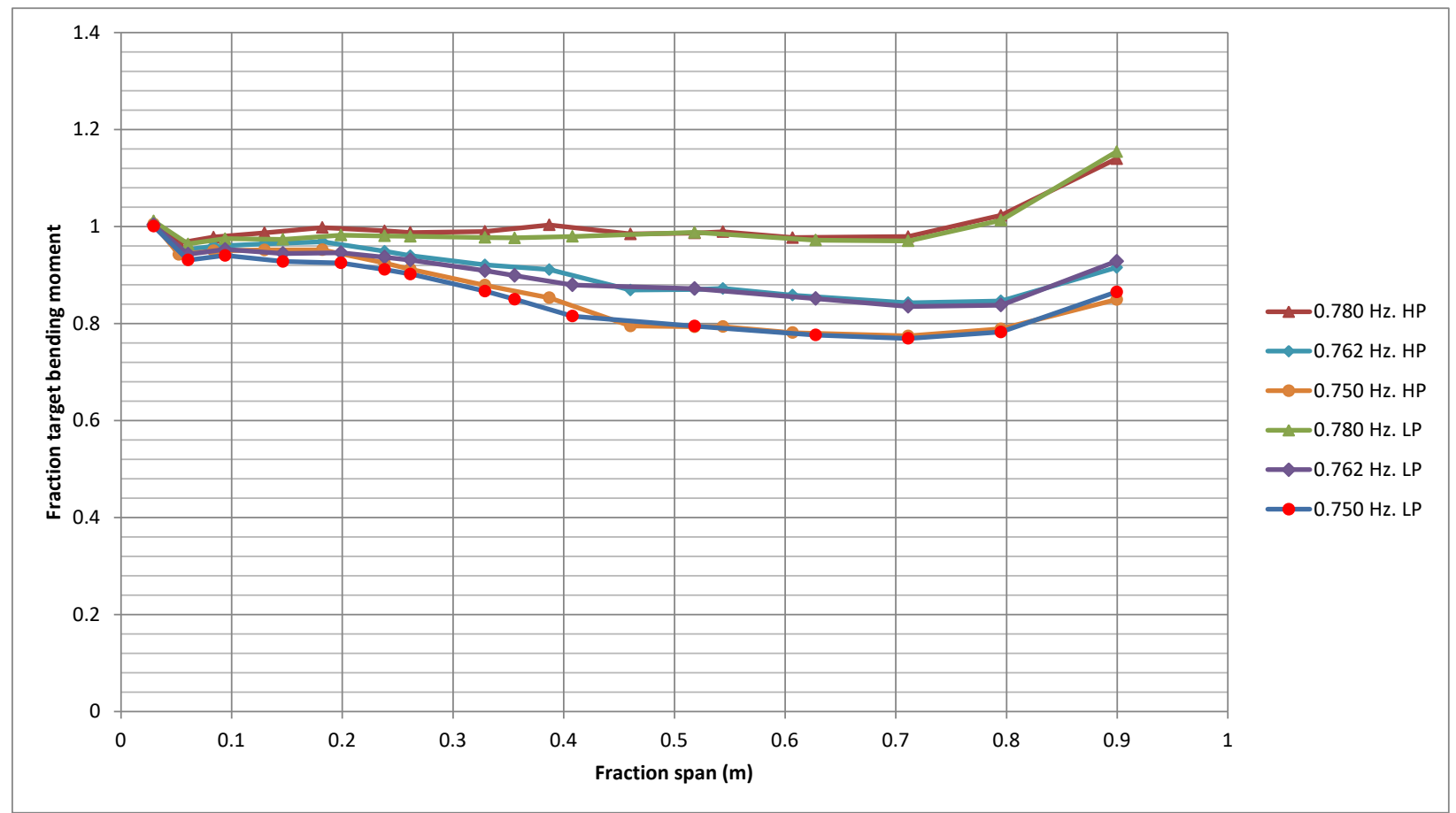

Figure 24. Modification of the bending moment by operating a GREX located at $43 \%$ span at different frequencies, effectively adding a virtual mass to this location as the frequency was decreased from $0.78 \mathrm{~Hz}$ to $0.75 \mathrm{~Hz}$. The force amplitude was adjusted to achieve the same strain amplitude at the first set of strain gauges at each frequency. 


\section{Resonance Fatigue Test Simulation}

A simplified two degree-of-freedom beam element model is used to predict the blade behavior during the simulated resonance tests. For biaxial test simulation, the model is run twice, once for the flapwise direction and once for the lead-lag direction. The two solutions are then superimposed on each other. The implementation is in Microsoft Excel using the add-in "Eigs()" function from PopTools (Hood n.d.) to compute the eigenvalues and eigenfrequencies. The model makes the key assumption that the total damping is relatively low, only a few percent of critical; thus, the operational mode shapes can be predicted adequately using undamped analysis. Also, because the system is operated at steady state with energy input equal to the damping, the maximum potential "spring" energy stored at maximum displacement is assumed to be equal to the maximum kinetic energy achieved at maximum velocity.

\subsection{Dynamic Model}

For the dynamic analysis to determine mode shapes and frequencies of resonance, a two degreeof-freedom beam element model is constructed by spitting the blade into short beam segments. Each node has two degrees of freedom, a displacement, and a rotation as shown in Figure 25.

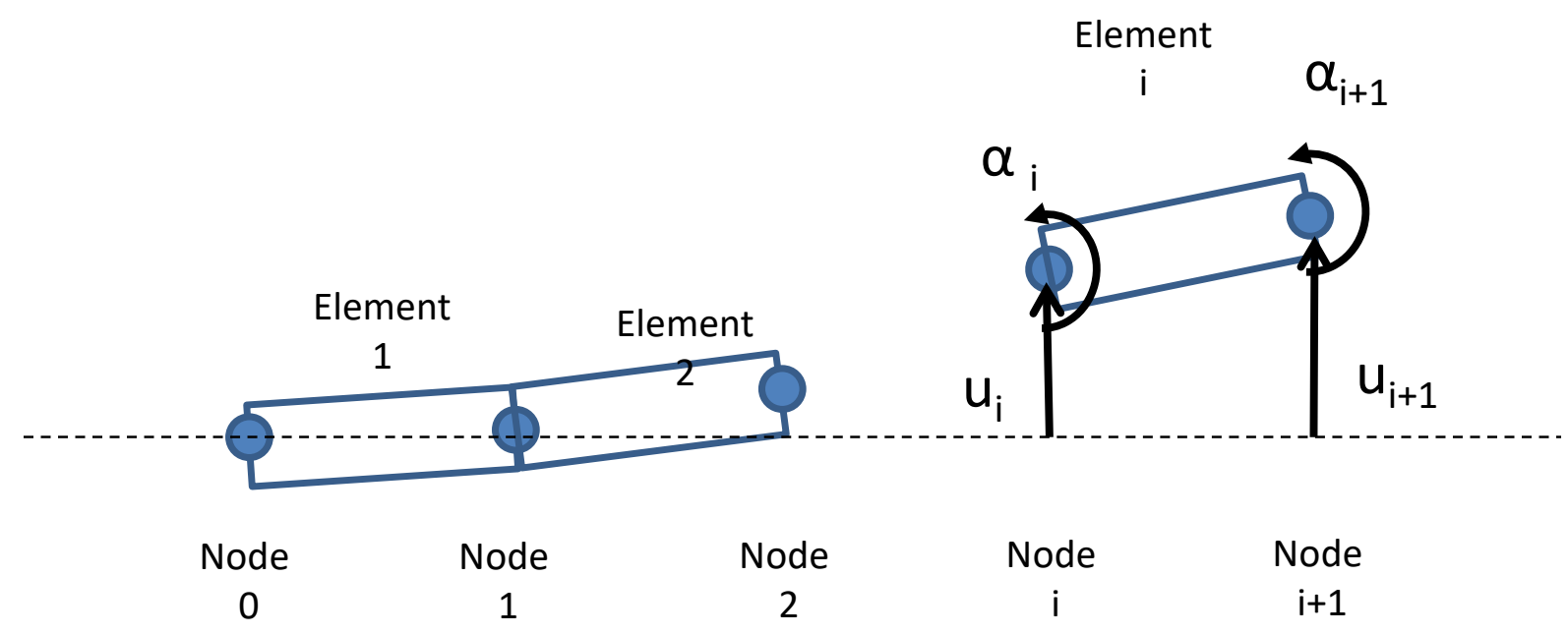

Figure 25. Finite element concept for dynamic analysis

The general equation for free oscillation of an undamped system is shown in equation 2:

$$
[M] \ddot{\vec{u}}+[K] \vec{u}=\vec{F}=0
$$

where $[M]$ is the mass matrix, $[K]$ is the stiffness matrix, $\vec{u}$ is the displacement vector, and $\vec{F}$ is the applied forcing function, which is neglected for the mode shape analysis as the system is highly underdamped so the forcing does not have a significant role in the overall mode shape. For this two degree-of-freedom system, the displacement vector is made up of the displacements and rotations of each node as follows in Eq. 3: 


$$
\vec{u}=\left\{\begin{array}{c}
u_{1} \\
\alpha_{1} \\
u_{2} \\
\alpha_{2} \\
u_{3} \\
\alpha_{3} \\
\vdots
\end{array}\right\}
$$

Note that $u_{0}$ and $\alpha_{0}$ are taken to be 0 , corresponding to the fixed boundary condition at the root of the blade where it is mounted on the test stand. To generate the mass and stiffness matrices corresponding to the blade, an approach of building and then combining submatrices representing the properties at each node as described in chapter 10 of (Shames and Dym 1996) is followed.

Euler-Bernoulli beam elements are used for the stiffness matrix while a lumped mass approach is used to approximate all of the mass of the elements and saddles at each node, resulting in a diagonal mass matrix and a simpler solution. Half of the mass of each element is approximated to reside at each node at either end of that element. Likewise, half of the rotational moment of inertia of each element is applied to each node. Each saddle or added point mass is taken to be located at a node, and the entire mass and rotation of inertia of that saddle, if provided, is applied to that node. Thus, the mass and moment of inertia of each element $i$ are divided up between the $i^{\text {th }}$ node and the previous node (i-1). This is done by assembling the mass matrix using a set of submatrices in Eq. 4 as follows.

$$
[m]^{(i)}=\left[\begin{array}{llll}
\frac{\lambda_{i} l_{i}}{2} & & & \\
& \frac{\lambda_{i} l_{i}{ }^{3}}{24} & \\
& & \frac{\lambda_{i} l_{i}}{2}+m_{s, i} & \\
& & \frac{\lambda_{i} l_{i}{ }^{3}}{24}+I_{s, i}
\end{array}\right]
$$

where $\lambda_{i}$ is the mass per unit length, $l_{i}$ is the length of the beam element $i$ and $m_{s, i}$, and $I_{s, i}$ are the mass and rotational moment of inertia of the saddle at node $i$. Then, the mass matrix for the nodes is formed using a combination of the properties of the element before and after that node by adding the elements $m_{j k}^{(i)}$ as follows in Eq. 5. The first two rows and columns are removed corresponding to the boundary conditions where the displacement and rotation of node 0 is 0 . 


$$
[M]=
$$

$$
\left[\begin{array}{ccccccc}
m_{33}^{(1)}+m_{11}^{(2)} & & & & & \\
& m_{44}^{(1)}+m_{22}^{(2)} & & & & & \\
& m_{33}^{(2)}+m_{11}^{(3)} & & & & \\
& & m_{44}^{(2)}+m_{22}^{(3)} & & & \\
& & & \ddots & & \\
& & & m_{33}^{(N)} & \\
& & & & m_{44}^{(N)}
\end{array}\right]
$$

Likewise, the subset of the stiffness matrix is formed for each element by combinations of the matrix for each element before and after the node so that the internal reactions of each element are accounted for in the motion of that node (Eq. 6):

$$
[k]^{(i)}=\frac{(E I)_{i}}{l_{i}^{3}}\left[\begin{array}{cccc}
12 & 6 l_{i} & -12 & 6 l_{i} \\
6 l_{i} & 4 l_{i}^{2} & -6 l_{i} & 2 l_{i}^{2} \\
-12 & -6 l_{i} & 12 & -6 l_{i} \\
6 l_{i} & 2 l_{i}^{2} & -6 l_{i} & 4 l_{i}^{2}
\end{array}\right]
$$

Thus, after removing the first two rows and columns corresponding to the boundary conditions at node 0 the submatrices are combined to form the complete stiffness matrix (Eq. 7):

$[K]=$

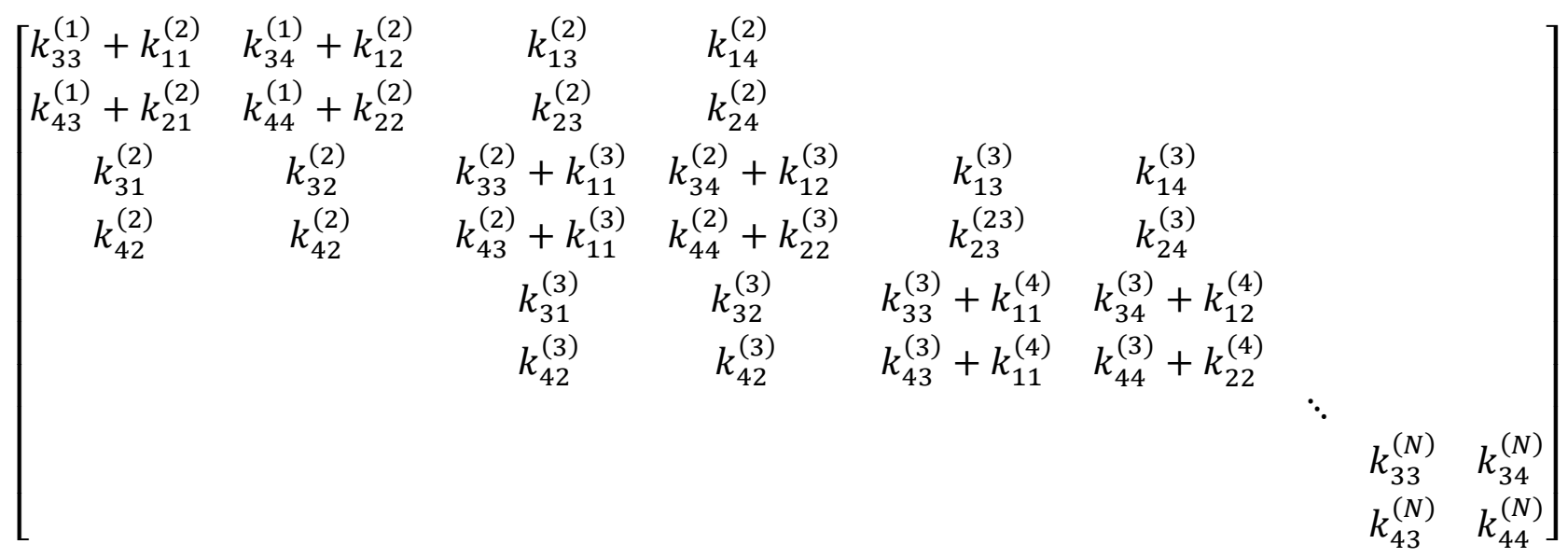


The solutions to the system of linear differential equations represented in Eq. 2 are given by the eigenvectors and eigenvalues of the matrix in Eq. 8:

$$
[M]^{-1}[K]
$$

The eigenvalues are the resonance frequencies in radians per second corresponding to each mode shape given by the eigenvectors. We are primarily interested in the first mode, although it is useful to consider the resonance frequencies for the second and third modes in both the flap and lead-lag directions to ensure that they are not a harmonic of the base excitation frequencies that will be used.

The final step in determining the deformed shape of the blade and corresponding applied loading is to scale the eigenvector to the appropriate test amplitude. To do this, we consider the moment and shear that must be applied at node 1 to achieve the deflection and rotation of this node given that node 0 is fixed. For a simple Euler beam, as shown in Figure 26, the deflection and rotation calculated for the superimposed moment $M$ and shear $V$ at the end of the beam element (at node 1) are given in Eq. 9 and 10.

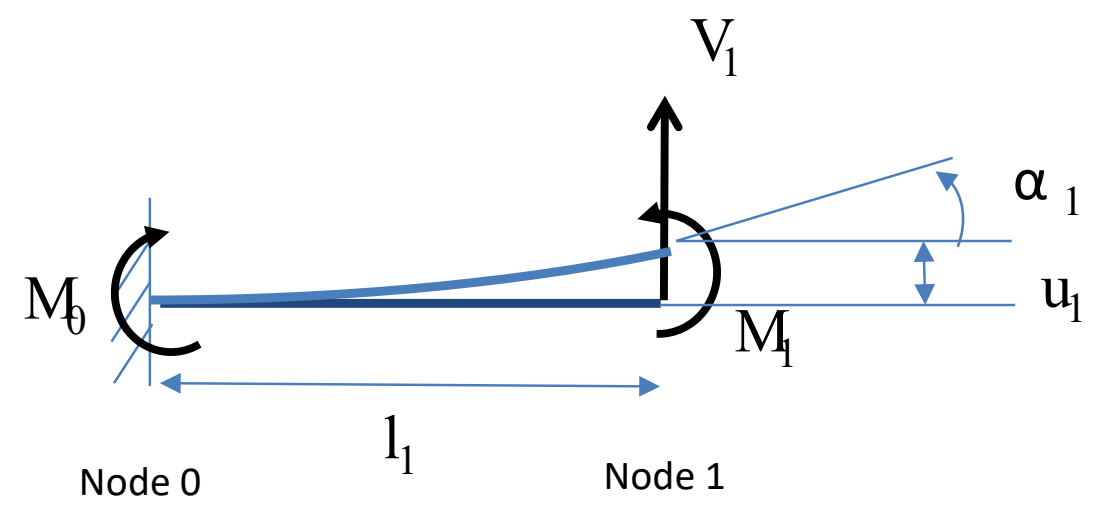

Figure 26. Deflection of element 1

$$
\begin{aligned}
& u_{1}=\frac{M_{1} l_{1}^{2}}{2(E I)_{1}}+\frac{V_{1} l_{1}^{3}}{3(E I)_{1}} \\
& \alpha_{1}=\frac{M_{1} l_{1}}{(E I)_{1}}+\frac{V_{1} l_{1}^{2}}{2(E I)_{1}}
\end{aligned}
$$


Solving these simultaneous equations for $M$ and $V$ produces Eq. 11 and 12:

$$
\begin{gathered}
V_{1}=-\frac{(E I)_{1}}{l_{1}^{2}}\left(6 \alpha_{1}-12 \frac{u_{1}}{l_{1}}\right) \\
M_{1}=\frac{(E I)_{1} \alpha_{1}}{l_{1}}-\frac{V_{1} l_{1}}{2}
\end{gathered}
$$

Equations 11 and 12 are used to determine the moment and shear at node 1 . Then the moment at the root of the blade, node zero is estimated as (Eq. 13):

$$
M_{0}=M_{1}+V_{1} l_{1}
$$

The above calculations are performed using the first two elements of the unscaled eigenvector corresponding to the lowest (first mode) resonance frequency. Then because $V$ and $M$ are linear functions of $u$ and $\alpha$ as shown in Eq. 11 and 12, the eigenvector can be scaled linearly to achieve the target root moment (Eq. 14):

$$
\vec{u}_{\text {scaled }}=\vec{u}_{\text {mode } 1} \frac{M_{T 0}}{M_{0 \text { unscaled }}}
$$

where $M_{T 0}$ is the target root moment amplitude. From here on only the scaled displacement vector will be used without specifically noting that $u_{i}$ and $\alpha_{i}$ are the scaled values. The moment and shear at each node can be calculated using the scaled eigenvector values for $u_{i}$ and $\alpha_{i}$ and considering the relative deflection and rotation of each element (Eq. 15 and 16).

$$
\begin{gathered}
V_{i}=-\frac{(E I)_{i}}{l_{i}^{2}}\left(6\left(\alpha_{i}-\alpha_{i-1}\right)-12 \frac{u_{i}-\left(u_{i-1}+l_{i} \alpha_{i-1}\right)}{l_{i}}\right) \\
M_{i}=\frac{(E I)_{i}\left(\alpha_{i}-\alpha_{i-1}\right)}{l_{i}}-\frac{V_{i} l_{i}}{2}
\end{gathered}
$$


The fraction target moment achieved is determined by comparing the dynamic range achieved to the test target moment at each node (Eq. 17):

$$
\text { Fraction target achieved }=\frac{M_{i}}{M_{T i}}
$$

\subsection{Energy Balance}

To maintain resonance oscillation at the target amplitude, the excitation system must add energy to the system at the same rate that it is removed from the mechanical blade system due to damping. Two types of damping are considered, structural damping and aerodynamic drag as the blade moves back and forth through the air. The energy removed from the blade is calculated separately for structural and aerodynamic damping and then added together. Two energy input devices are also considered, an idealized IREX type device moving a mass relative the blade in a sinusoidal displacement, or an idealized GREX type device that applies a sinusoidal forcing function to the blade. The objective of the following calculations are to estimate the energy input required for the simulated test at the target excitation amplitude and then to calculate the necessary IREX displacement amplitude or GREX force amplitude to keep the test at a constant amplitude.

\subsubsection{Structural Damping}

Structural damping is a result of the materials in a blade not being entirely elastic. Some of the strain energy introduced to the material is converted to heat through viscoelastic behavior and is not recovered as the displacement is reversed. We assume the structural damping may be modeled as an equivalent linear-viscous damper. The damping may be expressed in the form of a damping ratio, $\zeta$, typically represented as a percentage corresponding to the fraction of damping relative to a critically damped system.

Let us consider the blade to be a single degree-of-freedom oscillator subjected to linear-viscous damping. The equation of motion is defined in Eq. 18 as:

$$
m \ddot{x}+c \dot{x}+k x=F(t)
$$

where $\mathrm{f}$ is the excitation frequency in hertz and $\mathrm{F}$ is the amplitude of the applied forcing function. The undamped natural frequency for this one degree-of-freedom system is shown in Eq. 19:

$$
f_{n}=\frac{1}{2 \pi} \sqrt{\frac{k}{m}}
$$


And the damping ratio is defined as (Eq. 20):

$$
\zeta=\frac{c}{c_{c}}=\frac{c}{2 m\left(2 \pi f_{n}\right)}=\frac{c}{2 \sqrt{m k}}
$$

If we consider an unforced system with $F=0$ starting with an initial amplitude during cycle $q$ of $x_{q}$, the amplitude will decrease with each cycle. The log decrement damping is defined as the natural log of the change in amplitude from one cycle to the next (Eq. 21):

$$
\delta=\ln \left(\frac{x_{q}}{x_{q+1}}\right)
$$

where $x_{q}$ is the amplitude of a cycle $q$, and $x_{q+1}$ is the amplitude of the next successive cycle. The log decrement damping can also be related mathematically to the damping ratio as shown in Eq. 22:

$$
\delta=\frac{2 \pi \zeta}{\sqrt{1-\zeta^{2}}}
$$

The maximum energy stored in the spring during cycle $q$ is equal to the maximum potential energy, which occurs when the velocity is zero (Eq. 23):

$$
E_{q}=\frac{1}{2} k x_{q, \max }^{2}
$$

Solving for $x$ in Eq. 24:

$$
x_{q, \max }=\sqrt{\frac{2}{k} E_{q}}
$$

Thus, the log decrement can be related to the stored maximum potential energy for two successive cycles as shown in Eq. 25:

$$
\delta=\ln \left(\frac{\sqrt{\frac{2}{k} E_{q}}}{\sqrt{\frac{2}{k} E_{q+1}}}\right)=\ln \left(\sqrt{\frac{E_{q}}{E_{q+1}}}\right)=\frac{1}{2} \ln \frac{E_{q}}{E_{q+1}}
$$


The total strain energy for a simple beam with an applied moment can be calculated as shown in Eq. 26:

$$
E_{\text {moment only }}=\int \frac{M^{2}}{2 E I} d l=\sum_{i=1}^{N} \frac{M_{i}^{2} l_{i}}{2(E I)_{i}}
$$

where the summation is performed to account for the stored energy in each element. However, the blade as a cantilever beam is also subjected to shear. Calculating the strain energy due to shear is more complicated and requires knowledge of the cross section, shear distribution through the material, and the material shear modulus. As these properties are not typically available to this model, it is not possible to calculate the maximum shear strain energy. However, it is relatively easy to determine the maximum total kinetic energy by evaluating the system when the velocity is maximum and the strain energy is zero. We make the assumption that the system is highly underdamped $(\zeta<<1)$ so the loss in energy per cycle is small compared to the energy stored and thus the kinetic energy at maximum velocity is equal to the potential energy at maximum displacement (Eq. 27):

$$
E_{\text {potential max }} \cong E_{\text {kinetic } \max }=\int \frac{1}{2} m\left(V_{\max }\right)^{2}+\frac{1}{2} I \omega_{\max }^{2} d l
$$

The maximum velocity, $V_{\max }$, at node $i$ is a function of the displacement, which is assumed to be sinusoidal. The displacement amplitude is defined by the scaled displacement from equation 14, and the frequency is defined by the first eigenvalue (Eq. 28).

$$
V_{\max , i}=\left[\frac{d x_{i}}{d t}\right]_{\max }=\left[\frac{d}{d t} u_{i} \sin (2 \pi f t)\right]_{\max }=u_{i} 2 \pi f
$$

where $f$ is the resonance frequency of the first mode of the blade in hertz. Likewise, the maximum rotational velocity at node $i$ is:

$$
\omega_{\max , i}=\left[\frac{d \theta_{i}}{d t}\right]_{\max }=\left[\frac{d}{d t} \alpha_{i} \sin (2 \pi f t)\right]_{\max }=\alpha_{i} 2 \pi f
$$

Thus, taking the conservative estimate (higher energy) using the displacement and rotation of the node at the outboard end of the element (Eq. 30):

$$
E_{\text {kinetic } \max }=\sum_{i=1}^{N}\left(\frac{1}{2}\left(\lambda_{i} l_{i}+m_{s, i}\right)\left(u_{i} 2 \pi f\right)^{2}+\frac{1}{2}\left(\frac{m_{i} l_{i}^{2}}{12}+I_{s, i}\right)\left(\alpha_{i} 2 \pi f\right)^{2}\right)
$$


This estimate of the total energy will typically be a few percent different compared to the energy estimated using the applied moment in equation 26. For the purpose of calculating the structural energy loss, either result can be used. The dynamic analysis in Eq. 30 has been selected for implementation.

Now that we know the total energy in the system, the loss in energy per cycle, $\Delta E=E_{q+1}-E_{q}$, and from Eq. 25 the log decrement damping is given in Eq. 31:

$$
\delta=\frac{1}{2} \ln \frac{E_{q}}{E_{q+1}}=\frac{1}{2} \ln \frac{E_{q}}{E_{q}-\Delta E}
$$

where

$$
\frac{E_{q}}{E_{q}-\Delta E}=e^{2 \delta}
$$

Solving for $\Delta E$ and evaluating in terms of the structural damping ratio as shown in Eq. 32 yields the total energy absorbed through structural damping per cycle (Eq. 33):

$$
\Delta E_{\text {structural }}=E_{q}\left(1-e^{-2 \delta}\right)=E_{\text {kinetic } \max }\left(1-e^{-2 \delta}\right)=E_{\text {kinetic } \max }\left(1-e^{-2 \frac{2 \pi \zeta}{\sqrt{1-\zeta^{2}}}}\right)
$$

In Eq. 33, the log decrement damping, $\delta$, and damping ratio, $\zeta$, are taken as only representing the structural or equivalent linear damping of the system. The energy loss due to aerodynamic drag is considered separately. It should be noted that the structural energy loss is proportional to dynamic energy stored in the system and thus is proportional to the square of the test amplitude.

\subsubsection{Aerodynamic Energy Loss}

The aerodynamic energy loss per cycle is estimated by considering the effective drag force on each element of the blade. In general, drag force (F. M. White 1999) as a function of time is given as

$$
F_{\text {drag }}(t)=\frac{1}{2} \rho v(t)^{2} h l C_{D}
$$

where $\rho$ is the air density, typically taken as $1.2 \mathrm{~kg} / \mathrm{m}^{3}, v(t)$ is the velocity, $h$ is the height, and $l$ the length, so $h l$ is the cross sectional area and $C_{D}$ is the coefficient of drag. Because the damping force is proportional the velocity squared, this type of damping is sometimes referred to as velocity squared damping. For the blade in the lead-lag direction, $h l$ is taken as the thickness of 
the blade times the element length, whereas in the flap direction, $h l$ is the chord times the element length. For a given element:

$$
v_{i}(t)=\frac{d x_{i}}{d t}=\frac{d}{d t} u_{i} \sin (2 \pi f t)=u_{i} 2 \pi f \cos (2 \pi f t)
$$

The energy used over a cycle of time, $=\frac{1}{f}$, is the integral of the force times the displacement.

$$
\Delta E_{\text {Aero }}=\int_{\text {cycle }} F d x=\int_{0}^{\frac{1}{f}} F \frac{d x}{d t} d t
$$

Because the drag is a nonconservative force, we evaluate the energy for one-quarter of a cycle and multiply the result by four. This calculation assumes a symmetric drag coefficient for the blade moving in either direction and neglects effects of turbulence.

$$
\begin{aligned}
& \Delta E_{\text {Aero } i}=4 \int_{0}^{\frac{1}{4 f}} \frac{1}{2} \rho\left(u_{i} 2 \pi f \cos (2 \pi f t)\right)^{2} h_{i} l_{i} C_{D i}\left(u_{i} 2 \pi f \cos (2 \pi f t)\right) d t \\
& =2 \rho h_{i} l_{i} C_{D i} u_{i}^{3}(2 \pi f)^{3} \int_{0}^{\frac{1}{4 f}} \cos ^{3}(2 \pi f t) d t \\
& \begin{array}{c}
\Delta E_{\text {Aero } i}=2 \rho h_{i} l_{i} C_{D i} u_{i}{ }^{3}(2 \pi f)^{3}\left[\frac{3}{4(2 \pi f)} \sin (2 \pi f t)+\frac{1}{12(2 \pi f)} \sin (3(2 \pi f) t)\right]_{0}^{\frac{1}{4 f}} \\
=2 \rho h_{i} l_{i} C_{D i} u_{i}{ }^{3}(2 \pi f)^{3}\left[\left(\frac{3}{42 \pi f} \sin \left(\frac{\pi}{2}\right)+\frac{1}{12(2 \pi f)} \sin \left(3 \frac{\pi}{2}\right)\right)-0\right] \\
=2 \rho h_{i} l_{i} C_{D i} u_{i}{ }^{3}(2 \pi f)^{3}\left(\frac{3}{4(2 \pi f)}-\frac{1}{12(2 \pi f)}\right)
\end{array}
\end{aligned}
$$

or

$$
\Delta E_{\text {Aero } i}=\frac{4}{3} \rho h_{i} l_{i} C_{D i} u_{i}^{3}(2 \pi f)^{2}
$$


The total energy absorbed per cycle due to aerodynamic drag is found by summing the result of Eq. 39 for all elements. The conservative (higher energy) result is found by using the displacement at the outboard end of the element.

$$
\Delta E_{\text {Aero }}=\sum_{i=1}^{N} \frac{4}{3} \rho h_{i} l_{i} C_{D i} u_{i}^{3}(2 \pi f)^{2}
$$

Note that the aerodynamic energy loss is proportional to the cube of the displacement amplitude.

\subsubsection{Evaluating Damping Parameters}

There is no wind tunnel data available for what the coefficient of drag should be for an airfoil oscillating at relatively low frequencies, such as in a fatigue test. However, the coefficient of drag has been measured for symmetric airfoils at a wide range of angles of attack for the application of vertical-axis wind turbines. For a symmetric airfoil at low Reynolds numbers and 0 angle of attack, the coefficient of drag may be very low, around 0.03 , while the coefficient of drag for an airfoil at 90 degrees angle of attack has been measured to be around 1.8 (Sheldahl and Kilmas 1981). B. Montgomerie (1996) cites coefficient of drag data for airfoils at 90 degrees to be in the range of 1.45 to 2.06 depending on the shape. Because blades undergoing a structural fatigue test move back and forth in a sinusoidal fashion passing through their own wake and operate in an enclosed volume inside a laboratory, relatively close to the laboratory walls and floor, the effective coefficient of drag has been found to be higher than these numbers. A numerical simulation of a blade oscillating perpendicular to the chord with a displacement range of $1 \mathrm{~m}$ or $2 \mathrm{~m}$ in an enclosed volume has predicted equivalent effective drag coefficients of 5.3 and 4.45 respectively (Greaves 2013). Unfortunately, drag coefficients for higher amplitudes were not computed but it would be anticipated that they would continue to decrease and approach the steady state flow values as the test amplitude is increased.

The structural damping of the first mode of a large wind turbine blade measured during a modal impact experiment is typically in the range of $0.1 \%$ to $0.3 \%$ critical. However, losses in the excitation system either due to damping in the attachment between the system and the blade or due to not having a sinusoidal force function or not being exactly on resonance will result in more energy input being required than theoretically needed. It is difficult to separate the structural damping from these excitation system inefficiencies, so instead they are considered a combined total "structural" damping.

As the structural damping energy transfer is proportional to the amplitude squared and the aerodynamic damping energy transfer to the amplitude cubed, it is possible to curve fit the two values simultaneously to data collected while operating at steady state at a selection of different test amplitudes and measuring the energy input required to maintain steady state. Previous experience in curve fitting experimental data to match the measured energy input and test amplitude yielded the following results. A structural damping of about $0.7 \%$ critical works well for both flap and lead-lag fatigue tests for the size blade considered in this study regardless of the excitation technology used. For aerodynamic damping, coefficient of drag of about 2.1 fits experimental data for flap direction tests while a $C_{D}$ of 0.15 works for lead-lag direction tests. 


\subsubsection{Energy Input Calculations}

The energy added per cycle from the excitation equipment is evaluated in two different ways depending on whether inertial mass excitation (IREX) or direct forcing excitation (GREX) is used. In either case, the energy input is calculated by integrating the force times the distance over the cycle as shown in Eq. 41:

$$
\Delta E_{\text {added }}=\int_{\text {cycle }} F d x=\int_{0}^{\frac{1}{f}} F \frac{d x}{d t} d t
$$

The blade is assumed to move in a sinusoidal fashion with the local blade displacement amplitude, $u_{b}$, determined from the result of Eq. 14 for the node where the exciter is located. The equation of motion of the blade at the exciter location is then (Eq. 42):

$$
x_{b}(t)=u_{b} \sin (2 \pi f t)
$$

The velocity of the blade at the exciter location is calculated by Eq. 43:

$$
\frac{d x_{b}}{d t}=\frac{d}{d t} u_{b} \sin (2 \pi f t)=u_{b} 2 \pi f \cos (2 \pi f t)
$$

For an IREX, the force on the blade is equal but opposite to the force applied to move the shaker mass (moving part of the IREX), which is the moving mass times the total acceleration (Eq. 44):

$$
F_{I R E X \text { on Blade }}(t)=-m_{\text {moving }} a_{\text {moving mass }}(t)=-m_{\text {moving }}\left(a_{I}(t)+a_{b}(t)\right)
$$

where $a_{I}(t)$ is the acceleration of the exciter mass relative to the blade. The acceleration of the node of the blade at the exciter location is shown in Eq. 45:

$$
a_{b}(t)=\frac{d^{2} x_{b}}{d t^{2}}=\frac{d^{2}}{d t^{2}} u_{b} \sin (2 \pi f t)=-u_{b}(2 \pi f)^{2} \sin (2 \pi f t)
$$

The actuator displacement relative to the blade, $x_{I}$, is assumed to be 90 degrees out of phase (optimum resonance) ahead of the blade motion, so the equation of motion for the actuator relative to the blade is calculated by Eq. 46 :

$$
x_{I}(t)=u_{I} \sin \left(2 \pi f t+\frac{\pi}{2}\right)=u_{I} \cos (2 \pi f t)
$$


where $u_{I}$ is the displacement amplitude of the IREX actuator. The acceleration of the moving mass relative to the blade is calculated by Eq. 47:

$$
a_{I}(t)=\frac{d^{2} x_{I}}{d t^{2}}=\frac{d^{2}}{d t^{2}} u_{I} \cos (2 \pi f t)=-u_{I}(2 \pi f)^{2} \cos (2 \pi f t)
$$

Thus, from Eq. 41:

$$
\begin{gathered}
\Delta E_{I R E X}=\int_{0}^{\frac{1}{f}} m_{\text {moving }}\left(a_{I}(t)+a_{b}(t)\right) \frac{d x}{d t} d t \\
=\int_{0}^{\frac{1}{f}} m_{\text {moving }}\left(u_{I}(2 \pi f)^{2} \cos (2 \pi f t)+u_{b}(2 \pi f)^{2} \sin (2 \pi f t)\right) u_{b} 2 \pi f \cos (2 \pi f t) d t \\
=m_{\text {moving }}(2 \pi f)^{3} \int_{0}^{\frac{1}{f}}\left(u_{b} u_{I} \cos ^{2}(2 \pi f t)+u_{b}{ }^{2} \sin (2 \pi f t) \cos (2 \pi f t)\right) d t
\end{gathered}
$$

and integrating results in:

$$
\begin{gathered}
\Delta E_{I R E X}=m_{\text {moving }}(2 \pi f)^{3}\left(\frac{u_{b} u_{I}}{2 \pi f}\left[\frac{1}{2} 2 \pi f t+\frac{1}{4} \sin (4 \pi f t)\right]+\frac{u_{b}^{2}}{2 \pi f}\left[\frac{1}{2} \sin ^{2}(2 \pi f t)\right]\right)_{0}^{\frac{1}{f}} \\
=m_{\text {moving }}(2 \pi f)^{2} u_{b} u_{I}\left[\frac{1}{2} 2 \pi\right] \\
\Delta E_{I R E X}=m_{\text {moving }} 4 f^{2} \pi^{3} u_{b} u_{I}
\end{gathered}
$$

Thus, for the inertial mass type exciter, the energy input per cycle is proportional to the displacement of the mass, the displacement of the blade and the frequency squared.

For a GREX, the excitation force is applied directly by the actuator and leads the blade displacement by 90 degrees. Thus:

$$
F(t)=F_{G} \sin \left(2 \pi f t+\frac{\pi}{2}\right)=F_{G} \cos (2 \pi f t)
$$


where $F_{G}$ is the amplitude of the force applied by the actuator to the blade. The energy input from a GREX per cycle period is:

$$
\begin{gathered}
\Delta E_{G R E X}=\int_{0}^{\frac{1}{f}} F(t) \frac{d x}{d t} d t=\int_{0}^{\frac{1}{f}}\left(F_{G} \cos (2 \pi f t)\right) u_{b} 2 f \cos (2 \pi f t) d t \\
=2 \pi f u_{b} F_{G} \int_{0}^{\frac{1}{f}} \cos ^{2}(2 \pi f t) d t=2 \pi f u_{b} F_{G} \frac{1}{2 \pi f}\left[\frac{1}{2} 2 \pi f t+\frac{1}{4} \sin (4 \pi f t)\right]_{0}^{\frac{1}{f}}
\end{gathered}
$$

The result of this computation for the energy input per cycle from a GREX type device is:

$$
\triangle E_{G R E X}=F_{G} u_{b} \pi
$$

Unlike an IREX-type device, the energy input per cycle does not depend on the frequency and is only dependent on the applied force amplitude and the displacement of the blade at the excitation location. This is a significant advantage when operating tests on larger blades where the lowresonance frequency results in relatively little energy input from an inertial mass device and increasing the moving mass further reduces the test frequency and therefore does not necessarily increase the total energy input. However, the energy removed from the system due to structural and aerodynamic damping is a function of the test frequency and therefore the exciter amplitude $\left(F_{G}\right)$ required to maintain the test level will be dependent on the test frequency. In addition, imperfections in the real system operation, for example, deviations from a perfectly sinusoidal input function or not running at exactly the system resonance frequency will decrease the effective energy input. For the present model, these imperfections are included in the empirically determined equivalent structural damping coefficient as previously discussed rather than attempting to evaluate them in the energy input equations.

\subsubsection{Energy balance}

To determine the exciter amplitude required to achieve the target moment distribution for a given test setup the energy input per cycle is equated to the energy output per cycle (Eq. 54):

$$
\begin{gathered}
\Delta E_{\text {added }}=\Delta E_{\text {structural }}+\Delta E_{\text {aero }} \\
=\left(1-e^{-2 \frac{2 \pi \zeta}{\sqrt{1-\zeta^{2}}}}\right) \sum_{i=1}^{N}\left(\frac{1}{2}\left(\lambda_{i} l_{i}+m_{s, i}\right)\left(u_{i} 2 \pi f\right)^{2}+\frac{1}{2}\left(\frac{m_{i} l_{i}^{2}}{12}+I_{s, i}\right)\left(\alpha_{i} 2 \pi f\right)^{2}\right) \\
+\sum_{i=1}^{N} \frac{4}{3} \rho h_{i} l_{i} C_{D i} u_{i}{ }^{3}(2 \pi f)^{2}
\end{gathered}
$$


For a single IREX type device from Eq. 50 we can solve for the required displacement amplitude to obtain equilibrium and maintaine the test amplitude (Eq. 55):

$$
\begin{aligned}
u_{I}=\frac{\Delta E_{I R E X}}{m_{\text {moving }} 4 f^{2} \pi^{3} u_{b}} & \frac{1}{m_{\text {moving }} 4 f^{2} \pi^{3} u_{b}}\left[\left(1-e^{\left.-2 \frac{2 \pi \zeta}{\sqrt{1-\zeta^{2}}}\right)} \sum_{i=1}^{N}\left(\frac{1}{2}\left(\lambda_{i} l_{i}+m_{s, i}\right)\left(u_{i} 2 \pi f\right)^{2}\right.\right.\right. \\
& \left.\left.+\frac{1}{2}\left(\frac{m_{i} l_{i}^{2}}{12}+I_{s, i}\right)\left(\alpha_{i} 2 \pi f\right)^{2}\right)+\sum_{i=1}^{N} \frac{4}{3} \rho h_{i} l_{i} C_{D i} u_{i}^{3}(2 \pi f)^{2}\right] \\
& =\frac{1}{m_{\text {moving }} \pi u_{b}}\left[\left(1-e^{\left.-2 \frac{2 \pi \zeta}{\sqrt{1-\zeta^{2}}}\right)} \sum_{i=1}^{N}\left(\frac{1}{2}\left(\lambda_{i} l_{i}+m_{s, i}\right)\left(u_{i}\right)^{2}\right.\right.\right. \\
& \left.\left.+\frac{1}{2}\left(\frac{m_{i} l_{i}^{2}}{12}+I_{s, i}\right)\left(\alpha_{i}\right)^{2}\right)+\sum_{i=1}^{N} \frac{4}{3} \rho h_{i} l_{i} C_{D i} u_{i}^{3}\right]
\end{aligned}
$$

Thus the displacement amplitude required is a function of the blade mode shape and amplitude, and an inverse function of the moving mass and blade amplitude at the exciter location.

Likewise for a single GREX type device from Eq. 53 we can solve for the required force amplitude to obtain equilibrium and maintain the test amplitude (Eq. 56):

$$
\begin{aligned}
F_{G}=\frac{\Delta E_{G R E X}}{u_{b} \pi} & =\frac{1}{u_{b} \pi}\left[( 1 - e ^ { - 2 \frac { 2 \pi \zeta } { \sqrt { 1 - \zeta ^ { 2 } } } } ) \sum _ { i = 1 } ^ { N } \left(\frac{1}{2}\left(\lambda_{i} l_{i}+m_{s, i}\right)\left(u_{i} 2 \pi f\right)^{2}\right.\right. \\
& \left.\left.+\frac{1}{2}\left(\frac{m_{i} l_{i}^{2}}{12}+I_{s, i}\right)\left(\alpha_{i} 2 \pi f\right)^{2}\right)+\sum_{i=1}^{N} \frac{4}{3} \rho h_{i} l_{i} C_{D i} u_{i}^{3}(2 \pi f)^{2}\right]
\end{aligned}
$$

Thus the force amplitude required is a function of the overall blade mode shape and amplitude, and an inverse function of and blade amplitude at the exciter location. In addition, the applied GREX force required is a function of the frequency squared. 


\subsection{Gravitational Loading and Deformed Shape}

To determine the neutral position of the blade in the laboratory under gravity and the total moments and displacements including gravity, a separate finite element calculation is performed. Calculations are again performed using a two degree-of-freedom finite beam element model in Excel. However, rather than using stiffness and mass matrix calculations, the model implementation is iterative, computing the loads for a given position, then computing the displacements for those loads before recalculating the loads based on the new displacements.

The same elements and nodes in the span direction along the $z_{b}$ axis are used from the dynamic analysis. The gravitational constant, $g$, is taken to be $9.80665 \mathrm{~m} / \mathrm{s}^{2}$. Several other assumptions are made to simplify the analysis. In particular, the blade elements are taken to be axially rigid; thus, the length of each element and the total length of the blade do not change. Also, it is assumed that the original shape of the blade is a smooth curve and that a sufficient number of elements are used so that the change in angle from one element to the next is small.

The first step in the calculations is to transform the undeformed blade coordinates of each node to global coordinates. Until now, calculations have been performed in rotor coordinates as defined by the IEC 61400-23 standard (IEC_61400-23 2014). To include gravitational effects, we will first transform the problem to global coordinates that reference the laboratory mounting scenario such that gravity acts in the negative $z_{g}$ direction. An example is shown in Figure 27. To avoid confusion, the subscript $\mathrm{g}$ will be used for the position vector in the global coordinate system $\left\{x_{g}, y_{g}, z_{g}\right\}$. The transformation to global coordinates takes into account the pitch angle of the blade and the angle of the test stand as well as the offset of the root of the blade from the test stand due to the adapter plate, spacers, and so on.

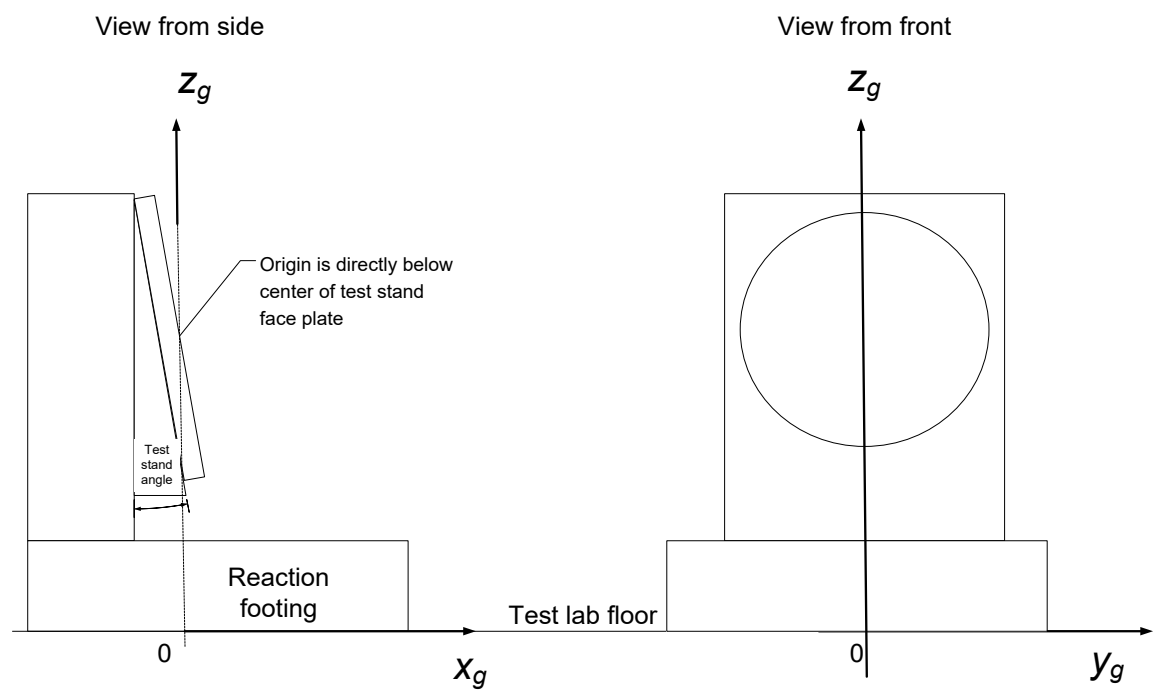

Figure 27. Example global coordinate system description referencing the test rig 
Each element $i$ of the blade is taken to be a uniform beam of length $l_{i}$ with mass $m_{b, i}=\lambda_{i} l_{i}$ and stiffness $E I_{i}$ in the vertical gravitationally loaded direction. The stiffness of the element is taken as the average of the stiffness at node $i-l$ and node $i$. The undeformed element length is calculated by Eq. 57 as:

$$
l_{i}=\sqrt{\left(x_{g, i}-x_{g, i-1}\right)^{2}+\left(y_{g, i}-y_{g, i-1}\right)^{2}+\left(z_{g, i}-z_{g, i-1}\right)^{2}}
$$

Thus, each element is taken to be a straight line segment connecting the node positions determined by the prebend and sweep geometry of the blade. Blade deformation due to gravity is assumed to be entirely in the vertical plane. This simplification means that torsion effects due to pre-bend, sweep, and flap/lead-lag coupling are not included in the analysis. However, any existing displacement of the blade in the $y_{g}$ direction will be maintained throughout the analysis and reflected in predicted position of the test article in the laboratory. The following analysis is performed in the two dimensional $x_{g}-z_{g}$ plane. The original (in zero gravity) angle of the blade at each node is estimated based on the location of the previous node.

$$
\alpha_{i, \text { original }}=\operatorname{atan}\left(\frac{z_{g, i}-z_{g, i-1}}{x_{g, i}-x_{g, i-1}}\right)_{\text {original }}
$$

The deflection at each node is calculated using cantilever beam tables superimposing the results from the internal moment and perpendicular shear force at that node. The local deflection, $d_{i}$, of each element in the direction perpendicular to that element is small, and therefore linear Euler beam theory applies to the element. This is shown graphically in Figure 28.

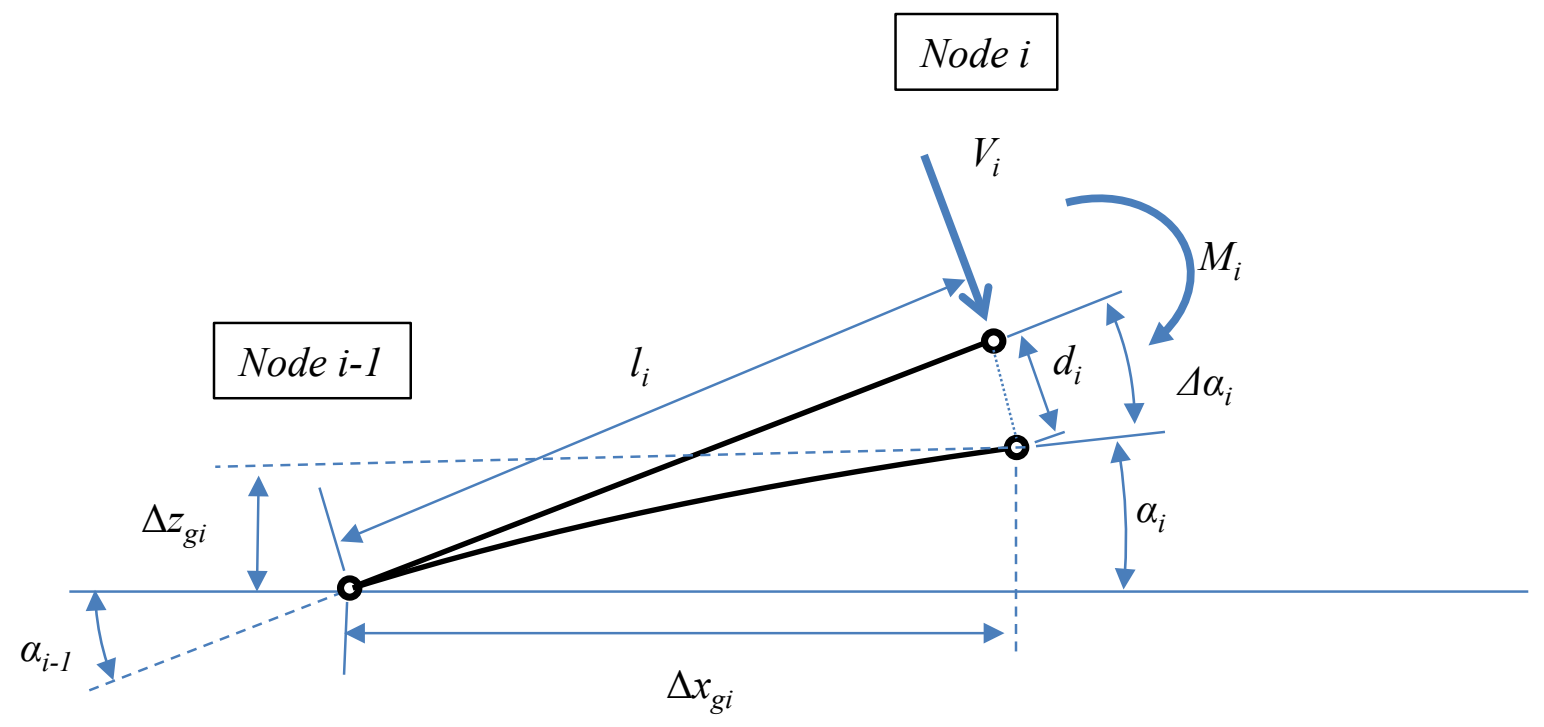

Figure 28. Deformation of element $i$ under shear and bending 
The change in the angle of node $i$ is given by Eq. 59:

$$
\Delta \alpha_{i}=-\frac{M_{i} l_{i}}{(E I)_{i}}-\frac{V_{i} l_{i}^{2}}{2(E I)_{i}}
$$

and is negative because positive rotation about $y_{g}$ is upwards in the global coordinate system while the reaction moments and forces are taken to be positive as shown. The Euler beam deflection is given by Eq. 60 :

$$
d_{i}=\frac{M_{i} l_{i}^{2}}{2(E I)_{i}}+\frac{P_{i} l_{i}^{3}}{3(E I)_{i}}
$$

The angle at each node is given by the angle of the undeformed blade at that node plus the sum of the change in angles at each node up until that point starting at the root of the blade (Eq. 61):

$$
\alpha_{i, \text { deformed }}=\alpha_{i, \text { original }}+\sum_{j=0}^{i} \Delta \alpha_{j}
$$

Making the assumption that the blade does not stretch axially and thus the length of each element remains constant, the new global position of node $i$ is calculated in Eq. 62 and 63 in terms of the position and angle of the previous node $i-1$ and the deformation $d_{i}$ calculated in Eq. 60 with reference to Figure 29.

$$
\begin{aligned}
& \Delta x_{g, i}=x_{g, i}-x_{g, i-1}=l_{i} \cos \left(\alpha_{i-1}\right)-d_{i} \sin \left(\alpha_{i-1}-\arcsin \left(\frac{\frac{d_{i}}{2}}{l_{i}}\right)\right) \\
& \Delta z_{g, i}=z_{g, i}-z_{g, i-1}=l_{i} \sin \left(\alpha_{i-1}\right)-d_{i} \cos \left(\alpha_{i-1}-\arcsin \left(\frac{\frac{d_{i}}{2}}{l_{i}}\right)\right)
\end{aligned}
$$

The deformed blade position is calculated iteratively along the blade from node 0 to node 200 (in the positive span direction). 


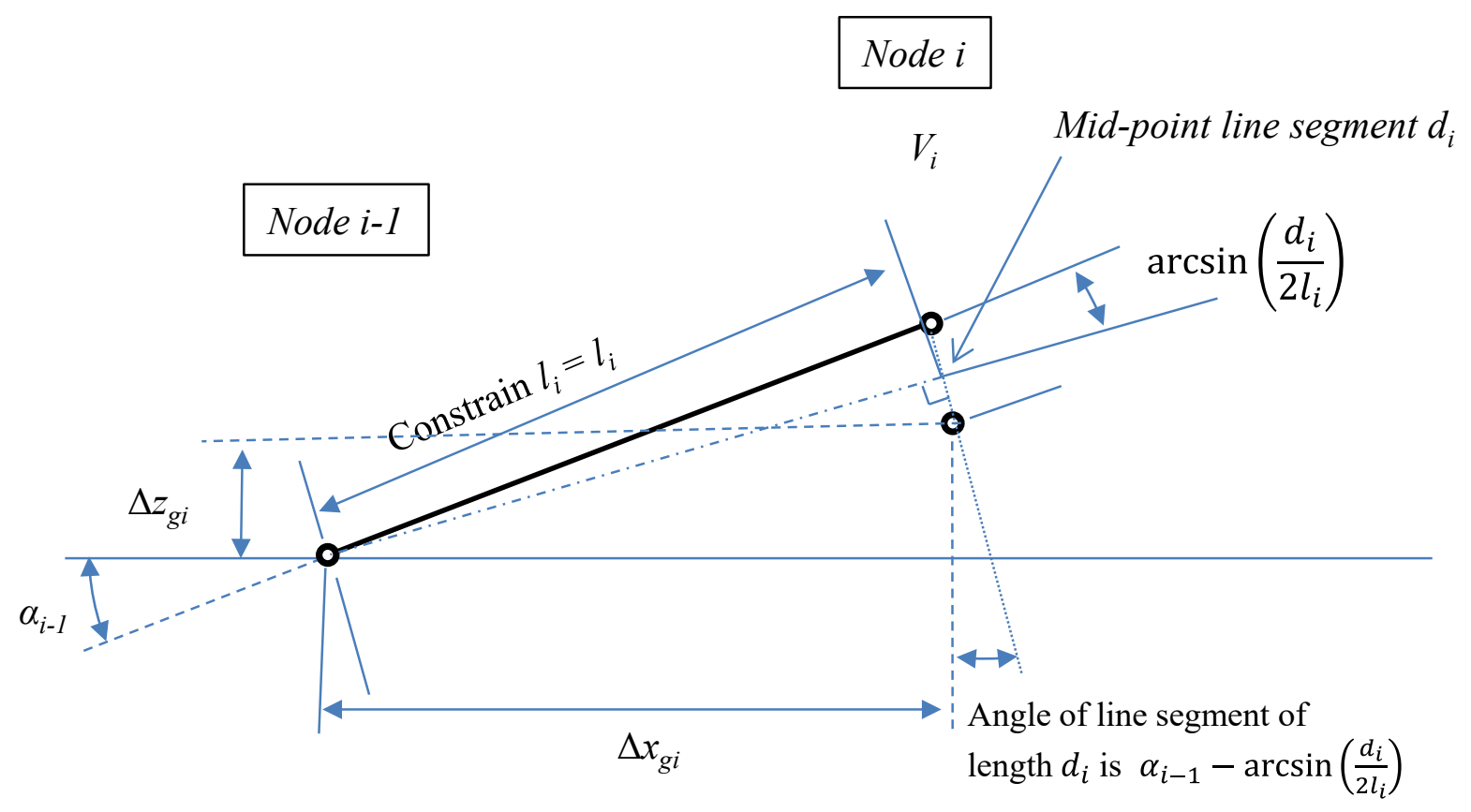

Figure 29. Geometry definition for calculation of updated position $X_{g}$ and $Z_{g}$

The bending moment $M$ and shear force $V$ are functions of the deformed position. The free-body diagram for an element is shown in Figure 30. As we are only interested in the blade under gravity, the applied force $\mathrm{F}$ is zero. $m_{b, i+l}$ is the mass of the blade element. $m_{s, i+l}$ is the saddle mass applied at a particular node $i+1$ and is zero for most nodes except where a saddle is located. Likewise, the applied force is zero except at nodes located where a saddle is present. The applied force at a saddle, $\mathrm{F}_{i+1}$, can in general be at an arbitrary angle $\beta_{\mathrm{i}+1}$ relative to vertical. However, for prediction calculations, $\mathrm{F}$ is taken to be perpendicular to the local blade so $\beta_{\mathrm{i}+1}=\alpha_{\mathrm{i}+1}$. In the case of the blade under gravity alone, $F=0$. 


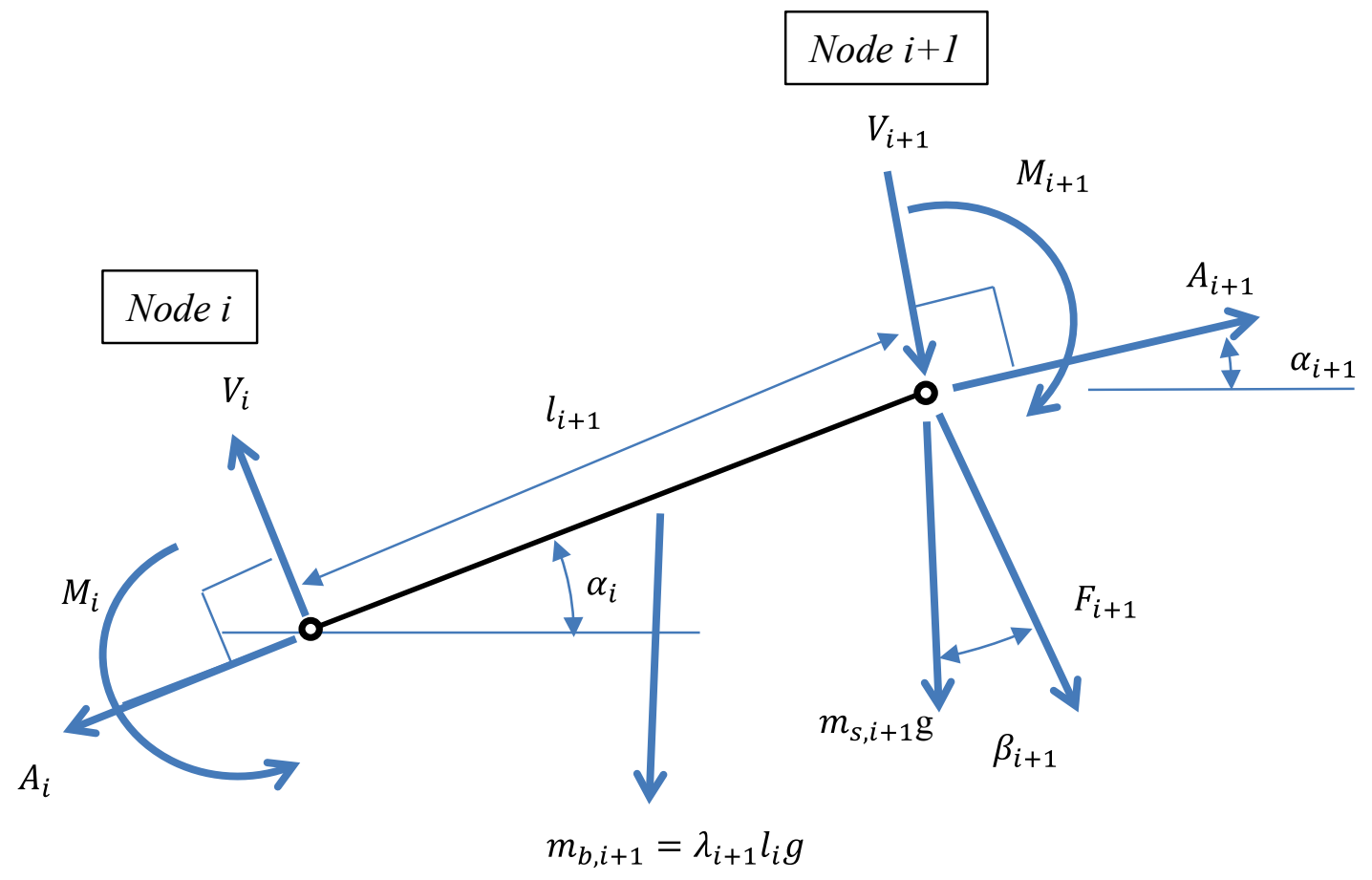

Figure 30. Free-body diagram of an element in deformed position

There is zero force at the tip of the blade, so calculations are performed working from the tip back toward the root. In each case, the forces and moments at the $i+1$ node are known, and the forces and moments at the $i^{\text {th }}$ node can be calculated. The final equations are:

$$
\begin{gathered}
A_{i}=A_{i+1} \cos \left(\alpha_{i}-\alpha_{i+1}\right)-\frac{g}{1000}\left(m_{b, i+1}+m_{s, i+1}\right) \sin \left(\alpha_{i}\right)-V_{i+1} \sin \left(\alpha_{i}-\alpha_{i+1}\right) \\
-F_{i+1} \sin \left(\alpha_{i}-\beta_{i+1}\right) \\
V_{i}=V_{i+1} \cos \left(\alpha_{i}-\alpha_{i+1}\right)+\frac{g}{1000}\left(m_{b, i+1}+m_{s, i+1}\right) \cos \left(\alpha_{i}\right)+A_{i+1} \sin \left(\alpha_{i}-\alpha_{i+1}\right) \\
+F_{i+1} \cos \left(\alpha_{i}-\beta_{i+1}\right) \\
M_{i}=M_{i+1}+\frac{g l_{i+1}}{1000}\left(\frac{m_{b, i+1}}{2}+m_{s, i+1}\right) \cos \left(\alpha_{i}\right)+V_{i+1} l_{i+1} \cos \left(\alpha_{i}-\alpha_{i+1}\right) \\
+A_{i+1} l_{i+1} \sin \left(\alpha_{i}-\alpha_{i+1}\right)+F_{i+1} l_{i+1} \cos \left(\alpha_{i}-\beta_{i+1}\right)
\end{gathered}
$$

Because the deformation depends on the moments and forces and the moments and forces depend on the deformation, the solution is iterative, first calculating deflection under a given load case, then calculating the moments and forces based on that deflection and repeating using the new moments and forces to calculate new deflections. For the case of dead weight loading 
only, the initial configuration is taken to be the undeformed blade. Three iterations were found to converge to at least four significant digits for the tip deflection and the root bending moment.

Once the mean moment and shear loading in the flap direction are determined, the maximum and minimum moments and shear during fatigue are calculated by superimposing the results of the dynamic and static analyses.

\subsection{Model Implementation}

The Excel implementation of the above analysis involves first defining the node locations along the blade span $\left(z_{b}\right)$ and then interpolating the blade properties at each node. The element properties are taken as the average of the properties at the nodes starting and ending each element. The nodes are selected to be evenly distributed along the blade span dimension with the exception of the nodes located closest to each saddle. To increase the accuracy for the relatively large point masses at saddle locations, the finite elements at the node closest to each saddle location is placed exactly at that saddle span location with corresponding longer and shorter elements on either side of it. Dynamic analysis ignores the prebend or sweep of the blade as well as any influence of the blade deformed shape under gravity. This two-DOF model is also unable to consider any torsion or out-of-plane coupling due to prebend and sweep. However, this geometry information and gravitational loading is taken into account later when the deformed position of the blade is calculated.

The analysis is performed twice, once in the flap direction and once in the lead-lag direction. For a biaxial fatigue test, it is assumed that these may be superimposed on each other without influencing one another. It is known that there will be some cross energy transfer as well as bend twist coupling due to the geometry of the blade between the two loading directions; however, for simplicity of the model and because torsional properties are rarely provided by blade manufacturers, this is neglected. The model should still be capable of providing reasonable estimates of the load distribution and energy input required in each direction sufficient to evaluate various test design scenarios.

Real saddle mass and virtual mass are added together at each node corresponding to a saddle location. Virtual mass is mass that only acts in one direction without influencing the other direction and could be physically implemented by locating mass off the blade on a slider table. Alternatively, positive or negative virtual mass can be used to simulate the influence of a GREX type actuator run slightly off resonance to introduce a force that is in phase or 180 degrees out of phase relative to the displacement of the blade. Virtual mass is included in the dynamic model of the blade for the corresponding loading direction but is not included when evaluating the deformation of the blade under gravity.

Experimentation has shown reasonable convergence with 100-150 nodes for typical blades. A total of 201 nodes are used in the analyses presented in this paper as this provides reasonable assurance of sufficient convergence while maintaining a numerically efficient model. 


\section{Traditional Single-Axis Test Design}

To contrast the loading that can be achieved with a biaxial fatigue test with traditional separate flap and lead-lag fatigue tests, optimized test designs are considered for each of these load cases. The obvious advantage to separating the two tests is that they can each be optimized to achieve the best target moment distribution for that loading direction. The number and location of saddle locations are often constrained by the blade manufacturer or certifier to avoid constraining specific critical sections of the test article. Also, to avoid putting excessive shear loads into a single saddle, masses will sometimes be distributed over two or more saddle locations that are placed close together, often within a meter or two of each other. In the case of these fictional tests, no such constraints are given. However, an effort is made to keep the test design and total mass on each saddle within the range of options typically selected for a certification test. The amount of allowable load overshoot along the span relative to the target is also a critical parameter. In general, more added mass is required to more accurately achieve the target moment distribution. This slows the test down by reducing the natural frequency, changes the R-ratio, and can impose very large mean flap loads on the blade that may not be called for by the manufacturer. Therefore, a compromise is typically selected that does not overload the blade more than a specified amount. Depending on the manufacturer, something in the range of a 10\% to $20 \%$ overload is typically accepted at some point along the span. Typically at least the first $70 \%$ of the blade span from the root toward the tip must be subjected to a moment range equal or greater than the target. Some manufacturers prefer to see as much as $90 \%$ of the blade span loaded to target.

\subsection{Flap Fatigue Test}

The bare blade oscillated in the flap direction results in the moment distribution shown in Figure 31. Significant damping mass will be required in the middle of the blade to achieve the target root moment without excessively overloading the middle and outer portions of the blade. 


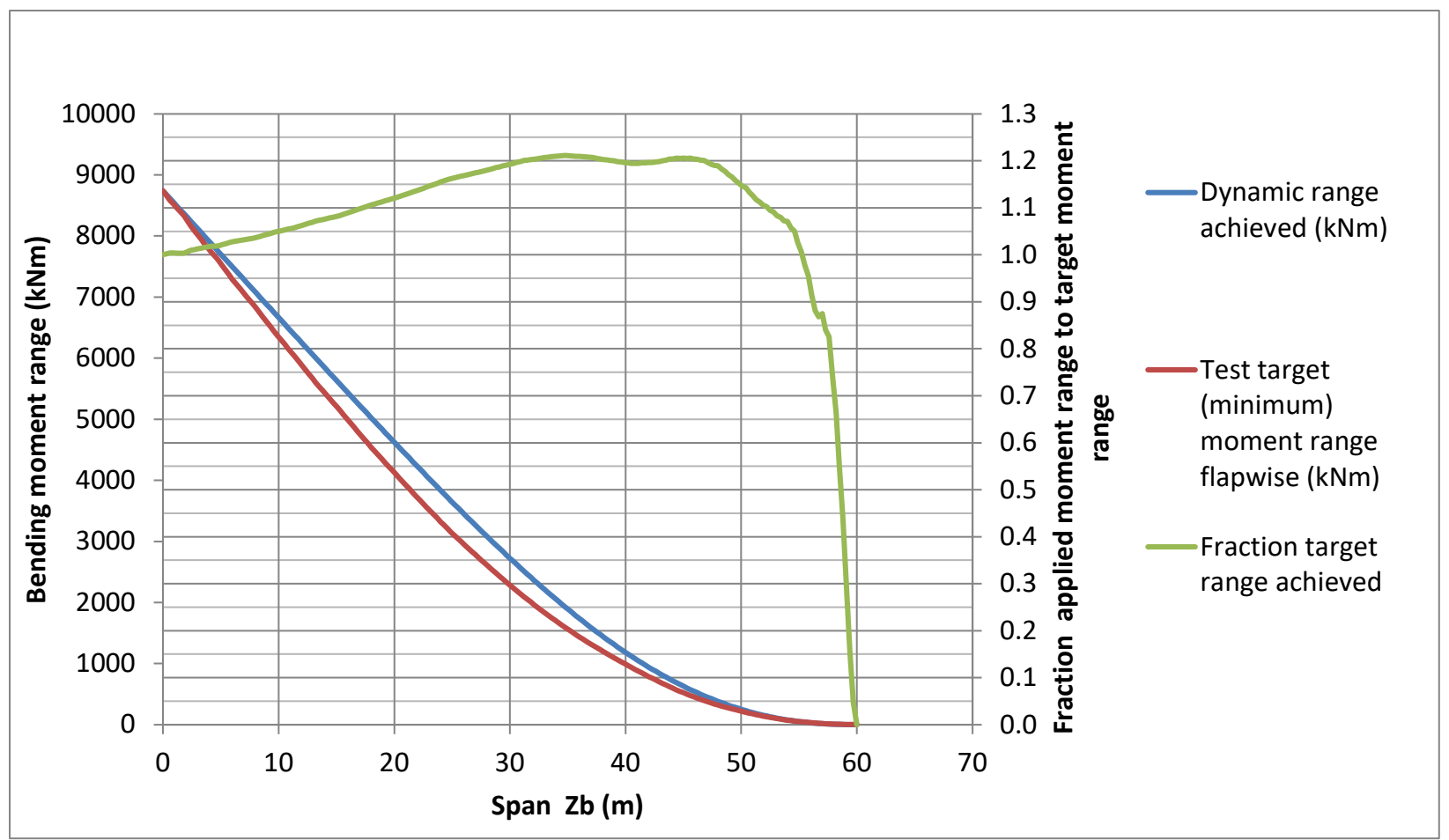

Figure 31. Bare blade moment distribution at resonance in flap direction. Natural frequency is $0.56 \mathrm{~Hz}$.

To increase the moment at the root relative to the outer portion of the blade, significant damping masses are required. Masses are added to achieve approximately the target flap moment over most of the blade span. The results are summarized in Table 7 . The test frequency is calculated to be $0.53 \mathrm{~Hz}$, and a GREX input force amplitude at $30.0 \mathrm{~m}$ span of $25.9 \mathrm{kN}$ is required to overcome the estimated $58.8 \mathrm{~kJ}$ of energy absorbed due to damping and aerodynamic drag each cycle. This GREX location is selected to minimize the force input required while staying within the stroke and velocity limits for the GREX.

Table 7. Proposed Uniaxial Flap Fatigue Test Configuration and Dynamics at Each Saddle

\begin{tabular}{|c|c|c|c|c|c|c|c|c|c|}
\hline $\begin{array}{l}\text { Saddle } \\
\text { location } \\
\text { (m) }\end{array}$ & $\begin{array}{l}\text { Saddle } \\
\text { mass } \\
(\mathbf{k g})\end{array}$ & $\begin{array}{l}\text { Fixed } \\
\text { added } \\
\text { mass } \\
(\mathbf{k g})\end{array}$ & $\begin{array}{l}\text { GREX } \\
\text { added } \\
\text { mass } \\
(\mathrm{kg})\end{array}$ & $\begin{array}{l}\text { GREX } \\
\text { force } \\
\text { amplitude } \\
\text { (kN) }\end{array}$ & $\begin{array}{l}\text { Total } \\
\text { flap } \\
\text { mass } \\
(\mathrm{kg}) \\
\end{array}$ & $\begin{array}{l}\text { Dynamic } \\
\text { Saddle } \\
\text { amplitude } \\
(\mathrm{m})\end{array}$ & $\begin{array}{l}\text { Max Flap } \\
\text { Acceleration } \\
\text { (g) }\end{array}$ & $\begin{array}{l}\text { Max } \\
\text { Flap } \\
\text { Velocity } \\
(\mathrm{m} / \mathrm{s}) \\
\end{array}$ & $\begin{array}{l}\text { Max } \\
\text { Flap } \\
\text { Saddle } \\
\text { force } \\
\text { (kN) } \\
\end{array}$ \\
\hline 18.0 & 1,000 & 1,000 & & & 2,000 & 0.17 & 0.19 & 0.56 & 1.11 \\
\hline 24.0 & 800 & 1,000 & & & 1,800 & 0.37 & 0.42 & 1.25 & 2.24 \\
\hline 30.0 & 600 & 1,000 & 200 & 25.9 & 1,800 & 0.72 & 0.82 & 2.41 & 4.34 \\
\hline 58.0 & & 20 & & & 20 & 5.53 & 6.27 & 18.44 & 0.37 \\
\hline 60.0 & & & & & & 6.09 & 6.91 & 20.31 & 0.00 \\
\hline
\end{tabular}


The saddle masses are approximately representative of typical saddles employed at the WTTC. The achieved flap fatigue moment distribution is plotted in Figure 32. To ensure that the blade is not overloaded, the maximum and minimum fatigue moment distributions are compared to the maximum flap and minimum flap static test target moment distributions in Figure 33, and the resulting R-ratio is plotted in Figure 34. As a target mean load is not typically provided by a test customer, no effort was made to achieve a specific mean load beyond keeping the total dead mass on the blade reasonable - in this case, $5,620 \mathrm{~kg}$ of mass will be added to the blade.

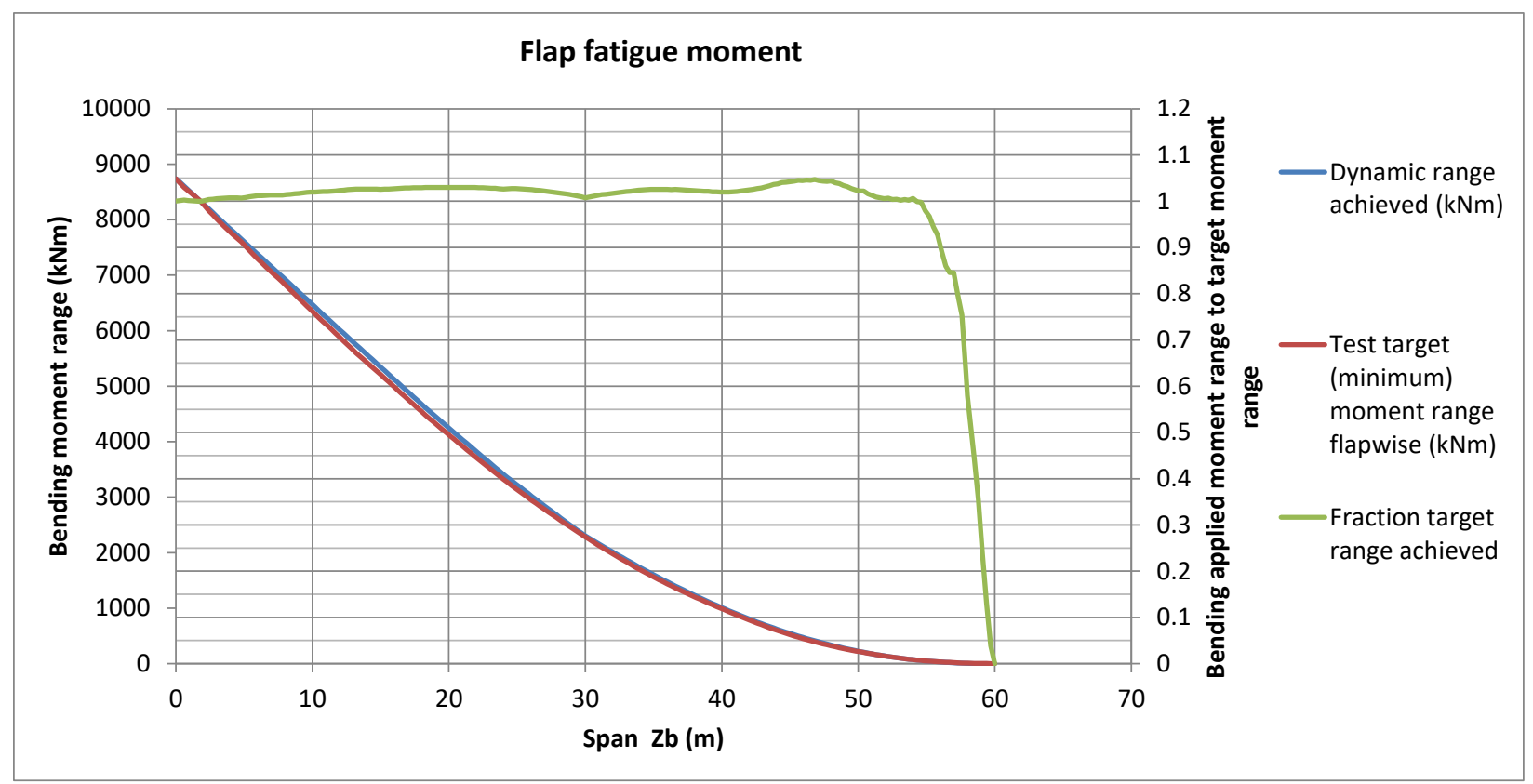

Figure 32. Flap fatigue test moment range achieved relative to target moment

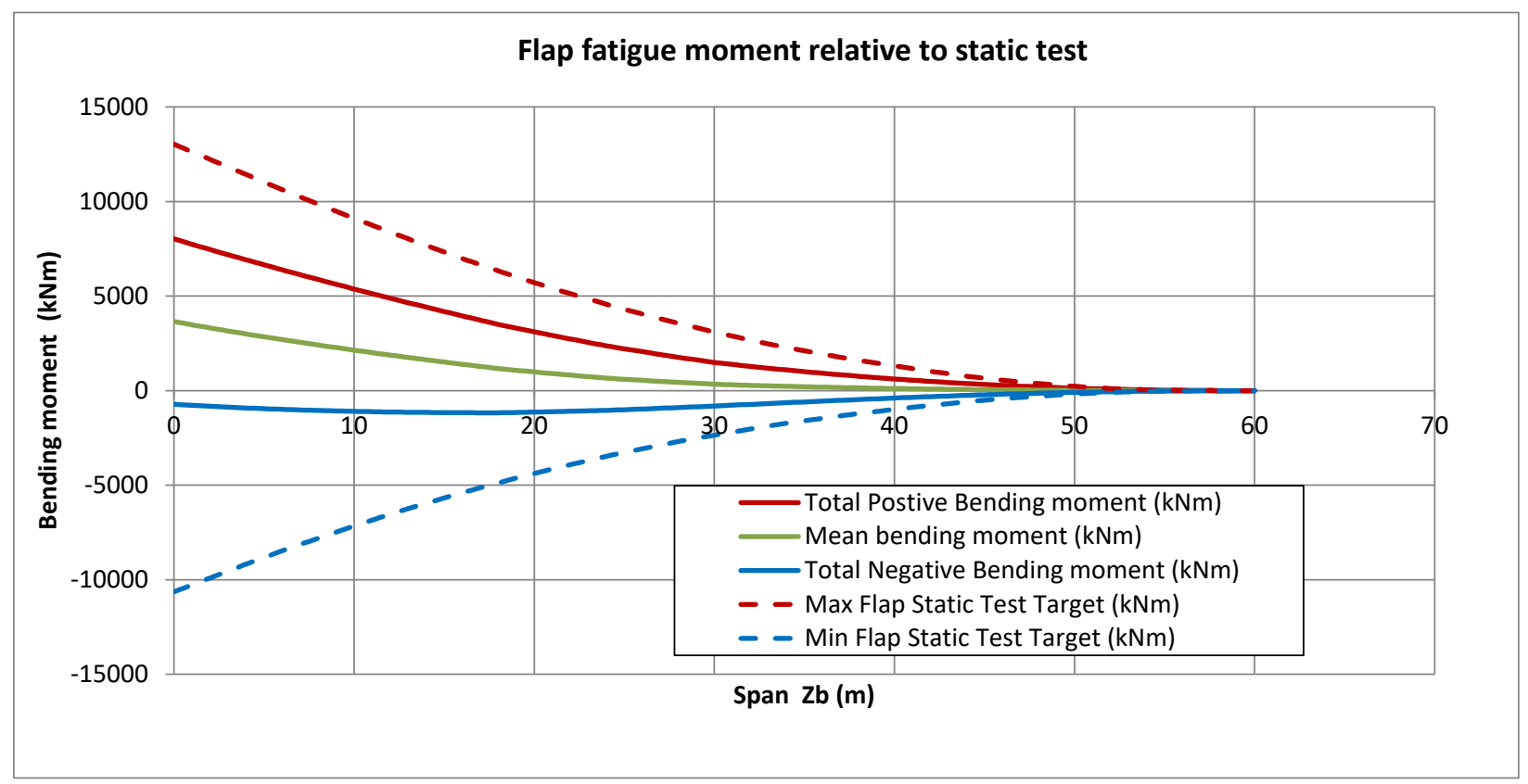

Figure 33. Bending moment extrema during flap fatigue test compared to static test target loads 


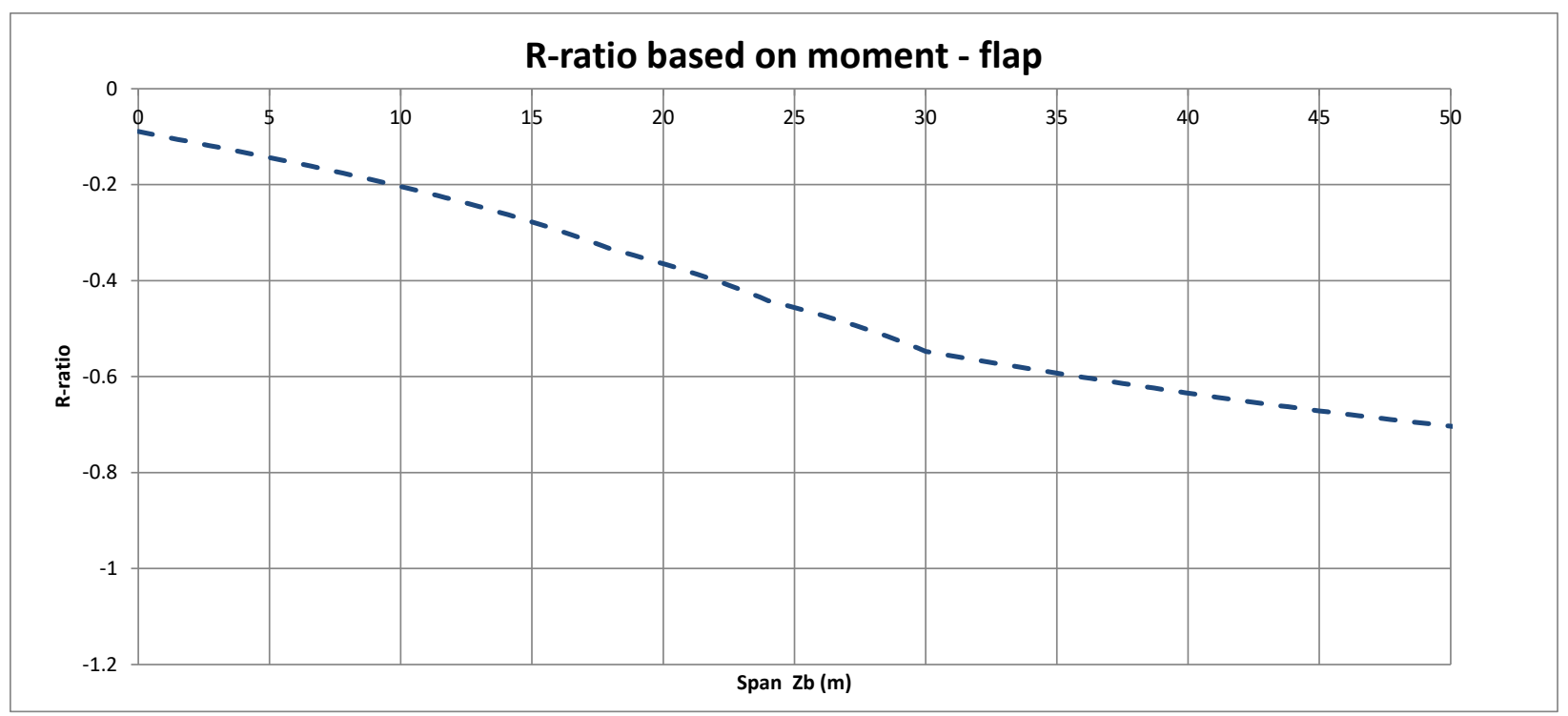

Figure 34. R-ratio (minimum moment/maximum moment) distribution for proposed flap fatigue test

\subsection{Lead-Lag Fatigue Test}

The bare blade oscillated in the lead-lag direction achieves the moment distribution shown in Figure 35. Significant damping mass will be required in the middle of the blade to achieve the target root moment without excessively overloading the middle and outer portions of the blade.

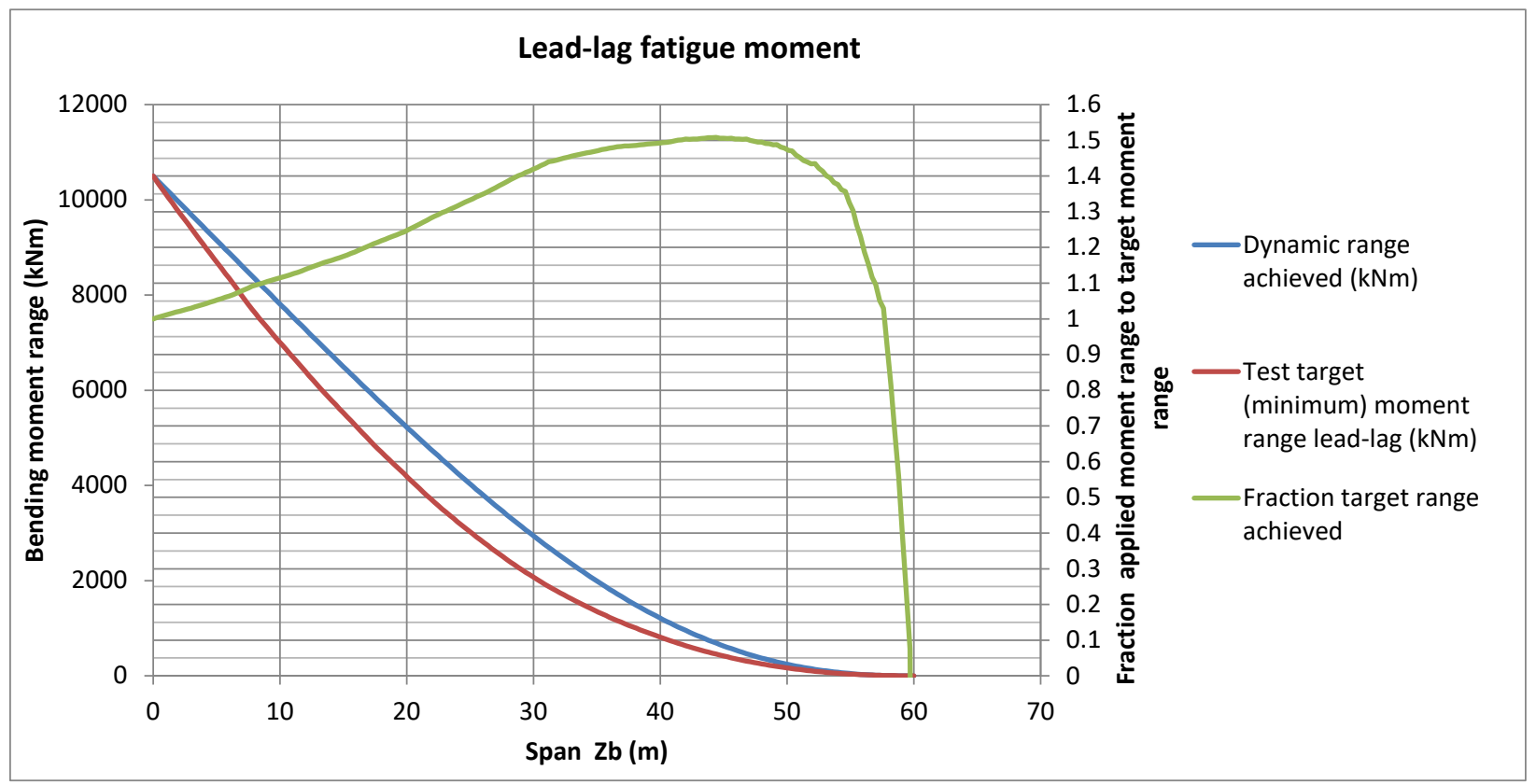

Figure 35. Bare blade moment distribution at resonance in lead-lag direction. Natural frequency is $1.01 \mathrm{~Hz}$. 
Masses are added to achieve approximately the target flap moment over most of the blade span. The results are summarized in Table 8. The test frequency is calculated to be $0.90 \mathrm{~Hz}$. With the IREX placed at $28.0 \mathrm{~m}$ span, an input displacement amplitude of $120 \mathrm{~mm}$ is required to overcome the estimated $3.62 \mathrm{~kJ}$ of energy loss due to damping and aerodynamic drag each cycle.

Table 8. Proposed Uniaxial Lead-Lag Fatigue Test Configuration and Dynamics at Each Saddle

\begin{tabular}{|c|c|c|c|c|c|c|c|c|c|}
\hline $\begin{array}{l}\text { Saddle } \\
\text { location } \\
\text { (m) }\end{array}$ & $\begin{array}{l}\text { Saddle } \\
\text { mass } \\
(\mathrm{kg})\end{array}$ & $\begin{array}{l}\text { Fixed } \\
\text { added } \\
\text { mass } \\
(\mathrm{kg})\end{array}$ & $\begin{array}{l}\text { IREX } \\
\text { nonmoving } \\
\text { mass } \\
(\mathbf{k g})\end{array}$ & $\begin{array}{l}\text { IREX } \\
\text { exciter } \\
\text { moving } \\
\text { mass } \\
\text { (kg) }\end{array}$ & $\begin{array}{l}\text { IREX } \\
\text { displace- } \\
\text { ment } \\
\text { amplitude } \\
(\mathrm{mm})\end{array}$ & $\begin{array}{l}\text { Total } \\
\text { lead-lag } \\
\text { mass } \\
(\mathrm{kg})\end{array}$ & $\begin{array}{l}\text { Dynamic } \\
\text { saddle } \\
\text { amplitude } \\
\text { (m) }\end{array}$ & $\begin{array}{l}\text { Accel- } \\
\text { eration } \\
\text { in } \mathrm{g} \\
\text { (g) }\end{array}$ & $\begin{array}{l}\text { Lead-lag } \\
\text { saddle } \\
\text { force } \\
\text { amplitude } \\
\text { (kN) }\end{array}$ \\
\hline 20.0 & 1,000 & 1,500 & & & & 2,500 & 0.15 & 0.48 & 11.88 \\
\hline 24.0 & 800 & 500 & & & & 1,300 & 0.22 & 0.71 & 9.02 \\
\hline 28.0 & 600 & & 400 & 1,000 & 120 & 2,000 & 0.30 & 0.98 & 19.22 \\
\hline 36.0 & 400 & 400 & & & & 800 & 0.51 & 1.69 & 13.25 \\
\hline 58.0 & 20 & & & & & 20 & 1.50 & 4.92 & 0.97 \\
\hline
\end{tabular}

The achieved lead-lag fatigue moment distribution is plotted in Figure 36. To ensure that the blade is not overloaded, the maximum and minimum fatigue moment distributions are compared to the maximum flap and minimum flap static test target moment distributions in Figure 37 . The R-ratio is -1 because the test is run horizontally. This closely resembles the loading the blade will see in the lead-lag direction when spinning on the turbine. In this case, $6,620 \mathrm{~kg}$ of mass will be added to the blade to keep within $10 \%$ overshoot of the target moment distribution.

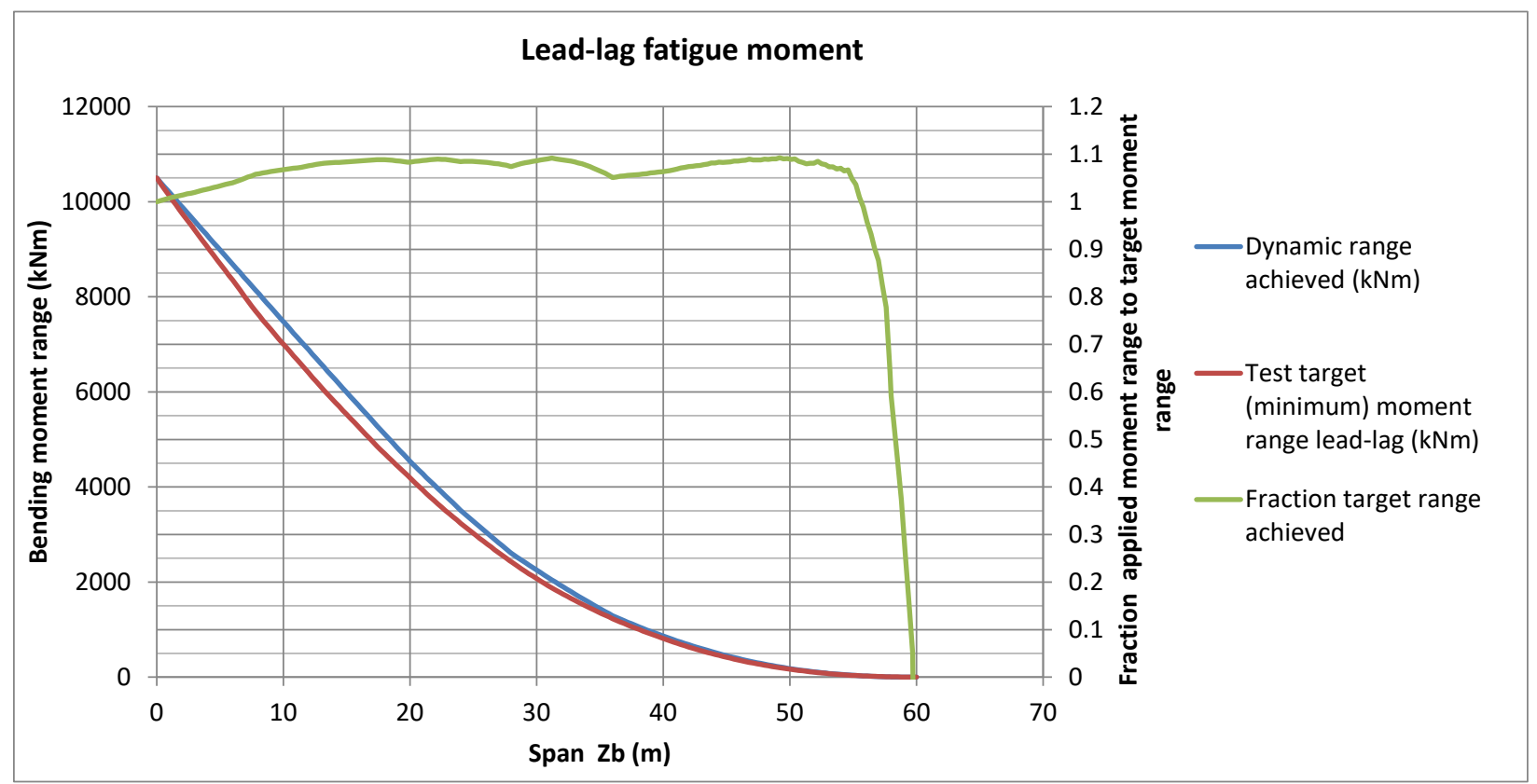

Figure 36. Lead-lag fatigue test moment range achieved relative to target moment 


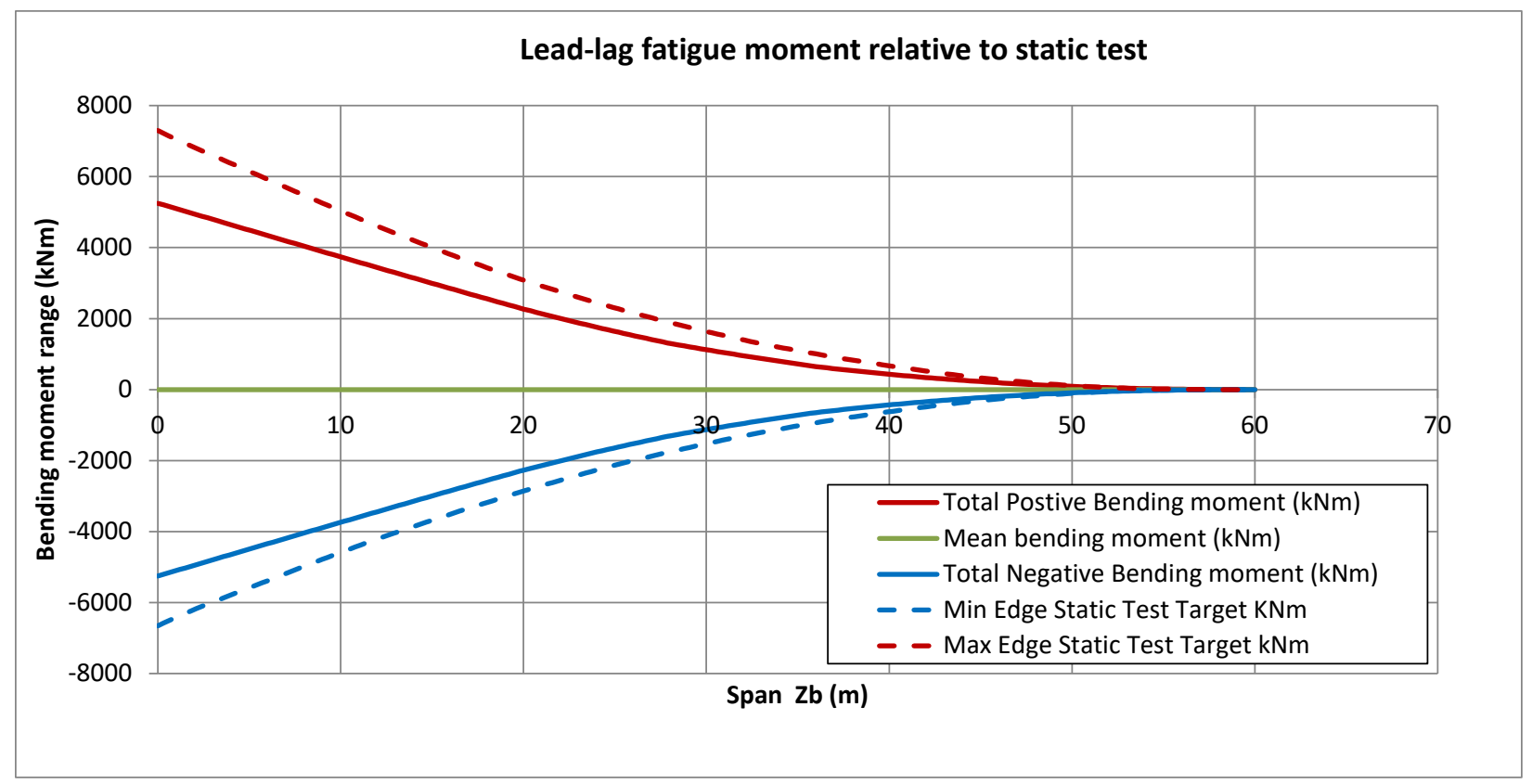

Figure 37. Lead-lag fatigue moment relative to maximum and minimum edge static test target moment 


\section{Biaxial Fatigue Test Design}

When considering a biaxial fatigue test design, both the flap and lead-lag moment distributions must be optimized together. Added mass at a given location will impact the mode shape in both the flap and lead-lag directions simultaneously. Virtual mass is an additional tool that can be used to influence one test direction without significantly impacting the other. This can be accomplished in a real test setup either with mass located off the blade or using a hydraulic actuator to apply a force in phase with the displacement. In the simulation, virtual mass is implemented by including those masses only in the mass matrix for one test direction and not in the other for the mode shape analysis. Virtual masses are not included in the static mean load calculations.

The other consideration is the relationship between the two test frequencies. If each direction is allowed to run at its own resonance frequency, then the phase angle between the flap and leadlag moments will change continuously. This result is sometimes referred to as a quantum biaxial fatigue test. An example of this type of test implemented on a 50-m turbine blade is described by Snowberg et al. (2014). Although relatively easy to configure, a quantum biaxial test has several drawbacks, including unavoidable variation in the energy transfer between the test directions resulting in a variable amplitude loading. The variable amplitude loads will be most obvious in the lead-lag direction due to the relatively low damping and thus greater sensitivity to changes in energy input. If there are fixed limits on the maximum load that can be applied the result under variable amplitude loading is that more cycles will be required to achieve the target damage equivalent load. The other drawback of a quantum biaxial resonance test is that at some points the blade will be loaded at the maximum flap and lead-lag loads simultaneously. This loading condition may significantly overload some of the panels and other components of the blade and could result in premature failure during the test due to load combinations that are not representative of those experienced on the turbine.

Using real and virtual mass it may be possible to achieve a simple ratio between the flap and lead-lag frequencies. When this is achieved, a fixed phase angle between the lead-lag and flap moments can be selected for operation of the test. This could enable more accurate loading of the blade where the phase angle is matched to experimental turbine data and should also result in the ability to maintain constant amplitude in both test directions. The resulting motion will follow a repeating Lissajous figure. The two frequency ratios of interest are $1: 1$, which results in an elliptical blade motion with an equal number of flap and lead-lag cycles and can in theory be adjusted to achieve the desired phase angle, and 1:2, which results in a figure eight pattern with twice as many lead-lag cycles as flap cycles. An additional challenge is to avoid exciting higher modes so care must be taken to ensure that the higher-order frequencies are not equal to a harmonic of the first flap and lead-lag mode frequencies.

\subsection{Quantum Test (Random Phase)}

For a quantum biaxial fatigue test, the goal is to optimize both the flap and lead-lag moments simultaneously. The goal is to achieve or exceed the target moment range over at least the first $70 \%$ of the span from the root toward the tip and ideally up to $90 \%$ of the blade should be loaded to the target level. From the uniaxial cases above, we can observe that significantly more added masses were required for the lead-lag fatigue test than the flap fatigue test to increase the root moment to the required level relative to the middle of the blade. For a quantum test, excluding 
the use of virtual mass, it is apparent that either the outer portion of the blade will be underloaded in the flap direction or overloaded in lead-lag. The compromise presented below achieves or nearly achieves the flap target moment over the entire tested span while overloading the blade in the lead-lag direction by $10 \%$ out to $35 \mathrm{~m}$ and up to $20 \%$ beyond that. While these overloads will significantly increase the damage equivalent load achieved on the outer portion of the blade, they are not uncommon for lead-lag fatigue tests where it can be particularly challenging to achieve the root target moment without exceeding the target on much of the blade. For this example, the lead-lag frequency is $0.89 \mathrm{~Hz}$ and the flap frequency is $0.51 \mathrm{~Hz}$. The mass distribution proposed is summarized in Table 9 along with the required excitation to maintain test amplitude. The predicted saddle amplitude, acceleration, and forces are given in Table 10. The resulting moment distribution is shown in Figure 38 and Figure 39 and the motion of the blade tip is shown in Figure 40.

Table 9. Mass Distribution for Quantum Biaxial Fatigue Test

\begin{tabular}{|c|c|c|c|c|c|c|c|c|}
\hline $\begin{array}{l}\text { Saddle } \\
\text { location } \\
\text { (m) }\end{array}$ & $\begin{array}{l}\text { Saddle } \\
\text { mass } \\
(\mathrm{kg})\end{array}$ & $\begin{array}{l}\text { Fixed } \\
\text { added } \\
\text { mass } \\
(\mathrm{kg})\end{array}$ & $\begin{array}{l}\text { IREX } \\
\text { nonmoving } \\
\text { mass } \\
(\mathbf{k g})\end{array}$ & $\begin{array}{l}\text { IREX } \\
\text { Exciter } \\
\text { moving } \\
\text { mass } \\
\text { (kg) }\end{array}$ & $\begin{array}{l}\text { IREX } \\
\text { displacement } \\
\text { amplitude } \\
(\mathrm{mm})\end{array}$ & $\begin{array}{l}\text { GREX } \\
\text { added } \\
\text { mass } \\
(\mathbf{k g})\end{array}$ & $\begin{array}{l}\text { GREX } \\
\text { force } \\
\text { amplitude } \\
\text { (kN) }\end{array}$ & $\begin{array}{l}\text { Total } \\
\text { real } \\
\text { saddle } \\
\text { mass } \\
(\mathrm{kg})\end{array}$ \\
\hline 20.0 & 1,000 & 1,500 & & & & & & 2,500 \\
\hline 24.0 & 800 & 800 & & & & & & 1,600 \\
\hline 28.0 & 600 & & 400 & 1,000 & 125 & 200 & 28.72 & 2,200 \\
\hline 36.0 & 400 & 200 & & & & & & 600 \\
\hline 56.0 & 70 & & & & & & & 70 \\
\hline 60.0 & & & & & & & & \\
\hline
\end{tabular}

Table 10. Saddle Amplitudes and Forces from Quantum Biaxial Fatigue Test Simulation

\begin{tabular}{l|llll|lll}
\hline & Flap & & & & Lead-lag & \\
\hline $\begin{array}{l}\text { Saddle } \\
\text { location } \\
(\mathbf{m})\end{array}$ & $\begin{array}{l}\text { Dynamic } \\
\text { saddle } \\
\text { amplitude } \\
\mathbf{( m )}\end{array}$ & $\begin{array}{l}\text { Accel- } \\
\text { eration } \\
\text { in } \mathbf{g} \\
\mathbf{( g )}\end{array}$ & $\begin{array}{l}\text { Max } \\
\text { flap } \\
\text { velocity } \\
\mathbf{( m / s )}\end{array}$ & $\begin{array}{l}\text { Flap } \\
\text { saddle } \\
\text { force } \\
\mathbf{( k N )}\end{array}$ & $\begin{array}{l}\text { Dynamic } \\
\text { saddle } \\
\text { amplitude } \\
(\mathbf{m})\end{array}$ & $\begin{array}{l}\text { Accel- } \\
\text { eration in } \\
\mathbf{g}\end{array}$ & $\begin{array}{l}\text { Lead-lag } \\
\text { saddle } \\
\text { force } \\
\text { amplitude } \\
\mathbf{( k N )}\end{array}$ \\
\hline 20.0 & 0.22 & 0.23 & 0.71 & 1.77 & 0.15 & 0.47 & 11.57 \\
24.0 & 0.37 & 0.39 & 1.19 & 1.90 & 0.22 & 0.69 & 10.83 \\
28.0 & 0.58 & 0.61 & 1.86 & 29.01 & 0.30 & 0.96 & 20.61 \\
36.0 & 1.25 & 1.30 & 4.00 & 2.40 & 0.52 & 1.65 & 9.70 \\
56.0 & 4.93 & 5.11 & 15.71 & 1.10 & 1.42 & 4.53 & 3.11 \\
60.0 & 6.01 & 6.23 & 19.16 & 0.00 & 1.64 & 5.25 & 0.00 \\
\hline
\end{tabular}




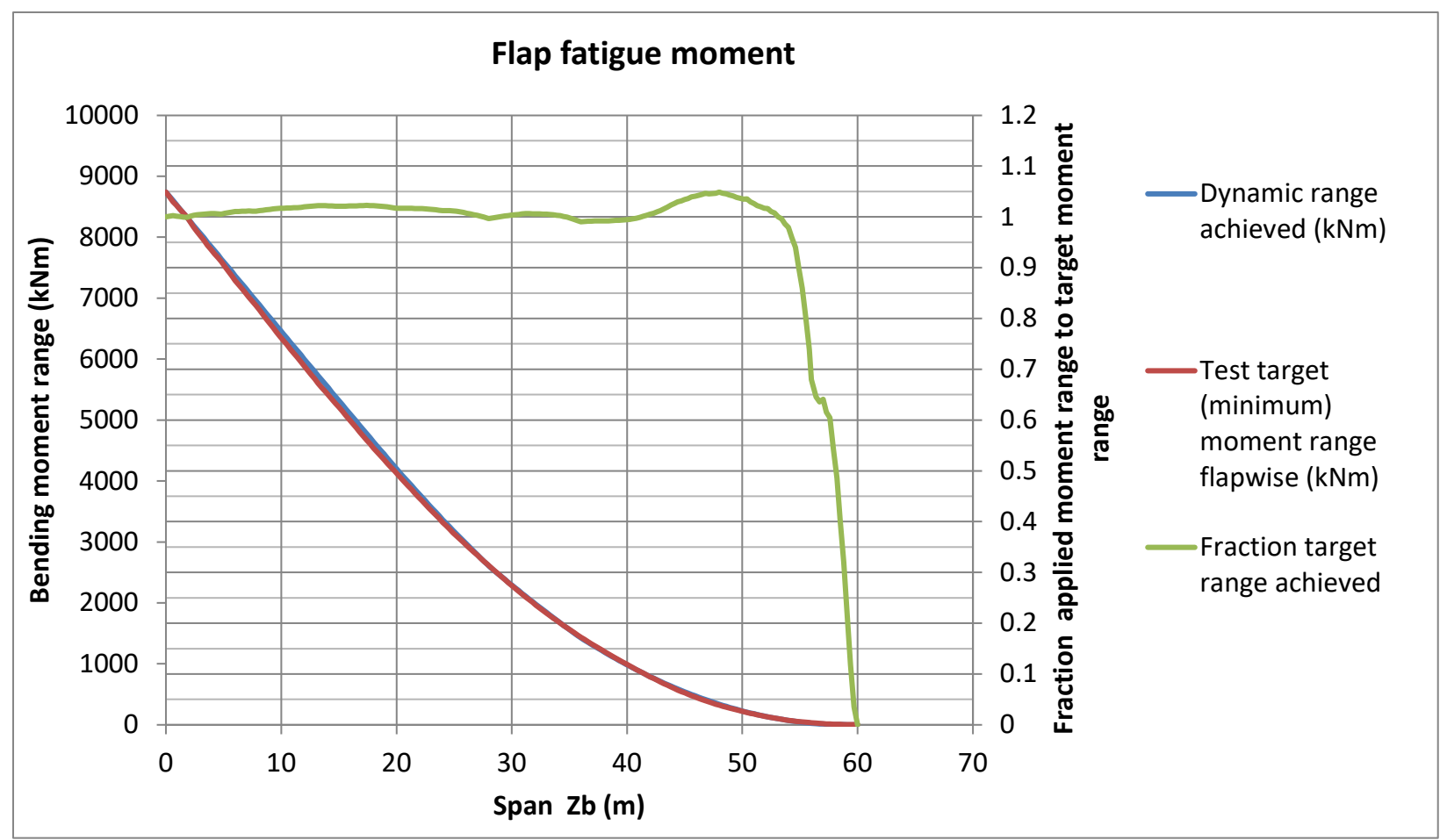

Figure 38. Quantum biaxial fatigue test flap direction moment distribution

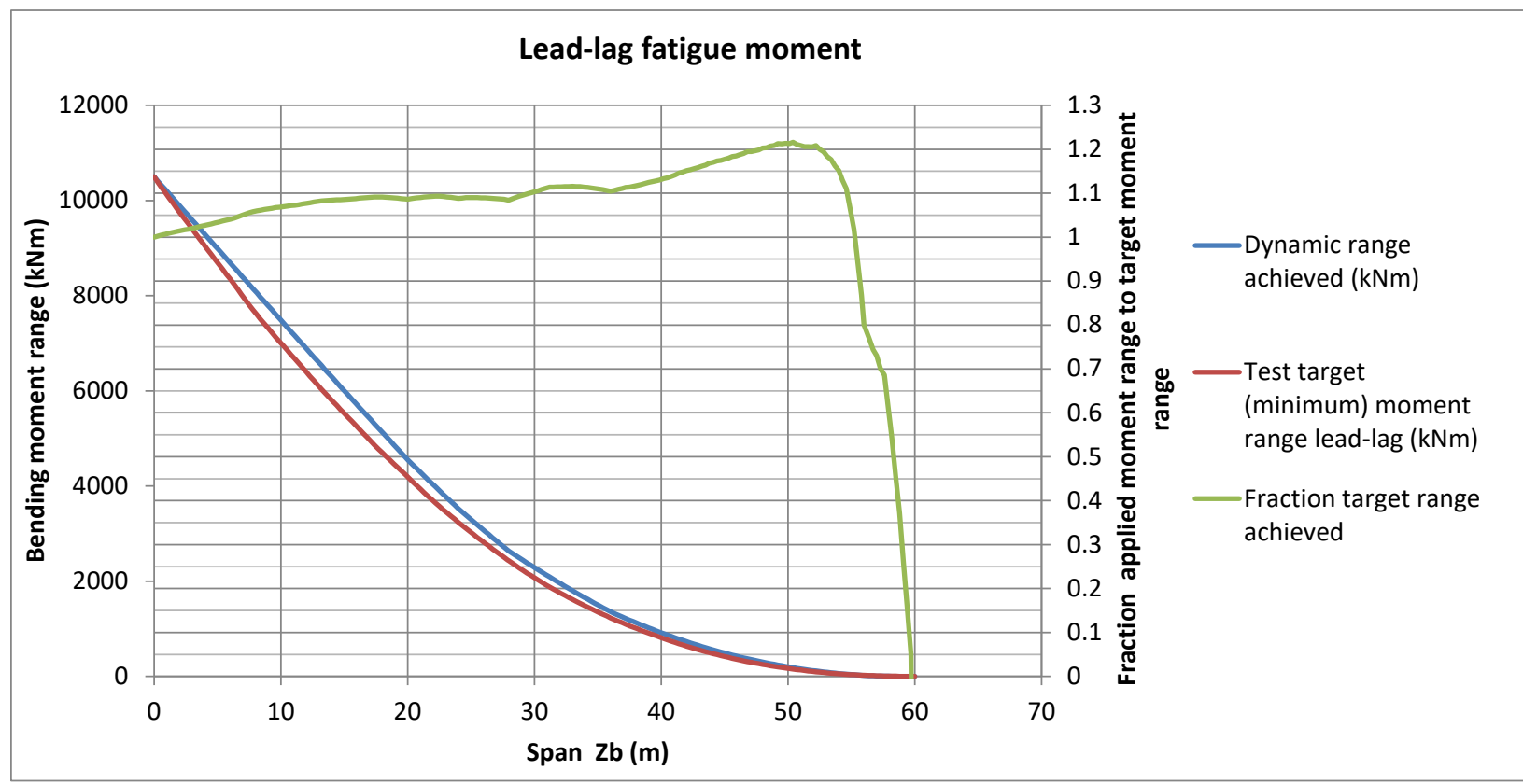

Figure 39. Quantum biaxial fatigue test lead-lag direction moment distribution 


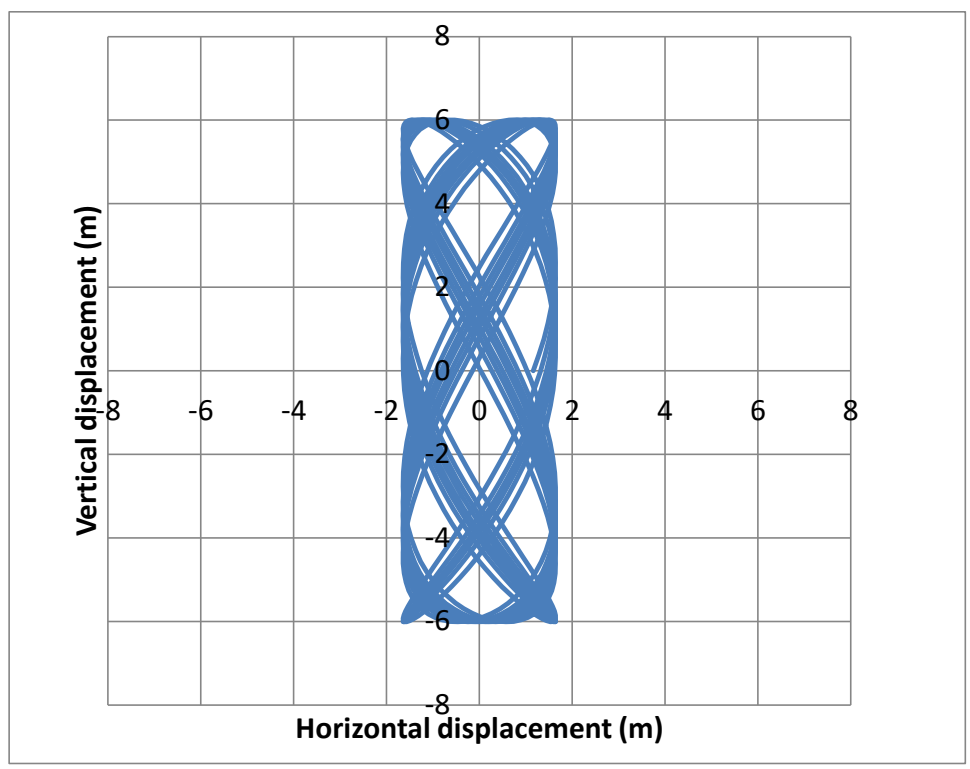

Figure 40. Motion pattern representing $\mathbf{3 0}$ seconds of test operation for quantum biaxial fatigue test

Because the lead-lag test direction only achieves 1.756 cycles for every flap fatigue cycle, it will only reach 1.756 million lead-lag cycles in the time it takes the flap fatigue test to reach 1 million cycles. The remaining 0.244 million lead-lag cycles could be run after that or alternatively, either the lead-lag fatigue load level could be increased or the flap loading decreased so that both test directions achieve the target damage equivalent load at the same time.

\subsection{Phase Locked 1:1}

There are several concepts used to achieve a 1:1 flap to lead-lag frequency ratio resulting in an elliptical blade motion. In general, either the flap frequency would need to be increased as proposed in the PHLEX project (Beckwith, White and Barsotti 2013) or the lead-lag frequency decreased as demonstrated in recent experiments in the Hybrid testing program previously described. Although both methods have been demonstrated at a smaller scale in research programs, neither has been attempted by NREL on a $50+\mathrm{m}$ utility-scale blade. Some biaxial tests using this approach have been conducted on larger blades at WMC although very limited information is available publically regarding these experiments (Westphal 2014). It is possible to use hydraulic actuators to increase the flap frequency by applying virtual mass in the flap direction This has been done at the WTTC for some uniaxial fatigue tests to modify the bending moment curve. However, maintaining stable control for an increase in frequency of more than about $0.05 \mathrm{~Hz}$ has not been possible on a megawatt-scale blade. In addition, in a PHLEX test, as the resonance frequency is forced higher, the outer portion of the blade will be overloaded relative to the root. Physical limits on the stroke of the GREX actuator prevent it from being applied farther outboard on the blade and the forces required to nearly double the flap frequency would be very high. Therefore, we will focus on the Hybrid test scenario, applying mass that only acts in the lead-lag direction to reduce the lead-lag frequency to equal the flap frequency.

The resulting test concept has an operational frequency of $0.511 \mathrm{~Hz}$. The proposed mass distribution is shown in Table 11, and the resulting displacements, acceleration, and force at each saddle are given in Table 12. Very large virtual masses—over 24 tons - are required to reduce 
the lead-lag test frequency. While impractical to implement this entirely using mass directly, the forces required are of a scope that implementation using a hydraulic actuator similar to a GREX but set up for horizontal loading should be considered. A force of $70 \mathrm{kN}$ would be required at the 28-m saddle with a displacement range of $0.6 \mathrm{~m}$. This could be accomplished using an actuator and bellcrank or other mechanical setup and would also eliminate the need for an IREX.

Alternatively, a real mass could be used in combination with a mechanical system to multiply the effective inertial mass by increasing the displacement of the mass relative to the displacement of the blade. Farther out, damping masses connected to the blade using linkages to only act in the lead-lag direction would likely be more practical. However, accommodating the large flap deflections would make implementing this virtual damping masses difficult and potentially require expensive hardware components. 
Table 11. Mass Configuration for Phase-Locked Biaxial Test with 1:1 Frequency Ratio Using an IREX in the Lead-Lag Direction and a GREX in the Flap Direction to Excite the Blade

\begin{tabular}{|c|c|c|c|c|c|c|c|c|c|c|}
\hline $\begin{array}{l}\text { Saddle } \\
\text { location } \\
\text { (m) }\end{array}$ & $\begin{array}{l}\text { Saddle } \\
\text { mass } \\
\text { (kg) }\end{array}$ & $\begin{array}{l}\text { Fixed } \\
\text { added } \\
\text { mass }\end{array}$ & $\begin{array}{l}\text { IREX } \\
\text { nonmoving } \\
\text { mass } \\
\text { (kg) }\end{array}$ & $\begin{array}{l}\text { IREX } \\
\text { exciter } \\
\text { moving } \\
\text { mass } \\
(\mathbf{k g})\end{array}$ & $\begin{array}{l}\text { IREX } \\
\text { displacement } \\
\text { amplitude } \\
(\mathrm{mm})\end{array}$ & $\begin{array}{l}\text { GREX added } \\
\text { mass } \\
(\mathrm{kg})\end{array}$ & $\begin{array}{l}\text { GREX force } \\
\text { amplitude } \\
\text { (kN) }\end{array}$ & $\begin{array}{l}\text { Total real } \\
\text { saddle } \\
\text { mass } \\
(\mathrm{kg})\end{array}$ & $\begin{array}{l}\text { Virtual } \\
\text { mass flap } \\
\text { dir only } \\
(\mathrm{kg})\end{array}$ & $\begin{array}{l}\text { Virtual } \\
\text { mass } \\
\text { lead-lag } \\
\text { dir only } \\
(\mathbf{k g})\end{array}$ \\
\hline 20.0 & 1,000 & 1,000 & & & & & & 2,000 & & \\
\hline 24.0 & 800 & 1,000 & & & & & & 1,800 & & \\
\hline 28.0 & 600 & & 400 & 1,000 & 119 & 200 & 31.38 & 2,200 & -500 & 20,550 \\
\hline 45.0 & 250 & & & & & & & 250 & & 3,500 \\
\hline 58.0 & 30 & & & & & & & 30 & & 500 \\
\hline 60.0 & & & & & & & & & & \\
\hline
\end{tabular}


Table 12. Displacement, Acceleration, and Forces for Phase-Locked Biaxial Test with 1:1 Frequency Ratio

\begin{tabular}{|c|c|c|c|c|c|c|c|}
\hline \multirow[b]{2}{*}{$\begin{array}{l}\text { Saddle } \\
\text { location } \\
\text { (m) }\end{array}$} & \multicolumn{4}{|l|}{ Flap } & \multicolumn{3}{|l|}{ Lead-lag } \\
\hline & $\begin{array}{l}\text { Dynamic } \\
\text { Saddle } \\
\text { amplitude } \\
(\mathrm{m})\end{array}$ & $\begin{array}{l}\text { Acceleration } \\
\text { (g) }\end{array}$ & $\begin{array}{l}\max \\
\text { flap } \\
\text { velocity } \\
(\mathrm{m} / \mathrm{s})\end{array}$ & $\begin{array}{l}\text { Flap } \\
\text { Saddle } \\
\text { force } \\
(\mathbf{k N})\end{array}$ & $\begin{array}{l}\text { Dynamic } \\
\text { Saddle } \\
\text { amplitude } \\
\text { (m) }\end{array}$ & $\begin{array}{l}\text { Acceleration } \\
\text { (g) }\end{array}$ & $\begin{array}{l}\text { Lead-lag } \\
\text { Saddle } \\
\text { force } \\
\text { amplitude } \\
(\mathrm{kN})\end{array}$ \\
\hline 20.0 & 0.22 & 0.24 & 0.72 & 1.44 & 0.15 & 0.16 & 3.06 \\
\hline 24.0 & 0.38 & 0.40 & 1.21 & 2.17 & 0.22 & 0.23 & 4.02 \\
\hline 28.0 & 0.59 & 0.62 & 1.90 & 31.54 & 0.30 & 0.31 & 70.26 \\
\hline 45.0 & 2.58 & 2.72 & 8.29 & 2.07 & 0.84 & 0.89 & 32.59 \\
\hline 58.0 & 5.63 & 5.93 & 18.09 & 0.54 & 1.48 & 1.56 & 8.09 \\
\hline 60.0 & 6.20 & 6.53 & 19.92 & 0.00 & 1.59 & 1.67 & 0.00 \\
\hline
\end{tabular}

Overall the loading distribution achieved in the flap direction is relatively good (Figure 41). However, in the lead-lag direction, shown in Figure 42, the blade ends up underloaded at the saddles where the virtual masses are applied and overloaded between them. This curve could be smoothed out by adding more saddles with more smaller virtual masses, but this would greatly increase the complexity of the test, especially outboard where the deflections are high.

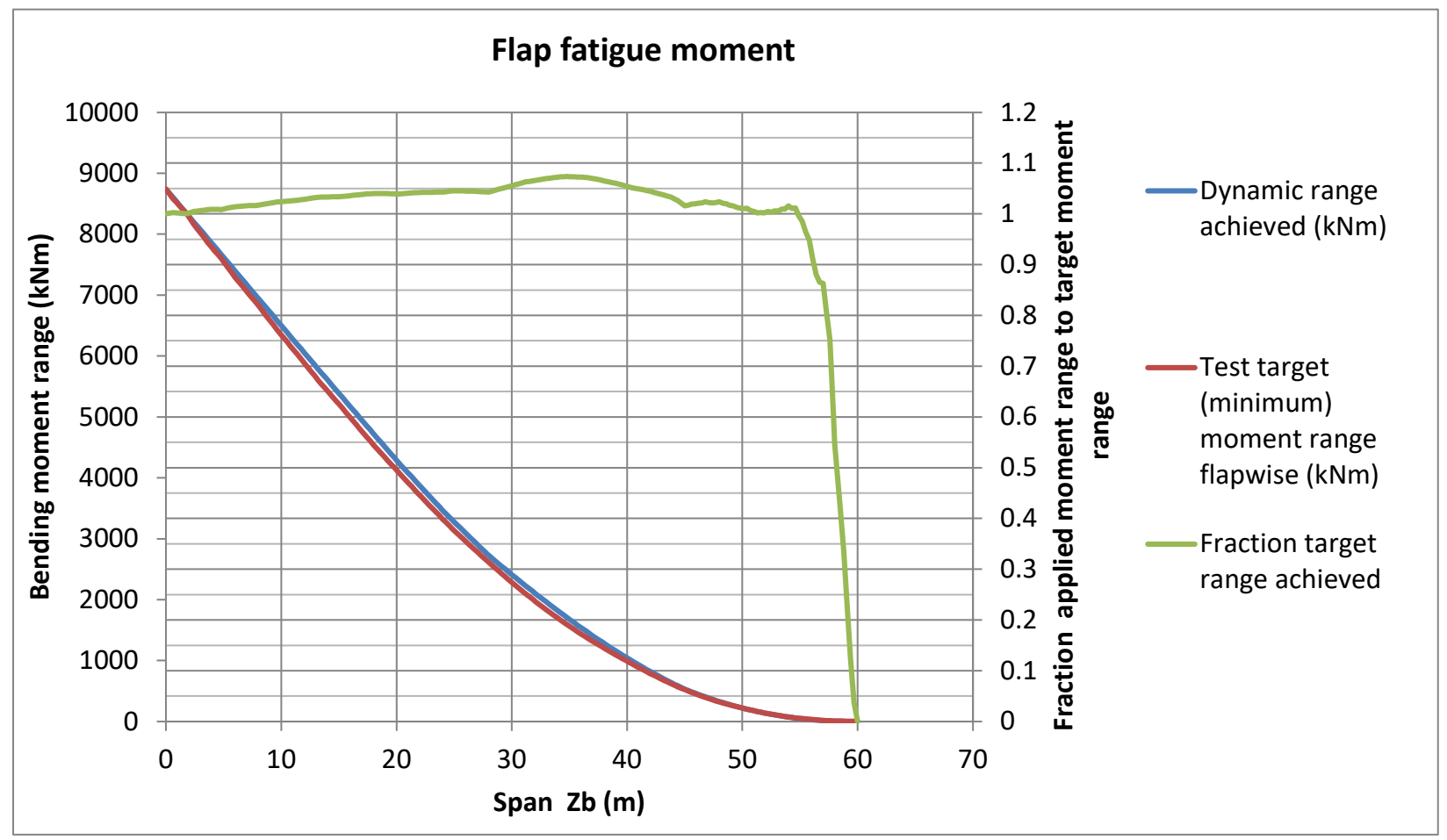

Figure 41. Flap bending moment distribution achieved with 1:1 frequency ratio test setup 


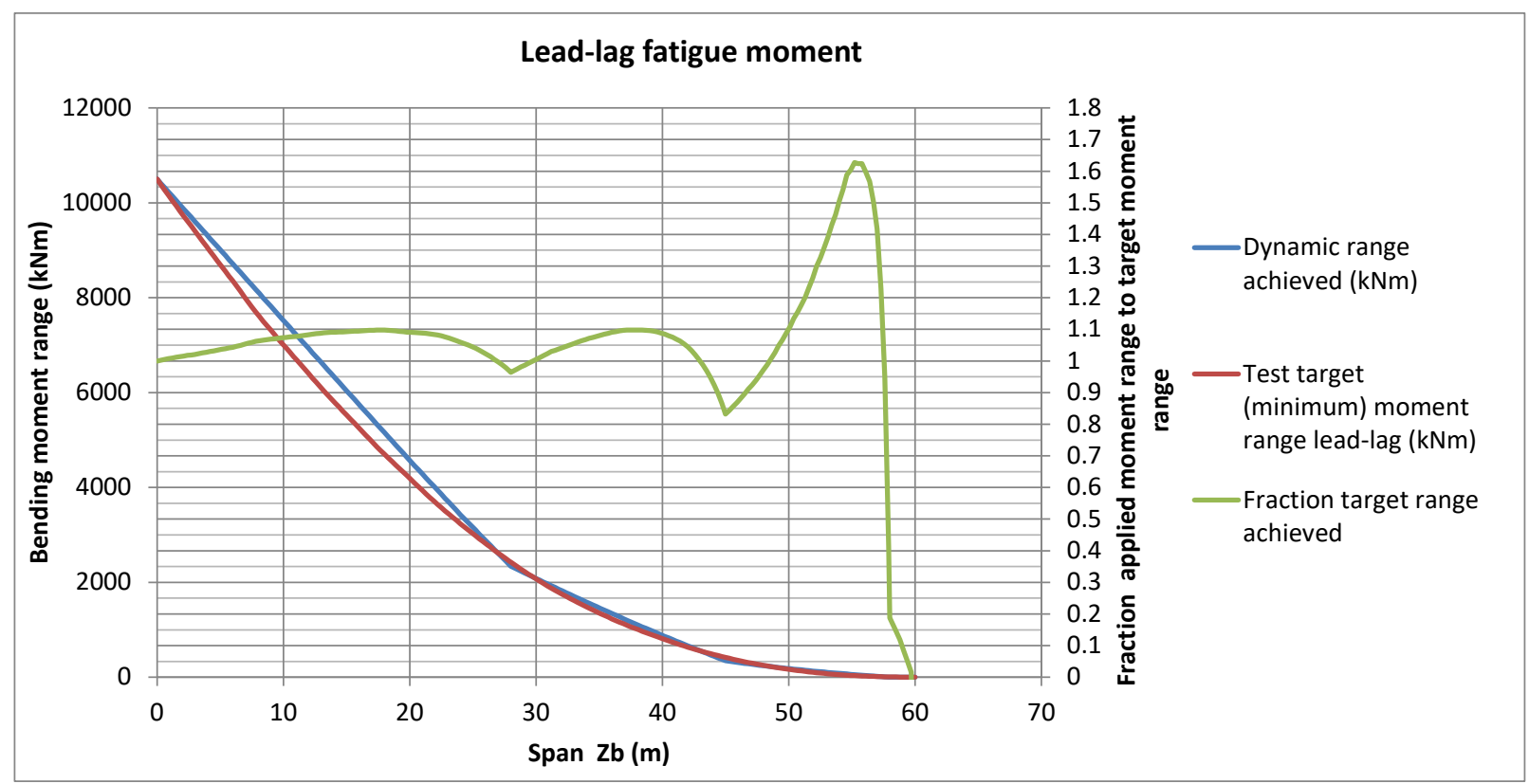

Figure 42. Lead-lag bending moment achieved with 1:1 frequency ratio test setup

In theory, any phase relationship could be maintained between the flap and lead-lag moments. The resulting test motion will range between an ellipse and a straight line as shown in Figure 43 . Preliminary experiments with the hybrid test have shown that it may be difficult to obtain the desired phase relationship using an IREX because of energy transfer between the flap and leadlag directions. This would also suggest a possible preference for a direct actuation system like the GREX in the lead-lag direction to gain more control of the phase angle. However, sophisticated control algorithms may be required to account for the changing geometry and load application angles as the blade moves. Other variations on the mechanical configuration may enable better separation of the lead-lag and flap excitation but there is likely always going to be some level of coupling due to the twisted structure of the blade.
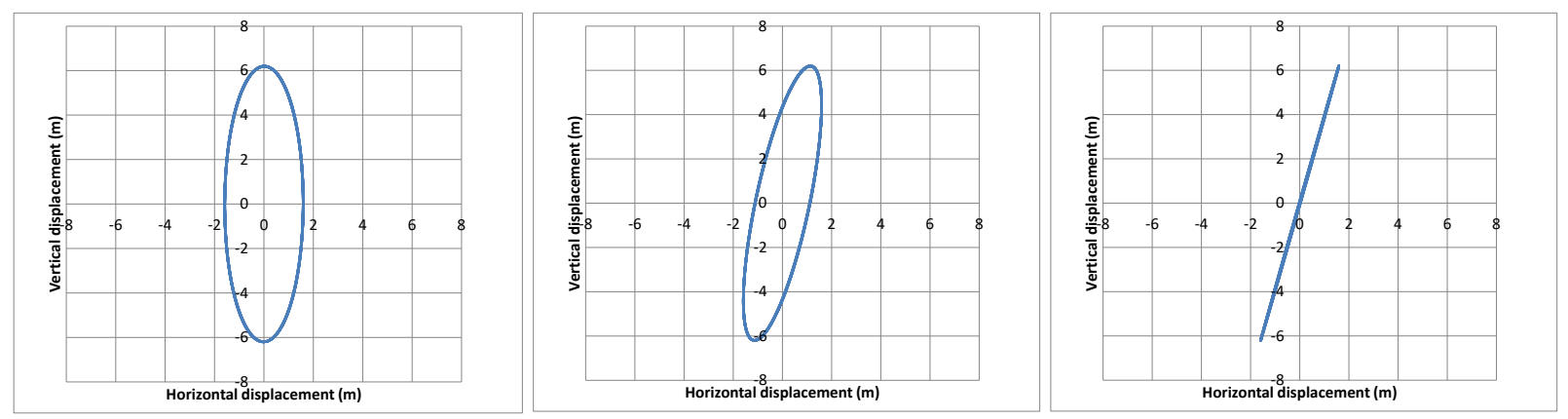

Figure 43. Displacement representation for 1:1 frequency ratio with phase angle of $90 \mathrm{deg}$ (left), 45 deg (center) and 0 deg (right). The mirror image of these is also possible.

One disadvantage of the 1:1 frequency is that the lead-lag direction will be tested at the flap frequency. Due to the relatively high fatigue loads in the lead-lag direction compared to static strength for large turbine blades (see Figure 37 for example), it is desirable not to accelerate the fatigue test as much as is common in the flap direction. Two million cycles or more are often required for lead-lag tests as is the case for this proposed fictional blade. As a result, to complete 
the damage equivalent load at the same time, the flap loading would need to be rescaled for 2 million cycles. The total testing time will be significantly longer than for a quantum test. In this case, 2 million cycles at $0.51 \mathrm{~Hz}$. will take 45 days-much longer than the 26 day quantum fatigue test and nearly as long as the single axis flap and lead-lag fatigue tests combined. While there may be advantages in terms of achieving more realistic load combinations during the fatigue test, reducing testing time is not likely to be a significant benefit for this type of test.

\subsection{Phase Locked 1:2}

A phase locked test with a ratio of $1: 2$ is also considered. This is potentially advantageous because the natural frequencies of the blade are closer to this ratio to begin with and typically lead-lag fatigue tests are designed with more cycles than flap fatigue tests to limit the peak loads. Again it would be very difficult to significantly increase the lead-lag fatigue test frequency so instead, we reduce the flap frequency by adding virtual mass in that direction. Starting with the optimized lead-lag fatigue test scenario we seek to achieve a flap frequency of half of the leadlag frequency or about $0.45 \mathrm{~Hz}$. To maintain a reasonable target moment distribution virtual masses that act in the flap direction must be attached near the tip of the blade which may be difficult to do mechanically. If a test article has natural frequencies that are closer to $1: 2$ to begin with, this approach may be more feasible.

The example developed below also compromises on the lead-lag load distribution to place saddles where they are needed to obtain the desired flap frequency and distribution. However, the overall result is relatively good from a load distribution standpoint.

The resulting test concept has an operational frequency of $0.4507 \mathrm{~Hz}$. in the flap direction and $0.9014 \mathrm{~Hz}$. in the lead-lag direction. The proposed mass distribution is shown in Table 13 and the resulting displacements, acceleration and force at each saddle is given in Table 14. The outboard virtual masses are reasonable with relatively small forces imposed on the saddles although a mechanism to handle the large displacement amplitudes of 2.5 and $5 \mathrm{~m}$, respectively, will be required. A mechanism capable of applying a virtual mass through a displacement range of $10 \mathrm{~m}$ without undue influence in the lead-lag direction could pose a significant design challenge. However, farther inboard, the $11 \mathrm{kN}$ in phase force required to achieve the virtual mass at the 28-m saddle can be easily accomplished with the GREX in combination with the $23.5 \mathrm{kN}$ excitation. 
Table 13. Mass Configuration for Phase-Locked Biaxial Test with 1:2 Frequency Ratio

\begin{tabular}{|c|c|c|c|c|c|c|c|c|c|}
\hline $\begin{array}{l}\text { Saddle } \\
\text { location } \\
\text { (m) }\end{array}$ & $\begin{array}{l}\text { Saddle } \\
\text { mass } \\
(\mathbf{k g})\end{array}$ & $\begin{array}{l}\text { Fixed } \\
\text { added } \\
\text { mass } \\
(\mathbf{k g})\end{array}$ & $\begin{array}{l}\text { IREX } \\
\text { nonmoving } \\
\text { mass } \\
\text { (kg) }\end{array}$ & $\begin{array}{l}\text { IREX } \\
\text { exciter } \\
\text { moving } \\
\text { mass } \\
\text { (kg) }\end{array}$ & $\begin{array}{l}\text { IREX } \\
\text { displacement } \\
\text { amplitude } \\
(\mathrm{mm})\end{array}$ & $\begin{array}{l}\text { GREX } \\
\text { added } \\
\text { mass } \\
(\mathrm{kg})\end{array}$ & $\begin{array}{l}\text { GREX } \\
\text { force } \\
\text { amplitude } \\
\text { (kN) }\end{array}$ & $\begin{array}{l}\text { Total } \\
\text { real } \\
\text { saddle } \\
\text { mass } \\
(\mathbf{k g})\end{array}$ & $\begin{array}{l}\text { Virtual } \\
\text { mass } \\
\text { flap } \\
\text { dir } \\
\text { only } \\
\text { (kg) }\end{array}$ \\
\hline 20.0 & 1,000 & 1,500 & & & & & & 2,500 & \\
\hline 24.0 & 800 & 500 & & & & & & 1,300 & \\
\hline 28.0 & 600 & & 400 & 1,000 & 126 & 200 & 23.46 & 2,200 & 2,400 \\
\hline 45.0 & 220 & & & & & & & 220 & 450 \\
\hline 56.0 & 45 & & & & & & & 45 & 105 \\
\hline 60.0 & & & & & & & & & \\
\hline
\end{tabular}

Table 14. Displacement, Acceleration, and Forces for Phase Locked Biaxial Test with 1:2 Frequency Ratio

\begin{tabular}{|c|c|c|c|c|c|c|c|}
\hline \multirow[b]{2}{*}{$\begin{array}{l}\text { Saddle } \\
\text { location } \\
\text { (m) }\end{array}$} & \multicolumn{4}{|l|}{ Flap } & \multicolumn{3}{|l|}{ Lead-lag } \\
\hline & $\begin{array}{l}\text { Dynamic } \\
\text { saddle } \\
\text { amplitude } \\
\text { (m) }\end{array}$ & $\begin{array}{l}\text { Acceleration } \\
\text { (g) }\end{array}$ & $\begin{array}{l}\text { Max } \\
\text { flap } \\
\text { velocity } \\
\text { (m/s) }\end{array}$ & $\begin{array}{l}\text { Flap } \\
\text { saddle } \\
\text { force } \\
(\mathbf{k N})\end{array}$ & $\begin{array}{l}\text { Dynamic } \\
\text { saddle } \\
\text { amplitude } \\
\text { (m) }\end{array}$ & $\begin{array}{l}\text { Acceleration } \\
\text { (g) }\end{array}$ & $\begin{array}{l}\text { Lead-lag } \\
\text { saddle } \\
\text { force } \\
\text { amplitude } \\
\text { (kN) }\end{array}$ \\
\hline 20.0 & 0.22 & 0.18 & 0.63 & 1.58 & 0.15 & 0.48 & 11.88 \\
\hline 24.0 & 0.37 & 0.31 & 1.06 & 1.38 & 0.22 & 0.71 & 9.04 \\
\hline 28.0 & 0.59 & 0.48 & 1.67 & 24.68 & 0.30 & 0.98 & 21.22 \\
\hline 45.0 & 2.55 & 2.08 & 7.22 & 4.83 & 0.87 & 2.86 & 6.16 \\
\hline 56.0 & 5.00 & 4.09 & 14.16 & 2.12 & 1.45 & 4.74 & 2.09 \\
\hline 60.0 & 6.08 & 4.97 & 17.22 & 0.00 & 1.68 & 5.50 & 0.00 \\
\hline
\end{tabular}

Overall the loading distribution achieved in the flap direction is relatively good (Figure 44). The lead-lag direction, shown in Figure 45, ends up slightly overloaded because of the need for saddles on the outer portion of the blade. 


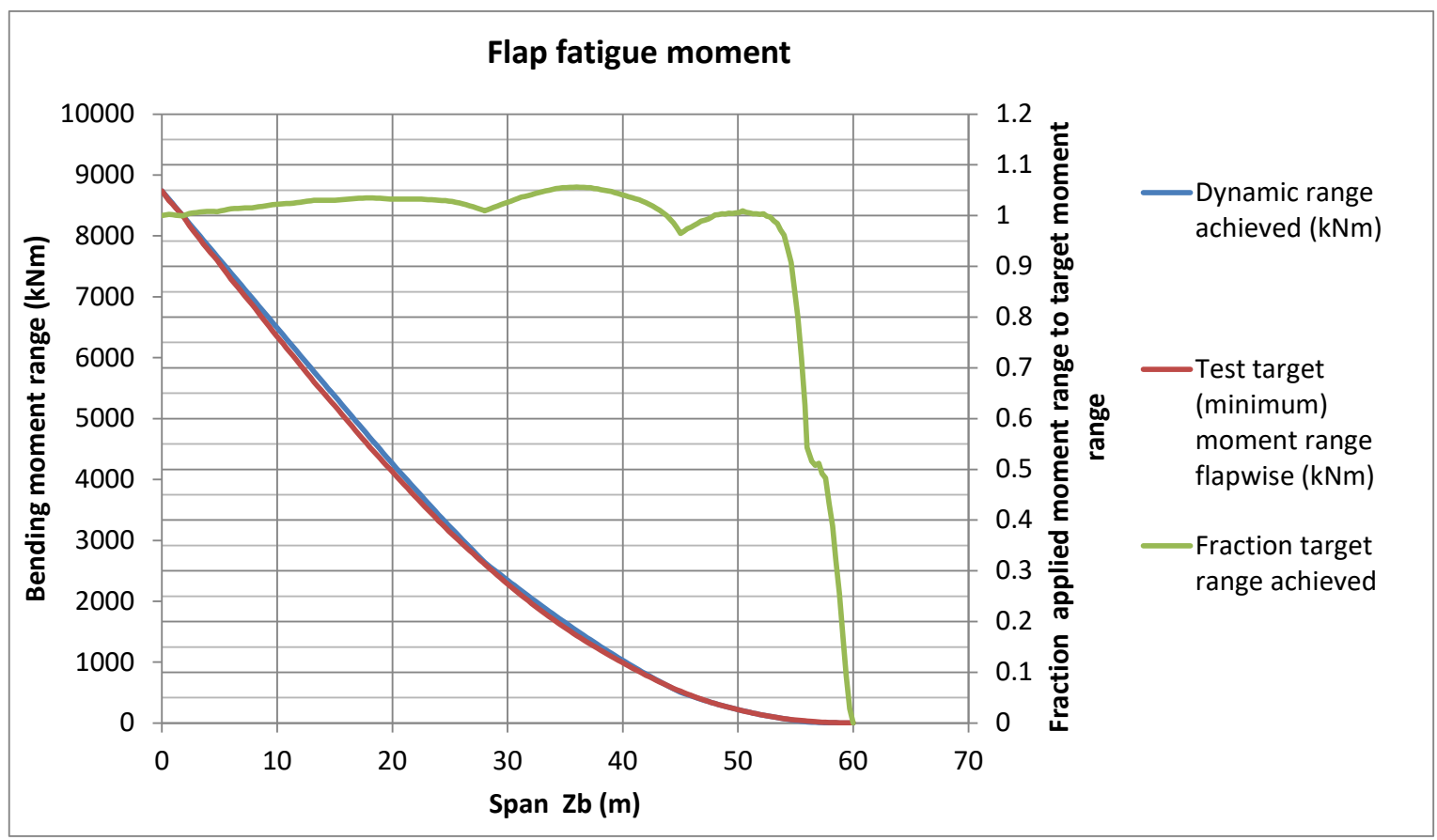

Figure 44. Flap bending moment distribution achieved with 1:2 frequency ratio test setup

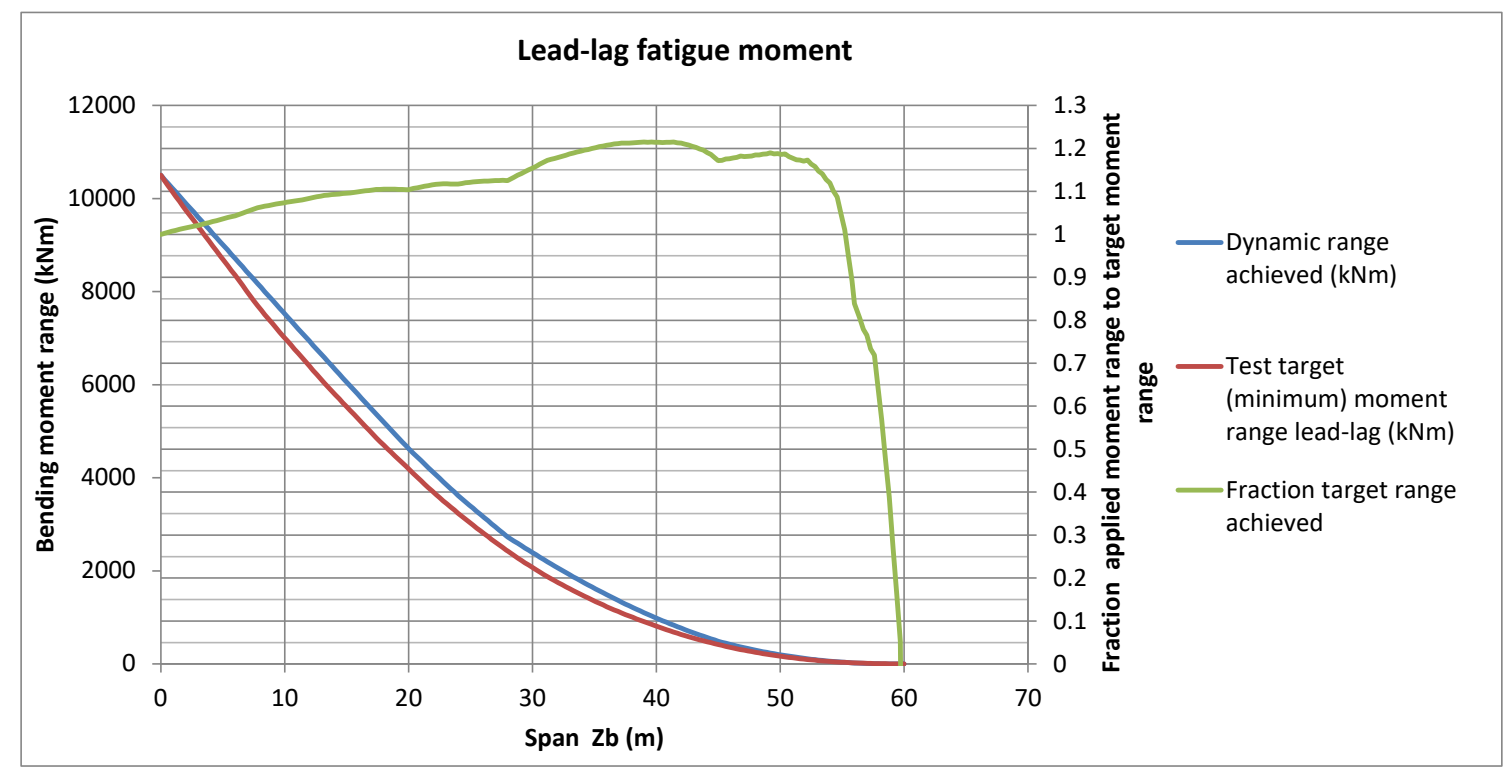

Figure 45. Lead-lag bending moment achieved with 1:2 frequency ratio test setup

Although the phase angles will not be constant, there will be two dominant phase relationships that could be used to test critical regions of the blade not fully tested in a uniaxial test. A range of phase relationships are possible (Figure 46), but most likely phase angles close to 0 and 180 degrees producing a figure eight would be preferable. 


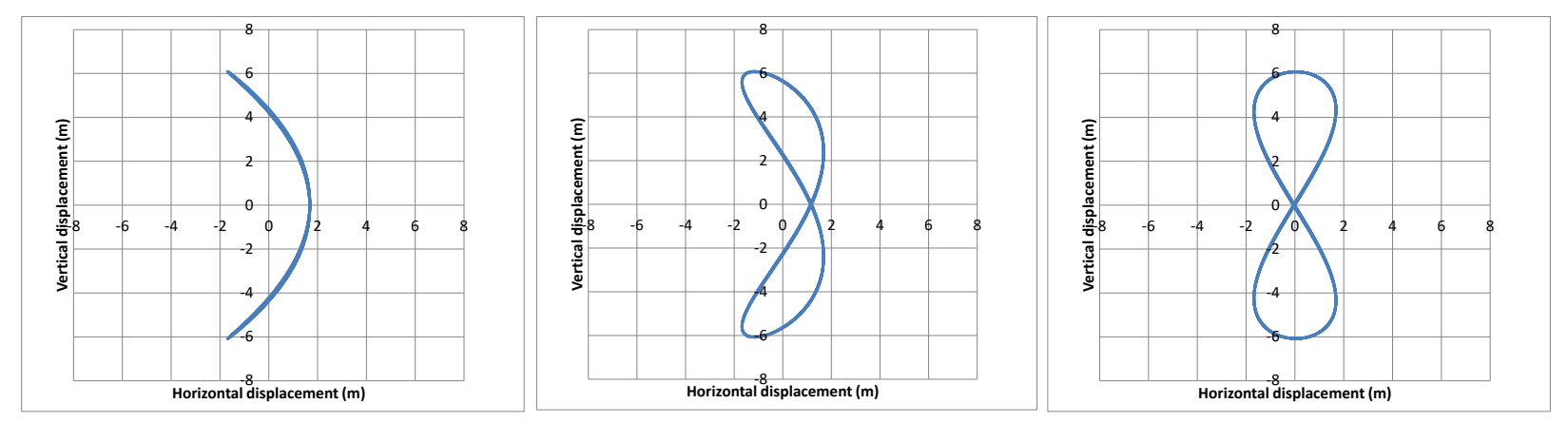

Figure 46. Displacement representation for 1:2 frequency ratio with phase angle of $90 \mathrm{deg}$ (left), 45 deg (center) and 0 deg (right). The mirror images of these are also possible.

The primary advantage of the 1:2 frequency ratio tests is that it is possible to complete the flap fatigue test simultaneously with the lead-lag test without a significant increase in the lead-lag fatigue test time. The ratio of the frequencies in this case is the same as the ratio of the target cycles to achieve damage equivalent load. Thus, in theory the damage equivalent load is achieved at the same time without modifying the test load level. However, the modeling approach incorporated here fails to evaluate the influence of blade twist, which will result in some coupling of the flap and lead-lag moments. Thus, actual results may still show variable amplitude loading, particularly in the lead-lag direction similar to those experienced by the blade during a quantum fatigue test. More complex time-dependent modeling or real experiments will be required to evaluate how significant this effect is.

\subsection{Total Test Time Comparison}

One of the primary motivations for conducting biaxial testing is to more thoroughly test the blade structure under loading representative of the loads seen on the turbine. However, due to commercial pressures in the industry, reducing test time is a secondary goal and a significant reduction in test time will help to promote a new test technology. Therefore, it is relevant to the industry to evaluate the possible changes in test time depending on the test method selected. It is noted in the previous discussion that not all biaxial test configurations lead to a substantial reduction in test time. This can be due to the reduction in test frequencies required to achieve the target moment or due to resulting load amplitude modulation as was seen by Snowberg et al. (2014) in the quantum biaxial test demonstration. It is hard to estimate the extent of the variable amplitude in the lead-lag direction based on the simplified test analysis performed in this study so this effect is not included in the analysis below. Future analysis or experiments will be required to evaluate how much error in these estimates results from this simplification.

In this analysis, only the operational test time at amplitude is calculated. Test setup, down time for inspections and equipment maintenance, and so on, is not included. Experience has shown a factor of between 1.2 and 1.5 times the operational test time is typical for actual blade tests; thus, the differences in operational test time will have less impact on the total program time than is represented here. However, for fatigue test with more cycles than assumed in this report, reducing operational test time can result in greater reduction in the overall test campaign time.

Assuming that a minimum of 1 million flap fatigue cycles and 2 million lead-lag fatigue cycles is required, the resulting total test time is shown in Figure 47. The phase-locked test with a frequency ratio of 1:2 provides the least total test operational time of 25.7 days for this example 
blade and set of target load cycles. Next is the quantum biaxial test at 26.0 days with the caveat that in both of these cases, some higher maximum load amplitude cycles must be accepted due to the expected load modulation or the total number of test cycles must be extended to achieve the required damage equivalent load. A phase-locked 1:1 test results in the longest total test time of 45.4 days although the result is negligibly different from the traditional sequential test approach of 43.6 days, particularly when considering the additional test setup time required to switch from flap to lead-lag tests.

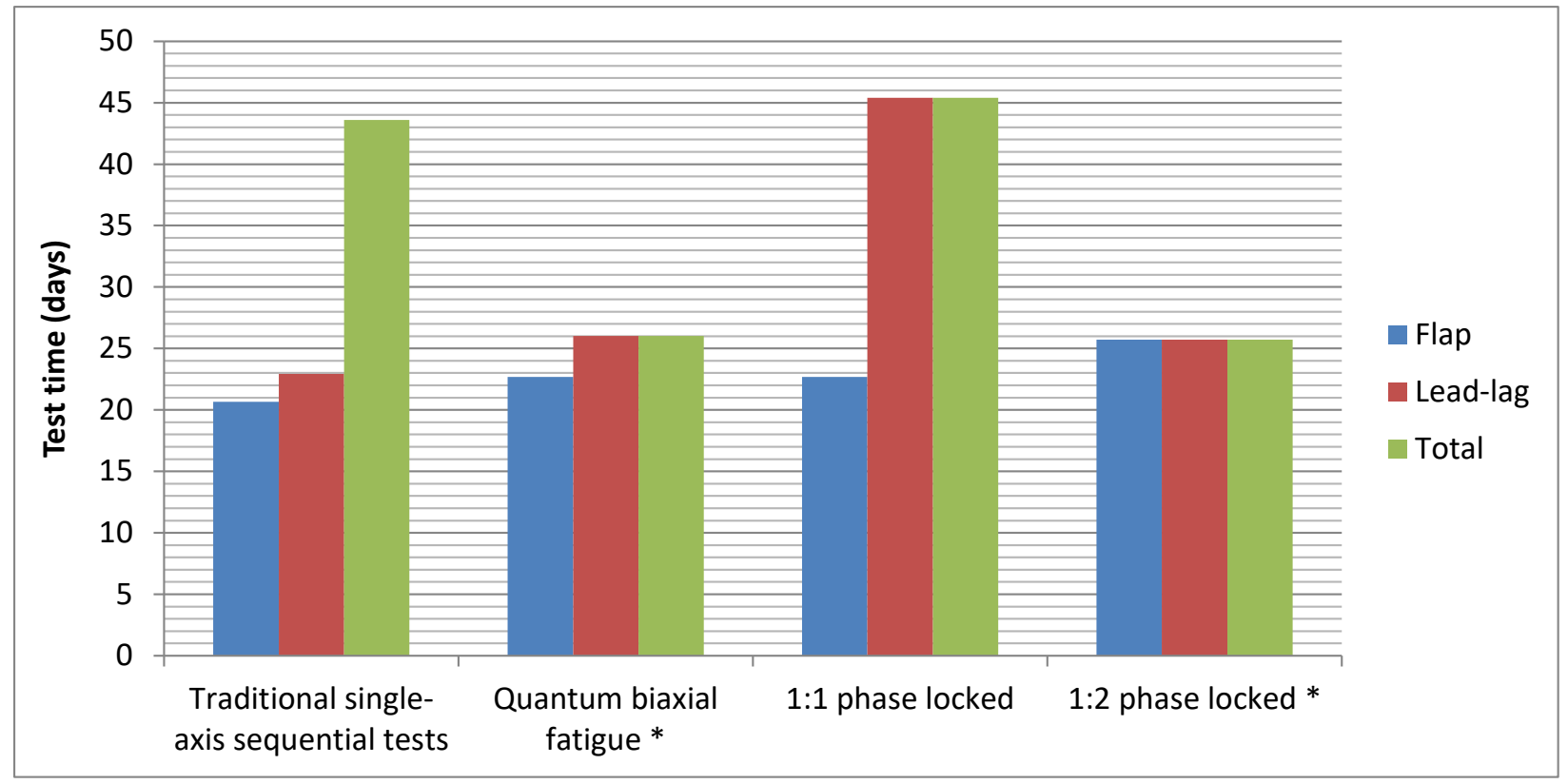

* Quantum biaxial test time and 1:2 phase locked time are possibly underestimated due to likely load amplitude modulation requiring more than the target number of cycles to achieve the desired damage equivalent load.

Figure 47. Comparison of test time between different test methods 


\section{Conclusion}

This report examined several potential biaxial fatigue test scenarios for a fictional $60-\mathrm{m}$ blade. Normalized properties of a number of real blades were combined to produce a fictional test article specification that is similar to current blades in production. Current test hardware available at the WTTC was considered for use in a test program along with several new concepts, including those employed by the Hybrid test research project where virtual mass is located off the blade and connected with a push rod such that it only impacts the test in one direction - either the lead-lag or flap but not both. In addition, a GREX or GREX-type hydraulic actuator device may be employed to both excite the blade with a force function at 90 degrees phase relative to the displacement and provide or remove virtual mass by applying a force inphase or 180 degrees out of phase with the displacement. This is accomplished by modifying the excitation frequency and resulting target phase angle for the actuator. The results in terms of bending moment distribution on the blade are the same regardless of whether real mass or an actuator is used to create a virtual mass so the virtual mass concept is useful for modeling these types of tests setups and for determining the appropriate hardware.

Four test configurations were considered. The traditional sequential test program where lead-lag and flap direction fatigue is performed separately is used as a baseline both to evaluate the possible accuracy of meeting the ideal target bending moment distribution as well as the total operational test time. Three alternative approaches for configuring a biaxial fatigue test were considered: a quantum biaxial fatigue test where the flap and lead-lag directions are excited at separate resonance frequencies resulting in a variable and nominally random phase angle between the two test directions; a phase-locked test with frequency ratio of 1:1 where the leadlag frequency is reduced to the flap frequency by adding virtual mass at multiple stations; and a phase-locked test with a frequency ratio of 1:2 where the flap frequency is reduced slightly using virtual masses to run at exactly one-half of the lead-lag frequency. In each case, attention was given to achieving the target bending moment distributions as accurately as possible; however, compromises were invariably required and individual analysis would be required to determine if the final load distribution is acceptable for a given blade. While each potential biaxial fatigue test configuration is possible to implement, the large virtual masses required for a 1:1 flap to lead-lag may be difficult to accomplish with current test equipment. More reasonable virtual masses are required for the 1:2 phase-locked test, although the large tip displacements will require the development of new hardware to implement them.

Although the quantum test system has been successfully implemented on a multimegawatt-scale blade in the past, the disadvantages of widely varying phase angles and modulating amplitude have so far precluded adoption of this method in most commercial certification test programs. Achieving a 1:1 phase-locked test has the advantage that the phase angle can be actively controlled to best match the phase angle experienced by the blade on the turbine. However, the drastic change in frequency required means that very large virtual masses or applied forces are required in the lead-lag direction, and it is difficult to achieve the target bending moment distribution along the whole blade accurately without the use of many virtual mass loading stations. Also, the test time may be extended beyond that of a traditional sequential test due to the typically higher lead-lag cycle count being executed at the flap frequency. 
Given the possible reduction in test time, the ability to achieve moment distributions relatively close to the target and the relatively small virtual masses required for the 1:2 phase-locked test approach appear to have a good chance of success in a commercial test program. Further research needs to be conducted regarding the impact of applying the lead-lag cycles with a combination of two different phase angles for every half flap cycle on the blade and whether this is an improvement in accuracy for a blade test compared to two sequential tests. An additional consideration is the design of small virtual masses to use at the tip of the blade where the flap direction deflection amplitude can be $5 \mathrm{~m}$ or more. Such a device will be required to enable this type of testing to proceed on most multimegawatt-scale wind turbine blades. 


\section{References}

Beckwith, Jenna, Darris White, and Domenic Barsotti. "Development of a Dual-Axis PhaseLocked Excitation (PHLEX) Resonant Fatigue Test Method for Wind Turbine Blades." ASME 2013 International Mechanical Engineering Congress and Exposition IMECE2013. San Diego, CA USA, 2013.

Desmond, Michael. "The Development of a Wind Turbine Blade Finite Element Momdel to Predict Loads and Deflections during Static and Fatigue Structural Testing." Thesis. Embry-Riddle Aeronautical University, December 16, 2009.

Greaves, Peter R. "Fatigue Analysis and Testing of a Wind Turbine Blade." Durham Thesis. Durham University, 2013.

Hood, Greg. Pop Tools. n.d. http://www.poptools.org/ (accessed September 24, 2015).

Hughes, S.D., W.D. Musial, and T. Stensland. "Implementation of a Two-Axis Servo-Hydraulic System for Full Scale Fatigue Testing of Wind Turbine Blades." Windpower 1999. Burlington, VT: NREL/CP-500-26896, 1999.

Hughes, Scott, Walter Musial, and Darris White. Dual-Axis Resonance Testing of Wind Turbine Blades. US Patent 8621934 B2. January 7, 2014.

IEC_61400-13. "Wind Turbine Generator Systems - Part 13 Measurement of Mechanical Loads." Technical Specification. June 2001.

IEC_61400-23. "Wind Turbines - Part 23: Full Scale Structural Testing of Wind Turbine Blades Ed 1.0." Technical Standard. International Electrotechnical Commission, April 2014.

Montgomerie, Bjorn. Drag Coeficient Distribution on a Wind at 90 Degrees to the Wind. Technical Report ECN-C--95-061, ECN, 1996.

Resor, Brian R. Definition of a 5MW/61.5m Wind Turbine Blade Reference Model. Sandia Report, Albuquerque, NM USA: Sandia National Laboratories, 2013.

Shames, Irving H., and Clive L. Dym. Energy and Finite Element Methods in Structural Mechanics. CRC Press, 1996.

Sheldahl, Robert E., and Paul C. Kilmas. Aerodynamic Characteristics of Seven Symmetrical Airfoil Sections Through 180-Degree Angle of Attack for Use in Aerodynamic Analysis of Vertical Axis Wind Turbines. SAND80-2114, Albuquerque NM: Sandia National Laboratories, 1981.

Snowberg, D., S. Dana, S. Hughes, and P. Berling. "Implementation of a Biaxial Resonant Fatigue Test Method on a Large Wind Turbine Blade." NREL/TP-5000-61127, National Renewable Energy Laboratory, Golden, CO, 2014.

Snowberg, David, and Scott Hughes. Blade Testing Equipment Development and Commercialization. NREL/TP-7A10-55342, Golden, CO: National Renewable Energy Laboratory, 2013.

Westphal, Tim. "Developments in Wind Turbine Blade Fatigue Testing." Sandia Blade Workshop. Albuquerque, NM, USA, 2014.

White, D., W. Musial, and S. Engberg. "Evaluation for the New B-REX Fatigue Test System for Multi-Megawatt Wind Turbine Blades." 43rd AIAA Aerospace Sciences Meeting and Exhibit. Reno, Nevada: National Renewable Energy Laboratory, 2004.

White, Darris. New Method for Dual-Axis Fatigue Testing of Large Wind Turbine Blades Using Resonance Excitation and Spectral Loading. NREL/TP-500-35268, Golden, CO: National Renewable Energy Laboratory, 2004. 
White, Darris, Michael Desmond, Waleed Gowharji, Jenna Beckwith, and Kenneth Meierjurgen. "Development of a Dual-Axis Phase-Locked Resonant Excitation Test Method for Fatigue Testing of Wind Turbine Blades." IMECE2011. Denver, CO, USA: ASME, 2011.

White, Frank M. Fluid Mechanics, 4th ed. Boston: McGraw-Hill, 1999. 